University of Louisville

ThinkIR: The University of Louisville's Institutional Repository

Electronic Theses and Dissertations

$5-2010$

\title{
Reading aloud in the writing center : a comparative analysis of three tutoring methods.
}

Rebecca Ryan Block 1979-

University of Louisville

Follow this and additional works at: https://ir.library.louisville.edu/etd

\section{Recommended Citation}

Block, Rebecca Ryan 1979-, "Reading aloud in the writing center : a comparative analysis of three tutoring methods." (2010). Electronic Theses and Dissertations. Paper 117.

https://doi.org/10.18297/etd/117

This Doctoral Dissertation is brought to you for free and open access by ThinkIR: The University of Louisville's Institutional Repository. It has been accepted for inclusion in Electronic Theses and Dissertations by an authorized administrator of ThinkIR: The University of Louisville's Institutional Repository. This title appears here courtesy of the author, who has retained all other copyrights. For more information, please contact thinkir@louisville.edu. 
READING ALOUD IN THE WRITING CENTER: A COMPARATIVE ANALYSIS OF THREE TUTORING METHODS

\author{
By \\ Rebecca R. Block \\ B.A., New College of Florida, 2001 \\ M.A., University of Louisville, 2006

\begin{abstract}
A Dissertation
Submitted to the Faculty of the

College of Arts and Sciences of the University of Louisville

In Partial Fulfillment of the Requirements

For the Degree of
\end{abstract} \\ Doctor of Philosophy \\ Department of English \\ University of Louisville \\ Louisville, KY
}

May 2010 
READING ALOUD IN THE WRITING CENTER: A COMPARATIVE ANALYSIS OF THREE TUTORING METHODS

\author{
By \\ Rebecca R. Block \\ B.A., New College of Florida, 2001 \\ M.A., University of Louisville, 2006 \\ A dissertation Approved on
}

March 29, 2010

by the following Dissertation Committee:

Dissertation Director: Joanna Wolfe

J. Carol Mattingly

Brian Leung

Dennis Hall

Ann Larson 


\title{
DEDICATION
}

This dissertation is dedicated to my parents

\author{
Rebecca J. C. Block
}

and

\section{Curtis J. Block}

who would have been so proud to see me finish my doctorate

and to my husband

\section{Mark J. Fasano}

who, I believe, is as proud as he is relieved. 


\section{ACKNOWLEDGEMENTS}

I would like to thank my advisor, Dr. Joanna Wolfe, for her indefatigable patience, assistance, and advice. I would also like to thank the other committee members, especially Dr. J. Carol Mattingly, who catalyzed my initial interest in writing center work, and all my family and friends who provided moral support and other assistance during this project: John Nowell, Elizabeth Daly, Jessica Koehler, Kelly Blewett, Cathy Love, Beth Mohon, and Melissa Wiser. 


\section{ABSTRACT \\ READING ALOUD IN THE WRITING CENTER: A COMPARATIVE ANALYSIS OF THREE TUTORING METHODS}

Rebecca R. Block

May 10, 2010

Reading aloud in writing center sessions is a common practice, one that is both understudied and under-theorized. In an attempt to begin to address this gap, this dissertation conducts an empirical analysis of three different methods of reading aloud in the writing center: clientread, tutor-read, and point-predict. Client-read and tutor-read are traditional approaches to reading in writing centers; point-predict was adapted into a tutoring method from a peer-review method by Barbara Sitko. In order to examine these methods, a study of 24 writing center sessions—eight of each method—-was conducted. Sessions were recorded, transcribed, and coded for initiator and writing issues discussed. Clients and tutors were given post-session surveys that asked for their assessment of the session and what they believed it focused upon. The four tutor participants were also interviewed about their thoughts on the study after they had the chance to work as Composition instructors.

This dissertation is divided into four chapters. Chapter One provides a literature review, Chapter Two addresses the transcript and survey analysis, Chapter Three uses tutors interviews to question common assumptions within writing center lore, and Chapter Four offers ideas for future research and implications for practice. The most striking finding of this study is the strong suggestion that reading methods have a significant impact on the outcome of tutoring sessionsespecially on the amount of attention given to global and local issues - and that current beliefs that having clients read aloud is the best way to ensure a global focus, client control, and client engagement may be incorrect. Specifically, this study found that traditional tutor-read sessions 
focused three-fourths of their conversation on local issues, whereas point-predict sessions focused only a fourth of their discussion on these issues and gave far more attention to organization, signposting, and content. Clients were also about twice as likely to initiate globally-focused discussions in point-predict sessions as in other session types. Consequently, this dissertation concludes that writing center practitioners need to more closely analyze the current reading methods they employ and seek out new reading methods that might be better suited at catalyzing global, engaged, client-focused sessions. 


\section{TABLE OF CONTENTS}

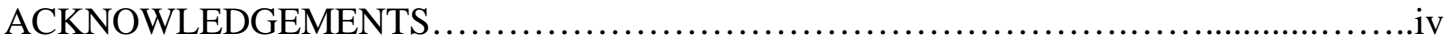

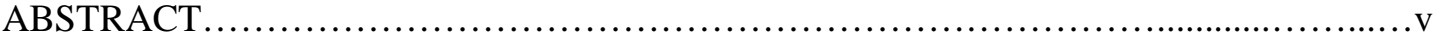

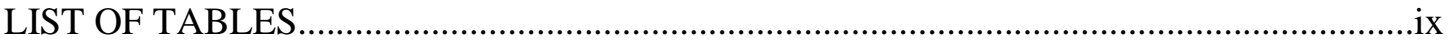

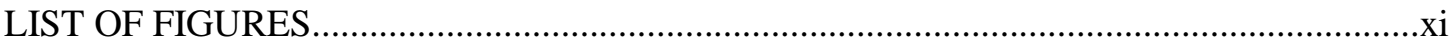

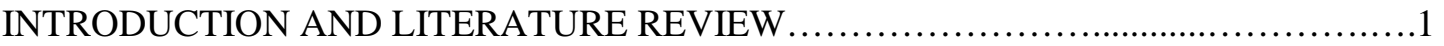

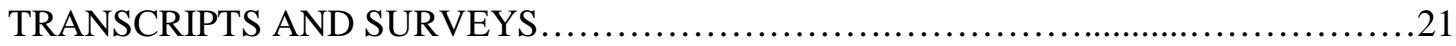

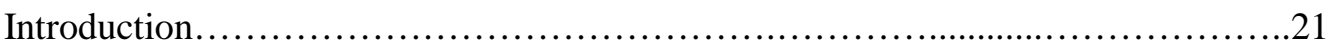

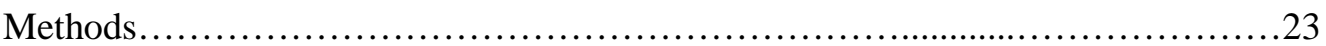

Results: Transcripts...........................................................33

Results: Surveys........................................................48

Discussion.................................................................5

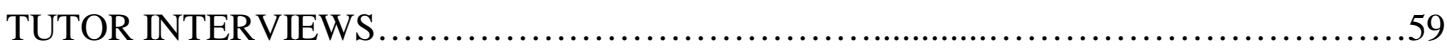

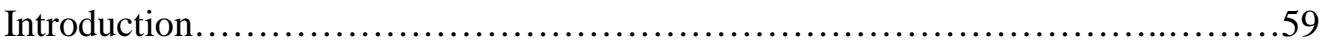

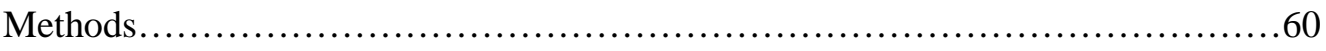

Results...................................................................62

Discussion............................................................. 88

IMPLICATIONS FOR FUTURE RESEARCH AND TUTOR TRAINING $. . . \ldots \ldots \ldots \ldots \ldots . . . . .91$

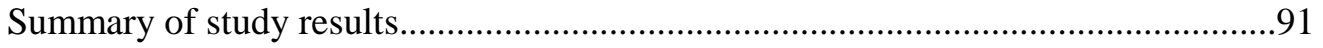

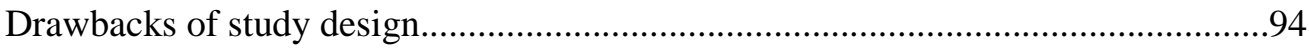

Implications for future research.........................................................................97

Implications for writing center practice...............................................................100

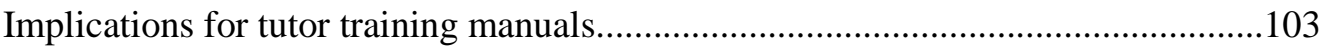




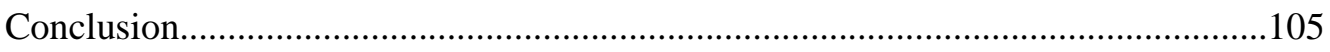

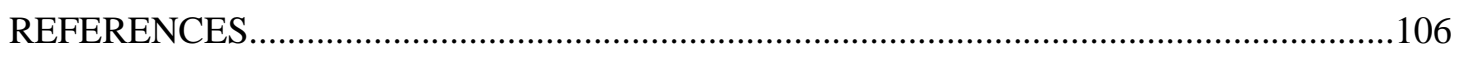

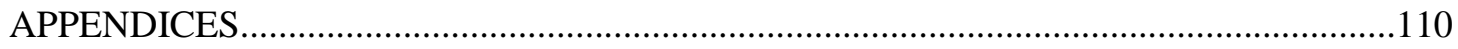

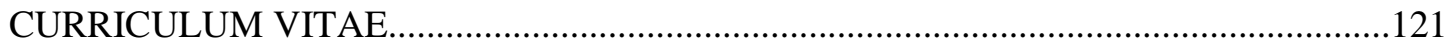




\section{LIST OF TABLES}

\section{TABLE}

PAGE

Table 2.1: The ten possible writing issues within topical chains 27

Table 2.2: Number of topical chains and turns across the three different types of sessions.......34

Table 2.3: The average number of turns and topical chains with writing issues across the three session types by tutor. .34

Table 2.4: Type of writing issue (as a percentage of topical chains containing writing issues) discussed in the three types of session.

Table 2.5: Percentage of topical chains containing writing issues initiated by clients or tutors across the three different types of sessions...

Table 2.6: Percentage of client-initiated topical chains containing writing issues that addressed sentence-level or formatting issues, content or evidence issues, and organization or signposting

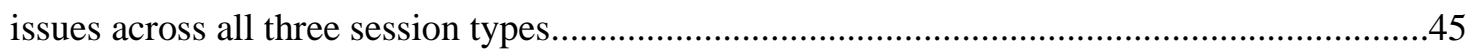
Table 2.7: Average client response across session type to the survey question "This consultation addressed ways I could revise for:" out of a 1 - 5 Likert scale, where 1 represented "Focused on a little" and 5 represented "Focused on a lot.".

Table 2.8: Average tutor response across session type to the survey question "This consultation addressed ways the client could revise for" out of a 1 - 5 Likert scale, where 1 represented "Focused on a little" and 5 represented "Focused on a lot.".

Table 2.9: Client responses to the question of what was most helpful to them about the session 
Table 3.1: The percentages of topical chains with writing issues that addressed content or evidence issues, organization or signposting issues, and sentence-level or formatting issues within

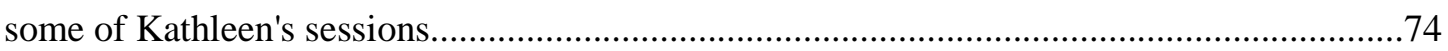




\section{LIST OF FIGURES}

FIGURES

PAGE

Figure 2.1: Percentage of topical chains containing writing issues that discussed concerns with content, evidence, organization, and signposting across the three session types........................37 Figure 2.1: The frequency with which issues of grammar, spelling, punctuation, syntax, diction or citation style arose in topical chains containing writing issues by tutor across the three conditions

Figure 2.3: The frequency with which issues of organization or signposting arose in topical chains containing writing issues by tutor across the three......

Figure 2.4: The frequency with which issues of content or evidence arose in topical chains containing writing issues by tutor across the three conditions 


\section{CHAPTER I}

\section{INTRODUCTION AND LITERATURE REVIEW}

\section{Writing center conversations on reading aloud}

Most writing center sessions begin, after some initial conversation, by the client's text being read aloud; usually the client is asked to do this reading. The ubiquity of this practice is evident in popular tutor training manuals: "One of you should read the paper aloud" (Ryan and Zimmerelli, 46); "Have the writer read the draft aloud" (Caposella, 10); "We recommend that you ask the writer to read the paper aloud to you while you take notes" (Gillespie and Lerner, 30). The reasons these manuals favor writers reading their own work tend to center around a few common concerns, particularly writer control, attention, self-initiated revision, and audience awareness. Caposella, for instance, lists having "the writer read the draft aloud" as one of the "ways to encourage a high level of involvement from the writer” (10). Other remarks from popular training manuals on these issues include:

Asking writers to read aloud engages them more in the tutoring session. (Ryan and Zimmerelli, 46)

Karen Spear points out, 'When writers hear their ideas in the presence of an audience, they understand themselves differently' (97). By reading his own work, a writer reinforces the fact that the draft belongs to him ... It also helps him hear passages that 'sound funny' even though they may look fine on paper. (Caposella, 10-11)

When the writer reads the paper, he accomplishes several things, in addition to keeping in control ... our anecdotal evidence is pretty good that the reader is listening . . . to the way the draft is working ... he's giving his draft a critical reading in ways that will help him revise. (Gillespie and Lerner, 30).

The possibility of tutors reading aloud is also mentioned, though it is generally portrayed as inferior to clients reading, as the previous quotes imply; however, tutors reading is generally believed preferable to silent reading. 
Occasionally, you may prefer to read, reacting and commenting as you go. In any case, do not simply let writers sit there and watch you read silently. (Ryan and Zimmerelli, 46)

If the writer is reluctant to read, you read the draft aloud. This is not as desirable as option C [having the writer read], but it is better than silent reading.

(Caposella, 11)

Not all writers will benefit equally from the practice of reading aloud, however. Some ESL writers will have great difficulty reading aloud ... If writers feel hesitant, don't force the issue. Offer to read for them. (Gillespie and Lerner, 30)

Only a few paragraphs out of these manuals, which typically include over 100 pages of advice on writing center practices, are spent on managing the read-aloud. This minimal focus is particularly surprising given that between one-third to two-thirds of the session time can be spent on reading, depending upon the total length of the session and the paper. In this study, the average reading in standard tutor-read or client-read sessions ended just under the half-way mark, for example.

Advice on how to conduct the reading itself is not only minimal but conflicted. Gillespie and Lerner emphasize the importance of reading the text straight through with little or no interruption, Caposella emphasizes that the writer should be invited to pause the reading and work on issues she notices as they come up, and Ryan and Zimmerelli indicate that the tutor should break in with questions, comments, and reactions during the reading.

As you listen [to the writer reading], you make a mental note not to interrupt, except to ask him to repeat something you didn't catch, and you listen to the whole paper. Listening to the whole thing from start to finish puts you in the role of the learner and the writer in the role of the expert. (Gillespie and Lerner, 30)

[The writer] can stop when he comes to a passage he wants to work on [if he is the one reading. If the tutor is reading]... ask the writer to follow along as you read, so the material will be fresh in her mind and she can stop you to discuss a passage, clarify a point, or ask a question. (Caposella, 11, emphasis added)

[If the writer is reading] explain that you will interrupt whenever you have a question or comment. Occasionally, you may prefer to read, reacting and commenting as you go... As writers talk about their ideas or read aloud, ask questions in order to help them clarify their thinking, and offer suggestions for improvement. (46, emphasis added)

Despite the clear variances in preferred practices, none of these tutor training manuals discuss the possibility of the others' approaches; in each, their advice is delivered as a simple statement of best practices. Depending on which manual the tutor read, he would conclude either that he 
should try to keep the reading going until it was concluded, encourage the client to pause the reading as she wished, or interrupt the reading himself with questions and suggestions; he would likely conclude that there isn't much debate over reading practices in a tutoring session.

However, clearly there is controversy over reading practices, beyond the conflicting advice across different training manuals. One place where this controversy is enacted is on WCenter, a listserv for writing center directors and similarly interested parties; here participants hold wide-ranging discussions on everything from administrative and funding challenges to emotionally trying tutors or clients; there are often over ten messages a day exchanged and the tone of these discussions is usually informal and friendly. Though WCenter is very popular-it has hundreds of subscribers, from writing centers across the country—and thus is influential in its reach, the transient and profuse nature of its discussions make it unlikely that those who are not part of a discussion when it happens will ever find that discussion later.

In the late nineties, WCenter was the site of a prolonged discussion on both the practice and theory of reading aloud in tutoring sessions. Portions of this discussion are transcribed within Paula Gillespie’s “Beyond the House of Lore.” Though the purpose of Gillespie’s article is to discuss the value of WCenter more broadly in complicating writing center lore, not to make any arguments about reading aloud, the examples she uses to make her point are all from the discussion that took place on WCenter about reading aloud practices. These excerpts reveal that reading aloud is much more contested than would appear from a survey of training guides and other scholarly literature on writing centers. The discussion on WCenter is triggered by a question about reading to ESL students by Vainis Aleksa:

At our center, it is common practice to take the time to ask students to read essays aloud to our tutors. When students do not want to read the essay, we offer to read it aloud for them. When we do this for ESL students, I'm wondering if it wouldn't be better to make some corrections as we read aloud, so that students could get more exposure to English. (qtd. in Gillespie 42)

However, the discussion quickly moves away from just what is best for ESL students and into a more general discussion about reading aloud practices. In this discussion a number of questions, 
hypotheses, and theoretical arguments are brought to the fore, including concerns about how reading methods affect client control and engagement, audience awareness, and attention to local versus global issues.

Concerns about client control and agency, and how reading practices intersect with them, catalyze this broader conversation about reading practices. That this conversation should arise is unsurprising, given the rationales stated in the tutor training manuals favoring writers reading their own texts aloud. Some writing center practitioners stated that they encouraged tutors to read aloud or that no one read aloud in response to Aleksa's comment, which prompted this remark by Neal Lerner:

I just have to be slightly contrary to the reading aloud thread. Isn't reading a student's paper aloud the verbal equivalent of the tutor "holding the pen" (to introduce another WC shibboleth) or writing all over the paper and thereby usurping ownership in some way? After all, what are students doing while we read their papers aloud? We'd like to think they're carefully listening...but do we know that for sure? At least when we have students read their own papers aloud, we can be reasonably sure they're focused on the task at hand. (qtd. in Gillespie 43, emphasis added)

Lerner's take here is very similar to that which underpins the perspectives in the previously cited tutor training manuals: clients should read their own papers to reify their sense of agency and control over the text. Gillespie also affirms this perspective, stating unequivocally in her WCenter posts that:

We ask students to read aloud, and we do so without tentativeness...Reading gives them [clients] a new, different context for knowing what they've written...we like the idea of giving control to the student; in reading, in emphasizing, the writer gets to choose what gets emphasis...The writer gets to interpret the paper for us. (47-8)

For both Lerner and Gillespie, then, the primary issues with reading appear to be about writer control, and this stance is presented in both their WCenter posts and their tutor training manual.

However, on WCenter, not everyone agrees that client control is the most important issue, nor that having "students read their own papers aloud" means that "we can be reasonably sure they're focused on the task at hand.” The issue of client attention and engagement is trickier 
than that, according to Beth Boquet, who notes that "I think we can't _assume_ that they're paying attention just cuz they're reading aloud. In fact, it might preclude their paying attention to the kinds of things we might want them to pay attention to." After pointing this out, she then notes that not all clients benefit as much from reading their own texts aloud as they do from hearing someone else read their text aloud; she describes a particular client, writing "when he read his paper aloud, he could not hear his own 'errors.' When I read it aloud, however, they were almost always apparent to him." She then goes on to say that while having clients read is generally preferred, if one knows the client well enough through having worked together repeatedly, one may know what "rules" to temporarily ignore (qtd. in Gillespie 43-4). In doing this, Boquet still leaves clients reading as the preferred activity, but her remarks make it harder to view this inclination as a simple one when considering how best to help clients hear their texts anew and engage their attention.

Other respondents takes a different tack, saying they prefer having tutors read clients' papers because doing so better facilitates audience awareness and the ability to pay attention. For example, Meg Larson notes that "when I read the student's paper, I'm reading with [objectivity] and unfamiliarity, like the paper's reader will do...Often the feedback I get is that it helps the student to hear it in another voice, helps the student understand what 'reader-based' prose is all about" (qtd. in Gillespie 44-5). Another practitioner, Sara Glennon, then points out another reason it can be beneficial to have tutors read, especially if the client has a learning disability, when she notes that "for some, reading aloud takes so much energy and concentration on the basic skills of decoding that they don't have anything left to listen to the words they're saying" (qtd. in Gillespie 45). Gillespie then acknowledges that "surely Sara's point applies to the larger population of writers who do not have learning disabilities" (45) —in other words, that it is possible many writers may find it easier to attend to their texts if they are not the ones reading them aloud. Interestingly, these points directly contradict the rationales presented in the tutor training manuals as to why having clients read aloud is preferable. Whereas writing center manuals say that having 
clients read increases their attention (Ryan and Zimmerelli, 46; Gillespie and Lerner, 30) and audience awareness (Caposella, 10-11), here Larson points out why tutors reading may be better suited at eliciting audience awareness from writers, and Glennon points out that reading may actually decrease, rather than increase, a writer's ability to pay attention.

Additionally, how respondents think reading methods affect the tendency to focus on local or global issues is also addressed. A few of the participants make casual references to their opinion that clients hear their own "errors” (Mullin qtd. in Gillespie 42-3; Boquet qtd. in Gillespie 43-4) or "missing words" (Larson qtd. in Gillespie 44-5) better if the tutor reads the paper. For Boquet and Larson, these are only part of the potential benefits of having the tutor read aloud, but if they believe tutor-read sessions are better at helping clients recognize their local errors it may indicate that tutor-read sessions provoke a greater focus on local errors. This is certainly the opinion of Gillespie, who says "if the tutor is reading the paper aloud, he or she can't do this [“think about large concerns first”], and might end up focusing on sentence-level concerns first” (46). Within this discussion, this particular claim goes uncontested, but given the ongoing support tutor-read methods receive from other participants and the fact that granting global issues priority status is the common goal of the vast majority of writing center practitioners, the lack of response to this point may be more of an indicator of participants not noticing this claim than agreement with it.

While this discussion happened on WCenter in 1998, a quick search of the archives reveals that the conversation on reading methods is just as unresolved today. Another discussion on reading aloud was sparked in the summer of 2009 by a different member of the listserv community, who wanted to know if the practice of encouraging clients to read aloud was common:

Our primary and most fundamental tutoring technique is to have the students...read their papers out loud...Many pedagogical reasons for doing this, but I'll assume you all know them...yes? no? I'm wondering if this is a technique the rest of you use? (Palm) 
As with the 1998 discussion, the responses to Palm’s query are incredibly varied. Some people note there are advantages to having tutors read, such as making it easier to set the pace of the session and pause for questions (Mueller), to prevent pronunciation difficulties for EFL students, or to allow writers to directly witness how the reader is reacting to their text (Harris, e-mail). Some express a preference, from slight to strong, for having clients read (e.g. Bassett; Jordan; Gantt), and some state that having anyone read an entire paper out loud is just not feasible in their writing center (Lapointe) or for their learning style (Levin). Others, meanwhile, point out that the decision of who reads has to be made based on a range of contextual factors, from those of native-language status to even "how much time has passed between the drafting and the reading" (Simpson). Interestingly, in this same message Simpson also states that "Long stretches of [reading aloud], either by writer or by tutor, can derail a tutorial. Reading all the way through a paper is not as productive as being a bit selective." This take is obviously quite different than what is advocated in Gillespie and Lerner's tutor training manual, where the tutor is encouraged to remain silent while the client reads the entire paper in one go.

Additionally, unlike with the 1998 conversation on local errors, here some claim that clients reading their own work helps them catch “mistakes” or “errors” (e.g. Byrne), while others note that tutors reading achieves this effect (e.g. Bassett). Though those who comment on this effect do not cite it as the sole reason they advocate for their preferred method, another participant picks up on the number of casual references to reading aloud as a way of helping clients recognize local issues and says:

We're talking a lot in these reading-out-loud posts about how the strategy helps with sentence-level issues, LOCs, and editing ... . all things that we tend to say hold secondary importance in the writing center to higher-order concerns like organization and generation of ideas. The end-point of reading out loud, as a primary strategy in the writing center, is also beginning to sound a lot like proofreading, which we typically dismiss as a writing center activity. (Price)

Subsequent to this comment, someone steps in to argue that tutors reading aloud actually helps tutors "pay attention to HOC [higher-order concerns]” (Biasiolli) and another participant seconds 
this claim (Rankin). Conversely, another person states that she believes that having clients read aloud helps both with addressing "LOC [lower-order concern] mistakes” and "HOCs” (Prodoehl). The original poster also mentions that he thinks having the tutor read makes it "too easy to slip into proofreading.” All of these wide ranging opinions, all based on anecdotal evidence, make it clear that there is not much agreement over the effects of reading methods on the attention given to local issues.

Toward the end of the 2009 discussion, the original poster chimes back in, expressing confusion over why anyone wouldn't have clients read their papers out loud, and describing an example of a tutor in their writing center who sometimes reads silently:

When he does that [reads silently], I can tell just by watching the body language of the student that the student is not engaged. I can see them sit back and wait for him to finish. That just confirms for me that the tutor shouldn't do the reading, even out loud; the student writer has to maintain ownership. (Palm)

As in the training manuals and the earlier WCenter conversation, issues of agency and engagement are cited as the primary reasons for writers to read their own texts aloud, and these claims are based on anecdotal evidence.

Although training manuals tend to advocate having clients read as the best practice in the majority of cases, these conversations on WCenter illustrate that this commonplace is not universally accepted. Given how these conversations clearly indicate that various directors and tutors have been questioning the limitations of always advising clients to read aloud for years, or even of reading aloud at all, the fact that there have been no published studies or analyses of writing center reading practices is surprising. ${ }^{1}$ This gap has not gone unremarked; at least two

\footnotetext{
${ }^{1}$ Though it is not a study or analysis, per se, one slight exception to this general trend is a piece by Jennifer Ritter on tutoring EFL clients in a collection of practical essays on writing center issues aimed at tutors. Ritter encourages tutors to really discuss the potential benefits and drawbacks of both the client or the tutor reading, in order to discover together what will work best in each individual tutoring situation (105-6).
} 
people in the 2009 WCenter conversation note the absence of research on this subject, and why this is problematic:

I'm wondering whether we have any research at all to substantiate the read-aloud strategy (whether by tutor or by writer) as an effective one for best practice in general--and what would make it so. I suspect that we have none. Seems to me we use this strategy in part because we believe it gives agency to the writer, because we are uncomfortable with the "teacherliness" of a tutor silently reading a paper, and because we aren't sure what else would work better. (Jordan)

Another participant notes a similar set of questions and concerns:

While reading out loud is clearly a common strategy in our writing centers, I'm wondering how well it really helps writers to become more effective and how well it really fits in with broader writing center philosophies and practices. And, I'm wondering if we have any research that clearly shows the effectiveness of reading out loud (or if we simply advocate its use because it's what we've always done or been taught to do). (Price)

One of the issues facing both tutors and writing center scholars, then, is how to bridge the gap between the mostly uncomplicated suggestions on how to approach reading client texts in writing center consultations and the more nuanced, but underdeveloped, perspectives offered on the practice in places like WCenter. There is a real need in the writing center community for research into the actual effects of different reading practices in tutoring sessions.

These anecdotally based conversations and their differences from the tutor training manuals prompt questions about what actual effects different reading strategies have on tutoring sessions. These questions point to two components of reading methods that are under debate: (1) who reads and (2) whether the whole text or only portions of the text should be read before offering reactions. Writing center practitioners seem to believe that variations in the writing method affect writer agency and control, engagement, audience awareness, and focus on global issues, but they are far from agreed-upon about which methods support these goals. The constant reference to anecdotal evidence, as well as Price and Jordan's specific comments on the lack of 
research, does seem to indicate a general awareness that there is a lack of research to support the "lore” about which method is best, though this lack seems to bother some practitioners less than others.

However, there is a body of research that begins to examine the effects of reading aloud on writers. This research uses think-aloud protocols as a method for heightening audience awareness and has been shown effective in promoting productive revision (Higgins; Harris, “Modeling”; Schriver, “Revising;” Sitko; Couzijn). Think-aloud protocols have substantial similarities to methods of reading aloud that encourage tutors and clients to pause frequently to offer reactions and ask questions. One tutor training manual, in fact, mentions alternate approaches to reading aloud that resemble think-aloud protocols (Ryan and Zimmerelli, 46-7). Even though think-aloud protocols are similar to reading aloud and justified as a pedagogical technique for reasons similar to those raised by writing center practitioners, especially regarding the promotion of audience awareness and engagement, this research has not been examined in writing center scholarship. Since these writing center goals are so similar to the effects catalyzed by these think-aloud protocols, examining studies like these suggests fruitful areas for inquiry in writing center research.

\section{Pedagogical research on thinking aloud}

The history of using think-aloud protocols in composition is a somewhat mixed one. They are perhaps best known for being used to try to discover the actual thinking processes of writers as they brainstormed and wrote (e.g. Flower and Hayes), a practice that fell out of favor as scholars pointed out issues with cognitive approaches to Composition in general (e.g. Rose, "Narrowing”; Berthoff). Specifically, some made the argument that the act of thinking aloud would, by its very nature, change the thinking process and therefore invalidate the results of studies conducted using this method. As Patricia Bizzell put it, "protocol analysis can lead to a 'self-fulfilling' prophecy because its assumption that the subject's words mirror her thinking allow 
the researcher to claim that certain thought processes have occurred if certain words appear in the protocol" (406). As a result of critiques like Bizzell's, protocol analysis stopped being used as a way of trying to discern what writers composing processes were based on what they "thought aloud" as they wrote.

However, observing people thinking aloud as a way of understanding how they are interpreting texts, rather than of determining "authentic" mental composing processes, has regularly been shown to be an extremely useful process as a tool for understanding texts (Schriver, Dynamics). This approach is often used within the fields of human-computer interaction (Kuniavsky) and technical communication to troubleshoot user interface and instruction manuals, as watching a reader try to interpret a text is a quick way of determining how effectively that text is communicating its message (Anderson, 425-7).

Within writing-centers, some early research used think-aloud protocols as a diagnostic tool for struggling writers, most notably Rose’s study on writer’s block (“Rigid Rules”). The goal of this study was to heighten writer's self-awareness of their own revising processes. In this study, he taped student writers writing and then showed them these tapes and asked them to comment on the writing strategies they were using as they watched themselves write. These strategies were then discussed with the students to help them identify which of their strategies were helping them overcome writer's block and which actually contributing to it. Most of the students who experienced writer's block were helped by this self-reflective and directed use of thinking aloud. However, while this use of thinking-aloud as a diagnostic tool was certainly valuable, it does not seem appropriate as a general writing center practice for clients who come in requesting help on a specific text.

Think-aloud protocols with different kind of pedagogical goal, that of modeling expert processes, have also been used to some extent in writing centers. Harris discusses the success she had at her "writing lab" working one-on-one with a student who was struggling in his 
composition course with writing. She turned to a combination of modeling and thinking-aloud as a means of helping him in their tutoring sessions. As she describes it:

I would demonstrate what I was describing by writing and by offering him a verbal protocol of what I was thinking as I wrote...We would begin by having him give me a topic to write on for fifteen to twenty minutes. I would begin by thinking about the rhetorical situation, the "who," "'what,"' "why," plus a few operators to achieve my goal. After these few minutes of planning, I would start writing and keep writing...When I was done, we would reverse roles, and I would then give him a topic. As much as possible, he would try to copy the behavior he had observed. All of these instructions were preceded by brief explanations of what he would observe and the principles he would try to use. (78)

Harris then notes that "after three one-hour sessions Mike's writing improved noticeably" (78). Though this example blends both modeling and think-aloud techniques, Harris's case-study is somewhat more promising than Rose's in terms of providing possible uses of thinking aloud within writing center practice, as this method could be employed within tutoring sessions with clients who were interested in working on specific texts.

Outside of the writing center, think-aloud techniques have been shown to be a useful pedagogical tool as well. For instance, Higgins recorded expert writers thinking aloud about how to organize and present evidence in order to make an effective written argument, another method of using thinking-aloud to produce expert modeling for writers. She then presented these recordings to student writers and had them analyze and name their own strategies based on what they heard, strategies they then used for organizing evidence within their own argumentative papers. Higgins reports that students found this process useful and that it seemed to help students move from simply parroting their evidence to actually making arguments with it.

Other studies have not only employed thinking aloud as a means of modeling expert writing and revision strategies, as Higgins and Harris did, they have also used thinking aloud as a 
way of providing audience feedback to writers . For example, in one particular study by Couzijn, two different methods that employed writers listening to someone thinking aloud were found to be more useful to improving writers' abilities to compose brief written arguments than the more common practice of “learning-by-doing.” In one form of thinking aloud, writers watched other writers think aloud as they composed the same kind of arguments the writer-observers were going to be composing later; in the other form of thinking aloud, writers wrote their initial brief arguments and then observed readers reading and thinking aloud about them. In this second method, readers were prompted to think aloud about what argument the writer was trying to make and whether and why the argument fit the assignment guidelines; this practice is similar, albeit more detailed, to the common writing center practice of examining clients' texts in relation to their assignments and helping clients see where they may be meeting or falling short of the expectations outlined therein. In Couzijn's study, both of these groups of writers were ultimately more successful with their written arguments than writers who were given textual models of the argument and the argument structure and then told to write their own (the "learning-by-doing" group); observing people thinking while writing and reading transferred to an improvement in writing skills for the observers (132). The implication of this study, then, is that thinking aloud is useful to writers both when listening to someone model the act of deciphering and responding to a writing assignment and when listening to a reader think through, react to, and evaluate the writers’ own attempt to respond to that assignment.

Other studies that employed think-aloud protocols discovered the usefulness of students listening to another reader's feedback on a text as a means of improving their own ability to identify and diagnose problems in texts on their own. For example, Schriver asked students to detect and diagnose confusing or problematic areas in the texts they were reading ("Revising”). Schriver found that students who did this and then followed this practice with observing a thinkaloud reaction from another reader doing this were better able to detect and diagnose problematic areas in new texts on their own than students who were taught with more common composition 
classroom methods (such as peer-review). This method helped, Schriver hypothesized, because it "appeared to illustrate the reader's active online processing, providing locative information about when and what derailed the reader's understanding" (203). The goal of Schriver's exercise was based on the premise that writers cannot make effective revisions to their essays if they cannot first detect and diagnose the problems the text will likely pose for their audience; one shortcoming of its scope is the fact that it did not have participants examine their own writing or make any revisions to their writing based on the practices, so the transferability of the practice is unknown. Still, despite this shortcoming, and especially in light of the other studies discussed above, the overall findings are promising for writing center practitioners. Generally, writing centers hope to help clients not simply with the text they bring but with their overall writing and revising skills. Schriver's study indicates that students who hear someone else think-aloud about specific problematic areas of a text and what effects those areas are having on her as a reader will improve their own ability to both detect and diagnose problematic areas of texts on their own. If this skill is transferable to their own writing, it would indicate that this method might be well suited to helping writing centers meet their goal of improving writers' general skills and not just their individual papers.

One study employed a structured method of thinking-aloud in response to texts that was similar to both Couzijn and Schriver's methods, but somewhat more directly suited to aiding in the revision of specific texts while still developing more broadly applicable writing skills (Sitko). As such, this study, though not conducted in a writing center but on peer-review practices in a composition classroom, is the most promising to writing centers. Sitko had students prepare for peer-review workshops by reading examples of, discussing, and then practicing a method of response to written texts that asks the reader to pause and summarize main points and predict what they expect will come next in the text. This method is hereafter referred to as the "pointpredict” method of reading aloud. The following example of a point-predict response comes from one of the transcripts within my study, and illustrates the practice: 
Reader: [Begins reading the writer's text] "Located on a lone white wall in the [name omitted] Art Museum lays a portrait entitled 'Emma Suarez' photographed by Alberto Garcia Alix. It is a photograph that on the surface looks to be just a woman with an expressionless face against a gray background, but upon further interpretation could prove to be...the black white good versus evil aspect portrayed throughout the photograph." [Stops reading] Okay...I find this "black white good versus evil" abstract to be confusing...in the way the words are lined up?

Writer: Right

Reader: That said, I'm interpreting what you're saying is...that the purpose of this paragraph was to locate me in the setting of the Art Museum and to show me this particular picture, Emma Suarez, and also I sense that you're kind of main subject matter is going to be the connection of the subject matter to the blackness and whiteness of the picture--

Writer: Right

Reader: --um, and so...my prediction here is that the following paragraph is going to be picking up with the black and white theme and kind of expanding it. Okay. [Resumes reading writer's text].

The purpose of the method is to help writers see how meaning is actually communicated to readers, giving writers specific information about where to revise their texts if it failed to communicate their intentions. Students who employed this method in their peer-review groups developed a stronger sense of rhetorical awareness and found the workshops, and the revision process, to be more productive. As with Schriver's method, Sitko's provides precisely located feedback for writers; as with Couzijn, it does so in a way that illustrates the reader's immediate reaction to the text. Thus, it incorporates many of the most promising elements of these other studies into one method.

Sitko's method introduces something new beyond what these other studies employed, however, by incorporating the element of prediction into the feedback. Having readers not only react generally to the writing but specifically make predictions as to what will come next gives writers the opportunity to compare their intentions with the expectations of their readers, thus potentially gaining a better understanding of not only what a reader's reaction is but how the writing is shaping future reactions to later parts of the text. The example of a reader responding in the previous paragraph helps illustrate this--rather than simply stopping with the reader saying "I find this 'black white good versus evil' abstract to be confusing," a comment that is certainly a 
valid and even valuable reaction, the reader goes on to summarize what she understands the main point to be thus far and what that causes her to predict for the rest of the paper. In this way, the writer has the opportunity to not only discover that something is confusing, but also to hear how her writing has created an interpretation and, subsequently, an expectation for the text. If this prediction does not match up with what the writer actually does, it gives the writer specific information about where there is a gap between their intentions and their text.

As a tutor and instructor, I was first drawn to this method due to the results of a pilot study on creative writers as part of my Master's thesis. One of the results of this pilot study was that writers were most likely to find feedback useful if that feedback demonstrated whether the reader "got" what the writer was trying to do with the text. As point-predict provides evidence of how the reader is understanding the text as she reads it, it seemed like it might be a good way of meeting this demand. Additionally, writers in this pilot study stated that feedback that tied specifics within the text to larger reactions or concerns was also an essential part of good feedback; the point-predict method also seemed well suited to meet this need since it requires readers to base their broader summaries and predictions about the text on the specific elements within the text that prompted those conclusions. Finally, this method appealed to me because Joanna Wolfe, Director of Composition at the University of Louisville, had often spoken of the method's usefulness within writing conferences with students, and it left me curious about the effects it might have on tutoring sessions.

\section{Applying thinking aloud research to writing center consultations}

Sitko's method, however, was not tried out in a writing center environment, and this change of environment will undoubtedly influence the results of my study, though how exactly this change in environment may change the results will be uncertain until the results are analyzed. However, one can make a few predictions as to how the various pros and cons of thinking aloud might play out in writing center sessions. One factor that could influence the importing of Sitko's 
method into a tutoring session is that, although the actual act of summarizing points and making predictions is at the heart of her study, her methods also employed having students first look at a model of a reader's point-predict response to a text, then a model of a writer thinking through this response and incorporating it into the revision process, and only then actually exchanging their writing with classmates and doing it themselves. Since tutoring sessions are only 45 minutes long it will be impossible to employ all three steps of this process, and this could potentially decrease or even eliminate the benefits of employing this method if it turns out that the preliminary steps are essential to generating a framework within which a writer can structure and use the pointpredict response. Thus, one of the goals of the study will be to determine whether any noticeable effects occur at all between point-predict sessions and more traditional session types. Additionally, one of the questions tutors will be asked to discuss after the study is completed is how their own training affected their ability to employ this method, and whether and how that training could be improved should future researchers or tutors wish to employ these methods.

The time limit of the session may pose another challenge as well, since presumably reading a text aloud without pausing to summarize and make predictions will take less time than reading a text aloud with those pauses. Thus, one of the questions this study will need to examine is whether the use of different reading methods affects the number of writing issues that are discussed. On a related note, this study will also need to examine whether the potential increase in time spent on the tutor talking decreases the number of issues clients raise during the session.

The potential effects of the methods themselves on what is discussed during tutoring sessions is one of the largest questions this study will seek to answer. Generally writing center manuals and practitioners both advise giving a higher priority to global issues than local ones-one of the concerns brought up in the more recent WCenter discussion on reading aloud practices regarded whether having clients read could increase the focus on local issues, for instance, and the original poster, Rebel Palm, responded that of course client-read sessions focused on global concerns first and foremost. Ryan and Zimmerelli's advice to tutors to "remember that it is better 
to cover larger, more global issues like content and organization before dealing with matters like sentence structure and surface errors" (21) reflects this goal accurately, and similar sentiments are echoed throughout writing center literature, tutor training manuals, and listservs. Just how reading practices intersect with this goal, then, will be important to examine.

The opinions expressed on WCenter also lend to questions about the levels of client engagement, control, and audience awareness. These questions are harder to answer, since determining how to measure for these factors is a tricky process. Thus, though this study will not seek to comprehensively answer these questions, it will seek to touch on them by analyzing levels and kinds of client initiation, client survey responses, and tutor perceptions of client engagement and behavior during the tutoring session. In this discussion in particular, the primary goal of this study will be to offer some hypotheses for future research and questions for tutors and writing directors to consider when analyzing their own reading processes.

In order to examine all these possibilities, this study will examine writing center consultations under three different conditions: writers reading their own work aloud, tutors reading writers’ work aloud, and tutors reading writers’ work aloud using Sitko’s method of pausing to think aloud about what the main points of the text appear to be and what they therefore predict will come next. Through this study, I hope to begin to answer questions about the differing effects of these practices on writers, tutors, and tutoring sessions. It is important to note that since this study is quasi-experimental in its approach, it will seek only to begin to outline the potential cause-effect relationships of these practices (Charney), giving future researchers on reading aloud better hypotheses and questions on which to base their studies.

\section{Research questions}

- What effect, if any, do different reading methods have on what kinds of writing issues are discussed in tutoring sessions? 
- What effect, if any, do different reading methods have on the amount and type of writing issues initiated by clients?

- Do different reading methods affect individual tutors differently? If so, how?

- How do clients and tutors perceive different reading methods?

- How do tutors' perceptions of reading methods compare to the results of the study data?

If there are differences, how do tutors explain or respond to these differences?

- What implications do the results of this study have on tutoring practices, if any, and for future research? In particular, what hypotheses might this study present on issues of importance to writing center directors and scholars, such as concerns about writer agency, engagement, and audience awareness?

\section{Chapter outline}

Chapter one, examines the pertinent background research on reading aloud and thinking aloud, and lays out the focus for the rest of the dissertation. Chapter two examines the results of the tutoring sessions and clients' and tutors' initial reactions to them. It does this by describing the methods employed for analyzing the transcript and survey data, examining the results of these methods, and discussing some of the implications of these findings. Some of the most significant findings indicate that the point-predict method leads to a substantially larger focus on global issues, such as content and organization, and a significantly lower focus on local issues, such as grammar and punctuation, than occur in the more traditional session types. Between the more traditional session types, client-read and tutor-read, tutor-read appears to focus even more on local issues than client-read sessions. Clients initiated discussions of writing issues in all sessions with about equal frequency, but in point-predict sessions the issues clients initiated were much more likely to be global than local, with the reverse trend in client-read and tutor-read sessions. 
Chapter three examines the tutors' thoughts in more detail, by combining further details from the transcript data with tutors' comments from a follow-up interview that was conducted eight months after the conclusion of the study. During this time, all four tutors had taken on teaching responsibilities, and so the effect of teaching on their perceptions of tutoring practices in general, and reading practices in particular, is also examined. These interviews help explain why point-predict had such a strong influence on the kinds of issues discussed in tutoring sessions and how reading structures affect tutoring sessions generally. It also explores what tutors' discussions reveal about the potential causes of tutoring sessions giving undue focus to local issues and complicates current understandings of client control and engagement. Chapter four, the final chapter, summarizes the implications of the preceding chapters on writing center practice and discusses possible avenues for future research. 


\section{CHAPTER II \\ TRANSCRIPTS AND SURVEYS}

\section{Introduction}

As discussed in the previous chapter, the practice of reading aloud in writing center consultations has been understudied. There is a particular need for an examination of the actual effects of different reading practices on tutoring sessions, as there is currently only hypotheses and anecdotal evidence underlying approaches to these practices (Gillespie, "Lore").

Furthermore, reading practices, when they are discussed at all, are generally focused on deciding between a simple duality: either the tutor reads aloud or the client does. This kind of discussion fails to take into account the possibility that different methods of clients or tutors reading aloud could have different effects on the consultation. As discussed, the result of this minimal consideration appears in the form of simple dictates in tutor training manuals, where tutors are generally advised to have the clients read aloud if at all possible. Suggestions like this fail to take into account the variety of writers, texts, and contexts that tutors will encounter, and are not supported by any real evidence.

One approach to reading texts aloud that has previously been studied only in classroom settings is Barbara Sitko's point-predict method, which involves readers pausing at least once a paragraph to summarize what they perceive the main point(s) of the text to be thus far and predict what they expect will come next. The purpose of this method is to allow writers to see, live and in detail, whether their intended meaning and structure is actually apparent to readers as they read it. As discussed previously, when this method was employed in peer-review settings in composition classrooms, writers found it useful at helping them understand what to revise and how to take 
readers into account in revision. Since writing centers are perpetually hoping to help writers improve their ability to revise, it is a method worth investigating within tutoring sessions. It could make it easier for tutors to pinpoint why something in the text does not appear to be working or enable clients to make a more tangible connection between what they have written and how it affects someone reading it. Alternately, it could prove to do nothing different from what current approaches to reading texts do. Either way, however, it is a useful technique to study in order to get a better understanding of how different reading methods might influence tutoring sessions.

This study begins to address the gaps discussed above by examining tutoring sessions under three different conditions: clients reading their texts aloud, tutors reading clients' texts aloud, and tutors reading clients' texts aloud while employing Barbara Sitko's point-predict method. The first two conditions are the two most common practices in writing centers; the third introduced the tutor participants to a new method of reading and responding to client texts. The goal of studying all three of these methods together was to discover what the actual effects were of traditional approaches to reading on tutoring sessions and client and tutor perception of these sessions, whether there was any appreciable difference between these effects, and what difference, if any, was made by introducing an entirely new method to the practice of reading aloud.

The specific research questions explored in this chapter include:

(1) What effect, if any, do different reading methods have on the kinds of issues that are discussed in tutoring sessions? Do certain reading methods elicit a greater focus on global concerns, like content or organization, or local concerns, like mechanics or syntax?

(2) Are there noticeable differences between the two traditional approaches to reading in tutoring sessions, client-read and tutor-read? If so, what are those differences? 
(3) What effect, if any, does introducing a new method of reading, point-predict, have on tutoring sessions?

(4) What effect, if any, do different reading methods have on how often clients initiate topics of discussion in tutoring sessions?

(5) What effect, if any, do different reading methods have on the kinds of writing issues that clients initiate in tutoring sessions?

(6) What are client and tutor perceptions and preferences regarding different methods of reading aloud? Do their perceptions support or conflict with the results of transcript analysis?

What follows in this chapter is a discussion of the methods employed to answer these questions, the results of the analyses of the sessions and the surveys clients and tutors completed, and a discussion of the implications of these results for writing center practices and future research.

\section{Methods}

\section{Participants}

\section{Clients}

Twenty-four clients of the University Writing Center participated in this study. They were chosen from clients who had already arranged appointments at the writing center during the late Spring of 2009. Nineteen of the 24 clients were female, 12 were between the ages of 18-22, three were between 23-30, and the remaining nine were 31 or older. Eight of the clients wrote "Freshman" as their year in school, one wrote "Sophomore," one "Junior," eleven "Senior," and the remaining three did not answer the question. Because of a data collection problem, many students did not answer the question about their native language; however, those answers that were collected indicate that at least two of the 24 are NNES. Majors came from across the university: three clients recorded "Marketing" or "Business" as their major, four wrote 
"Nursing," two wrote "English," three "Fine Art," five "Political Science," three "Justice Administration," one "Psychology," one "Biology," and two left the spot either blank or wrote "Undecided." As such, this group represents a fairly diverse selection of ages, majors, and years in school, a less diverse group in terms of gender, and an uncertain group in terms of Englishspeaking status.

Only clients who had at least 24 hours to revise the text they brought in were invited to join the study, as the collection of revisions was initially one of the central components of this study. The post-session survey revealed that the majority of clients (all but 4) actually had over two days to revise. Additionally, all but one were bringing assignments to be reviewed for the first time, though most (18 of the 24) had visited the WC before with different assignments.

\section{Tutors}

Four tutors participated in this study, each conducting two tutoring sessions of each session type. Thus, six sessions total (two client-read, two tutor-read, and two point-predict) were observed for each tutor. Tutors were selected based on willingness to participate in the study; because of the greater time commitment involved for tutors than was involved for clients, this naturally lead to volunteers who were more invested in reflecting upon their tutoring practices. All the tutors who were willing to participate were female and were first year Master's students pursuing a degree in English. All of the tutors were between 22 and 27 yrs. Tutors were given \$20 each as total compensation for their time.

\section{Procedures}

\section{Clients}

Clients who arrived for their appointments were asked if they might be interested in participating in a study that would involve audio-taping their session and then asking them to fill 
out a brief survey after their session. Those clients who said yes were asked if they had at least 24 hours until their final paper was due; if they had less than this amount of time they were excluded from the study. Clients were given an IRB consent form to read and sign before the start of the study; this form said only that the purpose of the study was to examine different methods of reading aloud in tutoring practices. Clients were not told anything else about the purpose of the study before beginning their sessions. When their session was over, they were given a two page survey to complete, described below. They were also given five dollars as compensation for their time, and the option to send in their revisions and answer a second survey for an additional ten dollars if they wished. Only about a third of the clients took this option; this will be discussed in more detail later.

Tutors

Tutors were not given any training or information about the purpose of the study, other than the general information that the researcher wished to learn more about different methods of reading aloud in tutoring sessions, before beginning their participation in the study. Tutors conducted all their client-read and tutor-read sessions before doing any point-predict sessions so as to prevent the point-predict method from influencing their tutoring. Tutors did not receive training in the point-predict method until their other sessions had already been completed (with one exception, which will be discussed in the later chapter on tutors).

Tutor training in the point-predict method consisted of tutors being shown a description of the method from Barbara Sitko's article, along with transcripts from that article detailing the method in practice. Tutors were then invited to observe the researcher employing the method on a copy of a real student paper. Each tutor then practiced the method on another paper in the group, and the researcher offered feedback as they did so. Tutors then had the opportunity to ask questions about the method before putting it into practice in a real session. All tutors introduced the point-predict method to the clients by reading from a brief script that explained the purpose of 
the method (see Appendix A). The first point-predict session that each tutor conducted was observed live by the researcher, and each tutor received further feedback about how to refine use of the method after that session. Both those initial sessions and their second unobserved sessions were included in the study results.

\section{Transcriptions}

As mentioned, sessions were audio-recorded. These tapes were then transcribed in full and prepared for coding. Transcript coding began when the reading of the text began and ended once all concerns with the text had been discussed, leaving off end-of-session chit-chat if there was any. Coding began at the reading as some tutors spent significantly longer talking before the reading than others, and some forgot to turn their tape recorders on for the first moments of their conversations. Beginning at the reading was the best way to ensure a consistent coding start point for all sessions.

\section{Transcript Coding}

\section{Topical chains}

Transcripts were broken down into topical chains. The topical chain, although imprecise, is an appropriate unit of analysis when the researcher is concerned with the extent and depth with which topics are developed (Geisler, 35), and, as this was one of the primary interests in this study, this was the discourse unit chosen. A topical chain was judged to end whenever the area of the paper being discussed was changed. So, for example, if the client and tutor were discussing the content of one paragraph, and they then moved to discussing another paragraph, it was marked as a new topical chain. Consequently, multiple writing issues could be discussed in a single topical chain, and the coding for writing issues, discussed below, took this into account. Areas of the text, rather than individual writing issues, were chosen as the breaking points 
because multiple writing issues were often raised in conjunction with one another, as later excerpts in the results section will illustrate.

\section{Coding category definitions}

\section{Topical chain initiator}

Topical chains were coded for initiation. Either the tutor or the client could initiate the topic under discussion in the topical chain. It was usually, but not always, the first speaker in the chain who was judged to be the initiator. For example, if a tutor said "What else do you want to talk about?" and the client said "My thesis statement," then it was the client who was marked as initiating the topic. Topical chains that involved the reintroduction of a subject previously discussed in the session were coded as being initiated by whomever reintroduced the subject, regardless of who initiated the subject previously. Instances where reading aloud was the only activity in the topical chain were coded as being initiated by the reader.

\section{Writing issue(s) discussed}

Each topical chain was coded for the presence of writing issues, though not all topical chains contained writing issues. A writing issue was defined as any explicit disjuncture between the paper as it was and as it might be. Topical chains with writing issues could contain up to four writing issues, though most contained less. The first writing issue code given a topical chain reflected the main subject of that chain, with the second slot marking the slightly less significant issue, and so on. Ten writing issues were identified: content, evidence, signposting, organization, syntax/diction, grammar or mechanics, citation style, writing conventions, writing and research strategies, and unclear. Table 2.1 describes how these were defined.

\section{Table 2.1: The ten possible writing issues within topical chains}

\begin{tabular}{lll}
\hline Code & Definition & Examples from transcripts \\
\hline Content & Any discussion of the actual & Tutor: Yeah, because this last \\
& subject matter of the paper, as & sentence, "In the end it results in a \\
it is or as it might be. & $\begin{array}{l}\text { teenage pregnancy all because the } \\
\text { parent wasn't there." That does }\end{array}$ \\
\hline
\end{tabular}




\begin{tabular}{|c|c|c|}
\hline & $\begin{array}{l}\text { This includes discussions of } \\
\text { the need for further content, } \\
\text { such as explanation, in body } \\
\text { paragraphs or the conclusion. } \\
\text { Discussions of content } \\
\text { frequently occur with } \\
\text { discussions of other global } \\
\text { writing issues. }\end{array}$ & $\begin{array}{l}\text { sound like the other things you } \\
\text { were talking about, particularly } \\
\text { emotional unfulfillment. So, maybe } \\
\text { instead of doing that there, } \\
\text { focusing, um, what they're actually } \\
\text { not getting from the parenting. } \\
\text { OR } \\
\text { Client: Should I explain what that } \\
\text { means? } \\
\text { Tutor: Yeah, I felt like that was } \\
\text { vague. } \\
\text { Client: Uh, the conclusion's a little } \\
\text { weak }\end{array}$ \\
\hline Evidence & $\begin{array}{l}\text { Any discussions on the use of } \\
\text { or need for support in a paper. } \\
\text { This can include discussions } \\
\text { on how to incorporate or } \\
\text { change the use of research } \\
\text { within a paper, where the } \\
\text { client might want more support } \\
\text { for claims and why, or what } \\
\text { form of evidence is needed or } \\
\text { already in use. }\end{array}$ & $\begin{array}{l}\text { Tutor: But if you have, you know, } \\
\text { like one or two really memorable } \\
\text { quotes, I think that might enhance } \\
\text { it. } \\
\text { Client: That was going to be } \\
\text { touched on in the research...but the } \\
\text { research didn't make any sense to } \\
\text { me, so I'm having a really hard time } \\
\text { with that. }\end{array}$ \\
\hline Signposting & $\begin{array}{l}\text { Any discussions of the use of } \\
\text { or need for forecasting what } \\
\text { appears later in the paper. } \\
\text { Most commonly this involves } \\
\text { discussion of the introduction } \\
\text { (especially the thesis } \\
\text { statement), topic sentences and } \\
\text { transitions, or subheadings. } \\
\text { Signposting was distinguished } \\
\text { from organization because we } \\
\text { hypothesized there would be } \\
\text { more discussions of } \\
\text { signposting specifically in } \\
\text { point-predict sessions, and we } \\
\text { wanted to be able to measure } \\
\text { whether this hypothesis was } \\
\text { accurate. }\end{array}$ & $\begin{array}{l}\text { Client: Okay, so I should maybe } \\
\text { have a transition right there? } \\
\text { OR } \\
\text { Tutor:... and because you have } \\
\text { those sub-headings...I thought that } \\
\text { you were just moving on to } \\
\text { completely different topics or } \\
\text { something. } \\
\text { Tutor: I saw a few things that could } \\
\text { be the thesis, so point out what } \\
\text { you're going for as a thesis. }\end{array}$ \\
\hline Organization/Structure & $\begin{array}{l}\text { Any discussion of the layout or } \\
\text { order of sections that cannot be } \\
\text { classified as signposting. } \\
\text { Discussions of organization } \\
\text { tended to be much broader } \\
\text { than signposting discussions }\end{array}$ & $\begin{array}{l}\text { Tutor: I think you have a couple of } \\
\text { options. It seems like it would } \\
\text { make sense to do it after you've } \\
\text { gone through with all your } \\
\text { interviews,... or it could make sense } \\
\text { in the conclusion, or,... if you feel } \\
\text { like it's that central, start with }\end{array}$ \\
\hline
\end{tabular}




\begin{tabular}{|c|c|c|}
\hline & & $\begin{array}{l}\text { putting it in the introduction too. } \\
\text { OR } \\
\text { Client: I knew this paragraph } \\
\text { wasn't in the right spot. Yeah, this } \\
\text { needs to go after that. }\end{array}$ \\
\hline Syntax and Diction & $\begin{array}{l}\text { Any discussions on the syntax } \\
\text { or diction that is currently in } \\
\text { the paper or that might be in } \\
\text { the paper. }\end{array}$ & $\begin{array}{l}\text { Tutor: Um, "all in the past," that } \\
\text { sort of struck me odd when I first } \\
\text { read that, 'cause it's like you're } \\
\text { referring to all...teachers...but "all } \\
\text { in the past," kind of sounds like } \\
\text { you're talking about a period in the } \\
\text { past, not all teachers. }\end{array}$ \\
\hline Citation Style & $\begin{array}{l}\text { Discussions of the } \\
\text { requirements of any citation } \\
\text { style, such as MLA, APA, } \\
\text { Chicago, etc. }\end{array}$ & $\begin{array}{l}\text { Client: I know I have to fix my } \\
\text { MLA, but I was just gonna hurry } \\
\text { through. }\end{array}$ \\
\hline $\begin{array}{l}\text { Grammar, Spelling, or } \\
\text { Punctuation }\end{array}$ & $\begin{array}{l}\text { Discussions of any rules of or } \\
\text { mistakes in spelling, grammar, } \\
\text { or punctuation. This category } \\
\text { also includes small formatting } \\
\text { issues, like spacing and } \\
\text { indenting, or any other form of } \\
\text { mechanics. }\end{array}$ & $\begin{array}{l}\text { Client: Okay, I'm gonna change } \\
\text { that too right there. } \\
\text { Tutor: Yeah, exactly, just the } \\
\text { subject-verb agreement. }\end{array}$ \\
\hline $\begin{array}{l}\text { Writing and research } \\
\text { strategies }\end{array}$ & $\begin{array}{l}\text { Discussions of procedures } \\
\text { writers can follow for } \\
\text { improving current and future } \\
\text { papers--revision, editing, and } \\
\text { research strategies, generally. }\end{array}$ & $\begin{array}{l}\text { Tutor: Yeah, and I would suggest, } \\
\text { yeah, after the session when you're } \\
\text { working on another paper, reading } \\
\text { out loud to yourself would be } \\
\text { helpful } \\
\text { OR } \\
\text { Client: So I can go ask a librarian } \\
\text { for help finding the research I } \\
\text { need? }\end{array}$ \\
\hline Writing conventions & $\begin{array}{l}\text { Discussions of the conventions } \\
\text { of particular genres of writing, } \\
\text { academic standards, } \\
\text { expectations implied or stated } \\
\text { in the assignment, and any } \\
\text { other non-mechanical } \\
\text { conventions of writing. }\end{array}$ & $\begin{array}{l}\text { Tutor: for the purposes of this } \\
\text { assignment, and the specific } \\
\text { drawing out of answers to answer } \\
\text { the question, do you feel like it's } \\
\text { appropriate to talk so much about } \\
\text { yourself? }\end{array}$ \\
\hline Unclear or generic & $\begin{array}{l}\text { Discussions where the } \\
\text { disjuncture alluded to is very } \\
\text { vague or the nature of the } \\
\text { disjuncture is uncertain. } \\
\text { Note: vague comments } \\
\text { without any disjunctures were } \\
\text { coded as having no writing } \\
\text { issue. }\end{array}$ & $\begin{array}{l}\text { Client: Overall do you think it's a } \\
\text { nice paper? } \\
\text { Tutor: Mm-hmm. I think the things } \\
\text { you need to work on are not really } \\
\text { huge, so, and you've picked a good } \\
\text { topic } \\
\text { OR } \\
\text { Client: [laughs] It's like that thing. } \\
\text { Tutor: Okay. } \\
\text { Client: I told you it was bad! } \\
\text { Tutor: No no no, it's alright. }\end{array}$ \\
\hline
\end{tabular}


If there was no writing issue, the topical chain was still coded for who initiated, but was simply marked as "No writing issue" in this category of the coding. Chains that were coded as lacking any writing issue typically fell into one or more of five different categories. The first was discussion of writing center procedures, such as explaining how much time there is or how to make additional appointments. The second was discussion of the paper's status, such as when it was due or what draft this was. The third was reassurance, such as a tutor saying "don't worry, this will be fine" or a client saying "thanks, that was really helpful." The fourth was reading aloud without any commentary that might indicate a disjuncture, whether this occurred through simple reading or through comments that offered brief readerly reactions or summarized what was just read without indicating any potential areas for revision. The fifth category was comprised of discussions unrelated to the assignment at hand, such as conversations about the weather, other classes, and so on. Though all of these kinds of discussions can be important to tutoring sessions in a broader sense, they were not of interest to this particular study's goals.

\section{Analysis of coding results}

Transcript coding results were primarily examined for trends in the occurrence of different kinds of writing issues amongst the different tutors and session types. Trends in the numbers of turns and topical chains with or without writing issues were also examined, as were trends in who initiated topical chains with writing issues and what kinds of issues were initiated. These results were then analyzed for validity using chi square statistical tests.

\section{Secondary coder}

A professional in the field was given five full transcripts, randomly selected, to code for initiation and writing issues to measure the reliability of the coding scheme. Prior to coding any transcripts, a norming session was conducted with the secondary coder. The inter-rater reliability 
of this coding proved to be $95.6 \%$, with $98 \%$ agreement on initiators, $98 \%$ agreement on which topical chains contained writing issues, and 91\% agreement on which writing issues were present in chains containing writing issues.

\section{Surveys}

Clients

After their sessions were over, clients were given a 19 question survey to complete (see Appendix B). The first section of this survey, containing nine questions, gathered demographic data about age, gender, major, year in school, and whether they were a native speaker of English. They were also asked what course the text they were working on was for, when the assignment was due, how often they had visited the writing center previously, and how often they had brought in this particular assignment previously.

The next section of the survey, containing four questions, asked for the client's evaluation of the study. Clients were asked to rate on a 5-point Likert scale how well they thought the consultation went. They were then asked, in open-ended questions, to describe what the most and least helpful portions of the consultation were for them. They were also asked to rate on a 5-point Likert scale how much the consultation helped them find ways to make their meaning clearer to readers. Finally, a question asked them to rate on a 6-pt Likert scale how much focus the session gave to each of eight different writing issues, such as grammar and spelling, content, organization, and so on.

The next section, containing three questions, asked clients to rate and discuss the portion of their session spent reading aloud. The first question asked, on a 5-point Likert scale, whether reading aloud was the most useful portion of the session; the second, also on a 5-point Likert scale, asked whether it was useless. The third question was open-ended, asking whether clients had any additional "thoughts, comments, or suggestions" about this portion of their session. 
The final section of the survey contained two questions. The first asked clients, on a 5point Likert scale, whether they would have liked more control over what was discussed in the consultation. The final question was open-ended, and asked whether they had any other thoughts about the session that they'd like to share.

The Likert scale responses to clients' surveys were analyzed with ANOVA statistical tests. Responses to the open-ended question “what was most helpful” were analyzed by coding clients' responses for up to three topics. These topics were chosen based on what clients actually mentioned, and included codes such as "content," "citation style," "reading method," and "audience." All codes were checked by a secondary coder. Only topics perceived by both raters were included for analysis.

\section{Tutors}

Tutors' surveys contained 13 questions, many of which were the same questions as the clients' surveys so that comparisons between tutor and client perceptions of the sessions could be conducted (see Appendix C). Since tutors' demographic data was already known, they were only asked two questions in the initial section: how many times they had worked with this particular client, and how many times they had worked on this particular assignment (with this client or any other).

In the next section, containing four questions, tutors were then asked the same questions as clients about how well they thought the consultation went and what they thought the most and least useful portions of the session were for the client. They were also asked the same 6-point Likert scale question as clients on the level of focus on different writing issues.

The tutors' question about the portion of the session spent reading aloud was slightly different from the one on the client survey. It asked, on a 5-point Likert scale, whether this section of the session "seemed to help the client with things s/he might not have gotten 
otherwise." If tutors selected "agree" or "strongly agree" they were asked to explain, via openended questions, what they thought it helped with and why.

Tutors were also asked three additional questions, all on 5-point Likert scales, about whether they thought the client "took control of his or her paper during most of the session," and how heavily the session focused on global and local issues. They were also, like the clients, given the opportunity to write down any additional thoughts they had about the session at the end of the survey in response to an open-ended question.

As with the clients' surveys, tutors' answers were analyzed with ANOVA.

\section{Revisions}

Unfortunately, the study was unable to conduct analyses of clients' revisions to their papers. As mentioned previously, clients were given the opportunity to send their revised papers, along with their answers to a post-revision survey, to the researcher for an additional \$10 compensation. The goal of this option was to provide further information about the actual effects of the sessions on client revision, to see whether different reading methods lead to a difference in revision strategies. However, since only eight clients decided to do this, and six of these eight were clients from tutor-read sessions, thus virtually eliminating the ability to compare effects across session type, the revision component of the study was eliminated. Ideally, future research conducted on a larger scale might be able to incorporate a study of client revisions to further our knowledge of the effects of different reading approaches in tutoring sessions.

\section{Results: Transcripts}

\section{How does the quantity of turns and topical chains differ across conditions?}

Table 2.2 demonstrates that there was a similar number of writing issues discussed in all three session types. While the number of topical chains without writing issues was higher in 
point-predict sessions than in the other two conditions, point-predict sessions still contained almost as many topical chains with writing issues as client-read sessions and more chains with writing issues than tutor-read sessions. Table 2.2 also demonstrates that point-predict sessions contained the most number of topical chains in general of any of the tutoring conditions and had more topical chains per turn than the other sessions.

Table 2.2: Number of topical chains and turns across the three different types of sessions

\begin{tabular}{lllll}
\hline Condition & $\begin{array}{l}\text { Topical chains } \\
\text { with writing } \\
\text { issues }\end{array}$ & $\begin{array}{l}\text { Topical chains } \\
\text { without writing } \\
\text { issues }\end{array}$ & $\begin{array}{l}\text { Total number of } \\
\text { topical chains }\end{array}$ & $\begin{array}{l}\text { Total number of } \\
\text { turns }\end{array}$ \\
\hline Client-read & $192(85 \%)$ & $34(15 \%)$ & 226 & 2,787 (avg 348) \\
Tutor-read & $154(84 \%)$ & $29(16 \%)$ & 183 & 3,097 (avg 387) \\
Point-Predict & $183(63 \%)$ & $108(37 \%)$ & 291 & 2,438 (avg 305) \\
\hline
\end{tabular}

This data is challenging to interpret. That point-predict sessions have more topical chains per turn occurs in large part because the nature of the method and the design of the coding scheme cause all pauses in the reading of the text to make a comment to become their own topical chain. Obviously, this occurs more often in point-predict sessions due to the nature of the method itself, so more topical chains occur during the reading portion of the session in this session type than in sessions where reading is done all at once, without frequent pauses for commentary. However, beyond this indication future research conducted on a larger scale is needed to determine exactly what the implications of the reduced number of turns in point-predict sessions may be.

Table 2.2 also illustrates that client-read and tutor-read sessions spend a similar percentage of their discussions on writing issues. However, tutor-read sessions, on the whole, contained fewer topical chains of either type than client-read sessions. Still, though tutor-read sessions contained far fewer topical chains, they contained substantially more turns than either client-read or point-predict sessions. As with point-predict sessions, this data is challenging to interpret, and more extensive future research designed to evaluate the significance of these trends would prove useful. 
Table 2.3: The average number of turns and topical chains with writing issues across the three session types by tutor

\begin{tabular}{lllllll}
\hline Tutor & $\begin{array}{l}\text { Client-read } \\
\text { Turns }\end{array}$ & WI chains & $\begin{array}{l}\text { Tutor-read } \\
\text { Turns }\end{array}$ & WI chains & $\begin{array}{l}\text { Point-predict } \\
\text { Turns }\end{array}$ & WI chains \\
\hline Maude & 71 & 8 & 104 & 10 & 140 & 14 \\
Clarissa & 202 & 22 & 418 & 18 & 369 & 22 \\
Kathleen & 468 & 34 & 392 & 22 & 237 & 27 \\
Beverly & 653 & 36 & 635 & 31 & 475 & 31 \\
\hline
\end{tabular}

Table 2.3 indicates that some, though not all, of the tutors followed the general trends that are outlined in Table 2.2. Maude, the tutor most inclined towards short sessions, saw an overall increase in her point-predict sessions in the number of turns and topical chains with writing issues that occurred as compared with both her client-read and tutor-read sessions, in contrast to the general trend. Clarissa, meanwhile, averaged fewer turns in her point-predict session than in tutor-read but more than in client-read, again differing from the general trend somewhat, albeit in a different way than Maude. Additionally, the number of topical chains containing writing issues came to the same average in both Clarissa's point-predict and client-read sessions, both of which were slightly higher than the average in her tutor-read sessions. Sessions conducted by Kathleen and Beverly, meanwhile, both contained the most turns in client-read sessions and the least in point-predict sessions; their point-predict sessions also averaged fewer chains with writing issues than their client-read averages. These last two tutors, then, most closely resemble the general trends described in Table 2.2, excepting the fact that their client-read, rather than tutor-read, sessions contained the highest number of turns. Overall, this table enriches the data provided by Table 2.2 by suggesting that tutors who tend to conduct very brief sessions when using traditional methods will discuss more writing issues when using a method like point-predict, whereas tutors who tend to take longer using traditional methods may cover slightly fewer writing issues when using a method like point-predict. 


\title{
What types of writing issues are discussed within the different tutoring conditions?
}

\author{
General Trends
}

Table 2.4 indicates that point-predict sessions were far more likely to address concerns with content, evidence, organization, or signposting than the other two session types, $\chi^{2}(6)=101, \underline{p}$ $<.001$. Almost two-thirds of the topical chains containing writing issues in point-predict addressed organization or signposting. By contrast, in client only $40 \%$ of topical chains containing writing issues addressed these concerns in client-read sessions and only $15 \%$ in tutorread sessions. Similarly, 56\% of the topical chains containing writing issues addressed issues of content or evidence in point-predict sessions, where again only $40 \%$ of client-read chains and only 32\% of tutor-read chains addressed these issues. Conversely, Table 2.4 also reveals the interesting finding that significantly fewer sentence-level issues arose in point-predict sessions. Only slightly over a fourth of topical chains containing writing issues touched on issues of grammar, spelling, punctuation, syntax, diction, or citation style in point-predict sessions, which is substantially less than the amount of topical chains that addressed these issues in client-read or tutor-read sessions. Overall, this data suggests that point-predict sessions were more likely to focus greater attention on global issues than local ones.

Table 2.4: Type of writing issue (as a percentage of topical chains containing writing issues) discussed in the three types of session.

\begin{tabular}{lllll}
\hline Condition & $\begin{array}{l}\text { Sentence level } \\
\text { or formatting }\end{array}$ & $\begin{array}{l}\text { Content or } \\
\text { evidence }\end{array}$ & $\begin{array}{l}\text { Organization or } \\
\text { signposting }\end{array}$ & Other (incl unclear) \\
\hline Client-read & $58 \%(n=111)$ & $40 \%(n=77)$ & $40 \%(n=77)$ & $27 \%(n=51)$ \\
Tutor-read & $76 \%(n=117)$ & $32 \%(n=49)$ & $15 \%(n=23)$ & $21 \%(n=32)$ \\
Point-Predict & $28 \%(n=51)$ & $56 \%(n=103)$ & $63 \%(n=116)$ & $19 \%(n=34)$ \\
\hline
\end{tabular}

Note: Because a topical chain could have more than one writing issue, percentages add up to more than $100 \%$

Table 2.4 also indicates substantial differences in the kinds of writing issues that arose between tutor-read and client-read sessions. Sessions where the tutor simply read the manuscript aloud were far more likely to focus on grammar, spelling, punctuation, syntax, diction or citation style than sessions where the client-read aloud, though in terms of raw data the actual number of 
topical chains containing writing issues that addressed these concerns were quite similar. Tutorread sessions also differed from client-read sessions when it came to addressing content and evidence as well, where both their percentage and raw number of topical chains addressing these issues were lower. Perhaps the most striking difference arose between tutor-read and client-read sessions in the area of organization and signposting; tutor-read sessions addressed these issues only about a third as often as client-read sessions did. Overall, these results indicate that, clientread sessions are more balanced between local and global issues than sessions where the tutor simply reads the paper aloud.

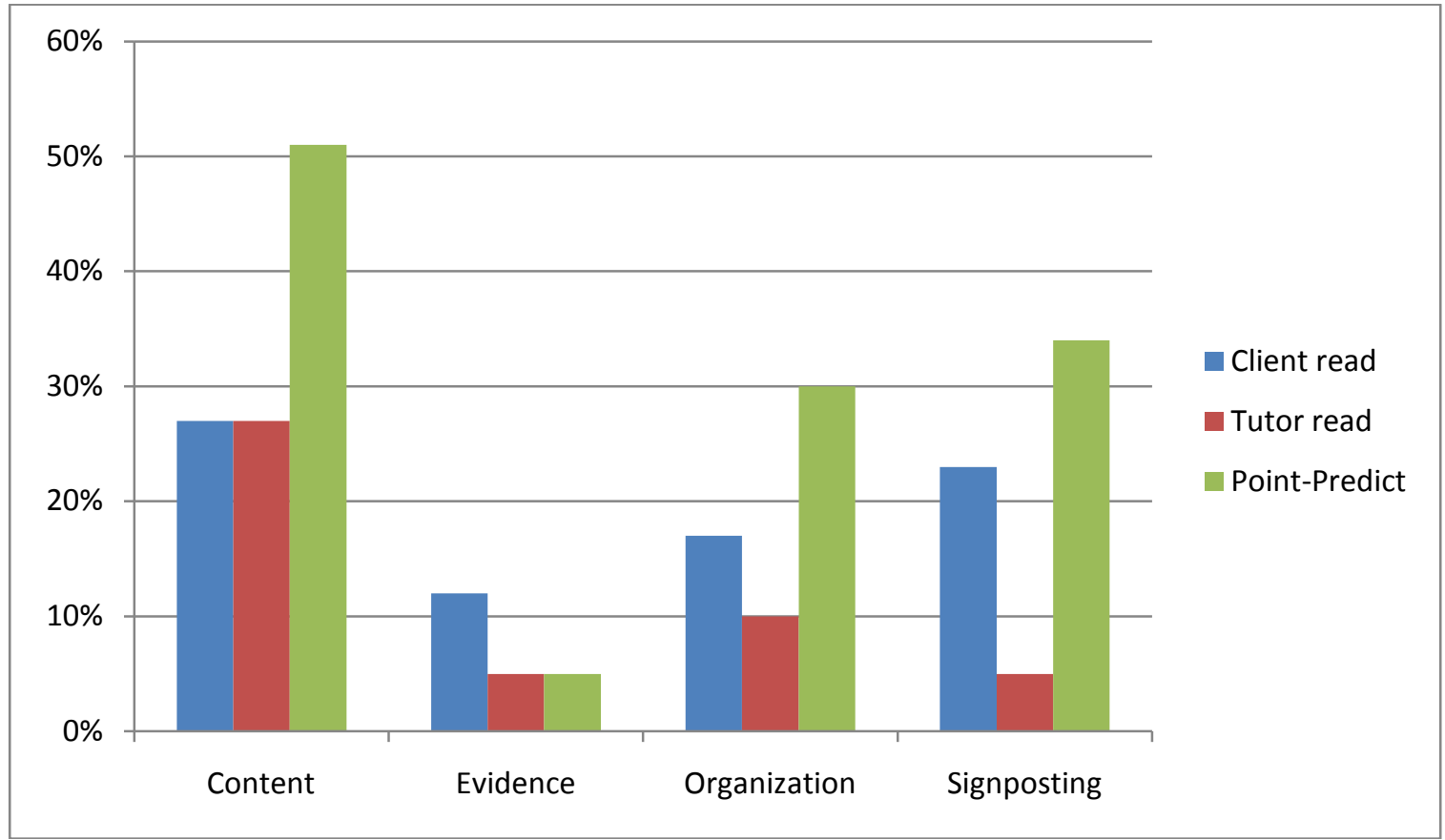

Figure 2.1: Percentage of topical chains containing writing issues that discussed concerns with content, evidence, organization, and signposting across the three session types. (Note: Because a topical chain could have more than one writing issue, percentages add up to more than one hundred percent.)

Figure 2.1 illustrates the trends of the more global concerns shown in Table 2.4 in more detail, showing that point-predict sessions addressed issues of content, signposting, and organization substantially more often than the other two session types. Particularly striking is the difference in signposting. Figure 2.1 indicates that signposting, a hallmark of successful academic writing, came up as a topic of discussion in about a third of the topical chains containing writing 
issues in point predict sessions, whereas it was only discussed in about a fourth of these topical chains in client-read sessions and in a mere five percent of these topical chains in tutor-read sessions, $\chi^{2}(2)=41, \underline{p}<.001$. The prevalence of this topic in point-predict sessions is perhaps unsurprising, since the focus of the method is on the reader's ability to summarize what has been discussed and predict what will be discussed next, and signposting is a crucial way of allowing readers to do this well. However, the trend is still remarkable given how little this writing issue came up in tutor-read sessions; it averages out to only one reference per tutor-read session, and most of the time it was not even the primary issue. A similar, though slightly less dramatic, trend is seen in organization, which came up in $30 \%$ of the discussions about potential areas for revision in point-predict sessions but in only $17 \%$ of these discussions in client-read sessions and only $10 \%$ in tutor-read sessions. Overall, this suggests that the format of a session can strongly influence how often larger structural concerns are discussed.

Discussions of content were about twice as common in point-predict sessions than either other tutoring approach $\chi^{2}(2)=29.2, \underline{p}<.001$. This result seems somewhat surprising at first, since the point-predict approach does not appear to focus on content as obviously as it does organizational and structural issues. However, an analysis of the actual transcripts themselves appears to indicate that this is likely the result of clients and tutors identifying confusing or insufficient content as a source of difficulties in summarizing points or making predictions, thus leading to discussions of ways to revise or expand upon the content of individual paragraphs or the paper as a whole. For example, if a writer's signposting doesn't seem to connect with what they've actually discussed, then it can lead to a discussion of revising the content to match that signposting.

The following exchange illustrates how point-predict methods can lead to discussions of a paper's content. This exchange occurs after the tutor, Clarissa, finishes reading and summarizing the main point of one of the body paragraphs in the client's paper: 
Tutor: One thing I was a little bit unclear about, since your last sentence says 'this is one of the first documented accounts of Christian persecution,' how exactly is it that this story illustrates Christian persecution?

Client: I guess 'cause--I guess I didn't really make it that clear because it was clear to me, but I didn't just write it out, but like where I had he was in prison for, like, protesting how the legal union of the marriage so that like because of his Christian beliefs he was in prison and like because Herodias didn't believe in those Christian views she wanted him beheaded.

Tutor: Ok. So I think you could add something--

Client: More about that? (Transcript 9, turns 50-53) ${ }^{2}$

As this excerpt illustrates, Clarissa pointing out her confusion with the connection between what the client wrote was her main point and what her content actually seemed to be expressing lead to a discussion of how to revise the content of that paragraph. In another point-predict session, another tutor, Kathleen, comments on how a mix of both unexpected content and varying structure across the last few paragraphs is confusing her.

Tutor: Ok, so we have kind of a repeat of the structure of the first paragraph, with kind of a visual analysis of an element of the painting and then a thematic element drawn from that. Whereas the thematic of the last paragraph was, you know, everyone's life is not going to be perfect, the thematic of this paragraph was that good will triumph over evil. So, I'm wishing that these different, um, analyses of the visual elements worked together for one thematic--

Client: right

Tutor: -- so I'm not able to really make a prediction of what you're going to do next, because you seem to be doing something different in each one.

Client: And I see that now, since you pointed it out. (Transcript 14, turns 101104, emphasis added)

Kathleen directly connects her inability to make a prediction with the confusing changes in the content (and the variance in the structure). Exchanges like these two were common in pointpredict sessions, and they support the conclusion that the nature of the point-predict method elicits a stronger focus on the content of clients' papers as part of the way to address concerns with the overall organization, structure, and clarity of the manuscript.

Figure 2.1 also illustrates the differences between tutor-read and client-read sessions in more detail, showing that the only area where a similar percentage of topical chains containing

\footnotetext{
${ }^{2}$ In order to present this quote more efficiently meaningless speech placeholders, such as "um" and "like", were left out of this and all other transcript quotes.
} 
writing issues addressed a global concern was in matters of content. When it came to evidence, organization, and signposting, tutor-read sessions spent substantially fewer topical chains on these issues. Interestingly, client-read sessions' discussion of evidence was not only higher than those within tutor-read sessions but those within point-predict sessions as well; why this would be the case is hard to determine. However, as in comparisons between point-predict and tutor-read sessions, the most striking is the difference between tutor-read and client-read sessions in matters of signposting. Only five percent of tutor-read sessions addressed this issue, whereas $23 \%$ of client-read sessions discussed this issue. Overall, this indicates that, while client-read and tutorread sessions contained a similar focus on content, client-read sessions focused more heavily on all other non-sentence level issues than tutor-read sessions did.

\section{Tutor-specific trends}

Though all of the tutors followed the general trend of discussing sentence level and formatting issues less often and organizational and content issues more often in point-predict sessions than in the more traditional tutoring conditions, each tutor followed this trend in differing degrees. Figures 2.2, 2.3, and 2.4 show how each individual tutor responded to the different tutoring conditions in more detail with regards to the kinds of writing issues that arose.

Figure 2.2 reveals that all tutors followed the general trend of having point-predict sessions where discussions of sentence level and formatting issues occurred less frequently than in the client-read or tutor-read sessions, though some tutors were affected less dramatically than others. While Maude, Clarissa, and Kathleen all tended to discuss these concerns significantly less in their point-predict sessions, Beverly addressed these issues only slightly less often in her point-predict sessions (just one percent less than in her client read sessions, and 20\% less than in her tutor read sessions). Beverly is the only tutor who appears to discuss sentence level and formatting issues almost as frequently in point-predict sessions as she does in client-read sessions; the possible reasons for these differences will be discussed in more depth in the next 
chapter. Overall, however, Figure 2.2 still suggests that the amount of attention given to sentence level and formatting issues changes significantly for most tutors depending upon the tutoring methods employed, and that these issues came up less frequently in point-predict sessions than the other two session types for all tutors.

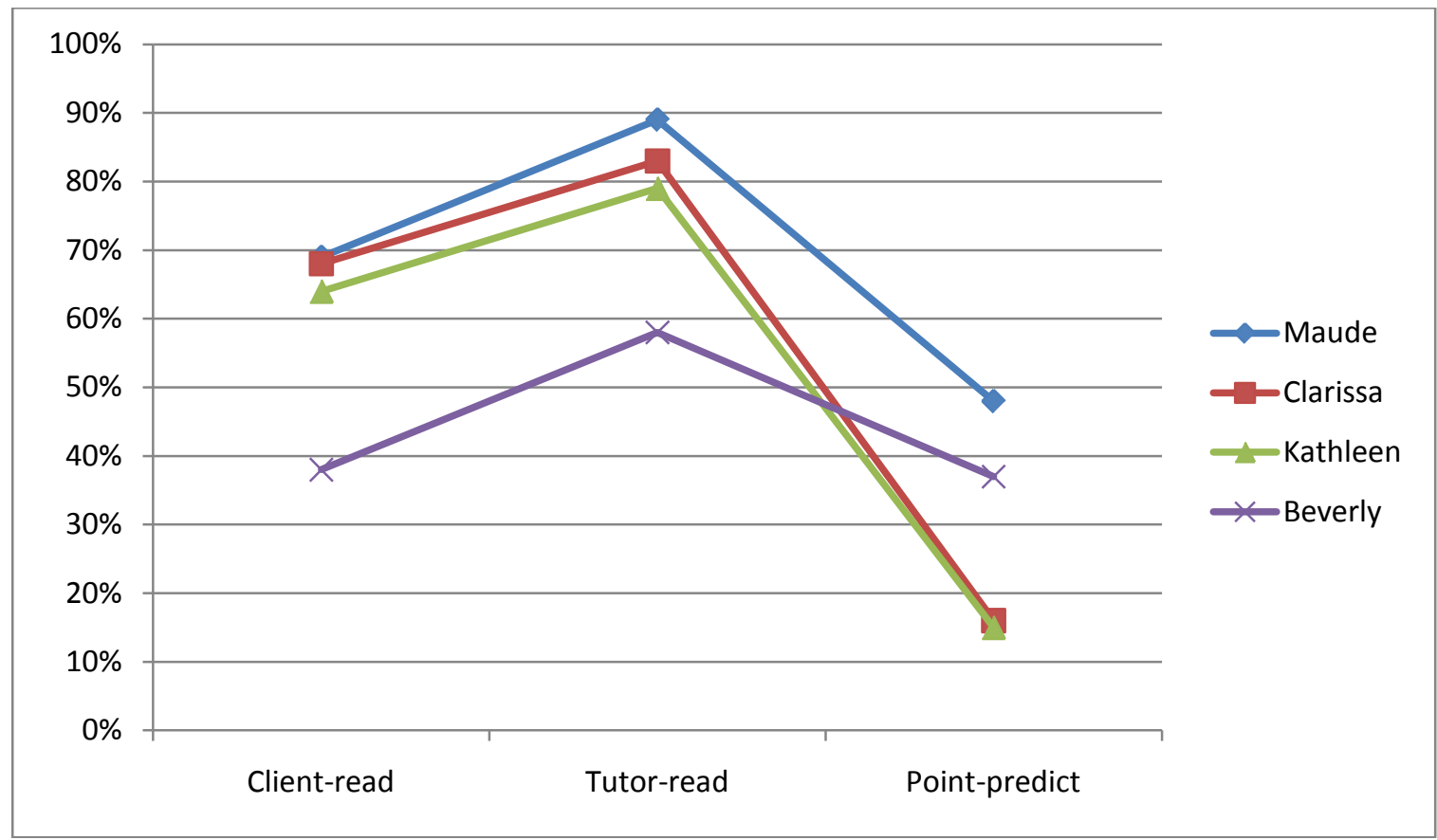

Figure 2.1: The frequency with which issues of grammar, spelling, punctuation, syntax, diction or citation style arose in topical chains containing writing issues by tutor across the three conditions (Note: percentages add to more than a hundred because each topical chain could contain multiple writing issues)

Figure 2.2 also reveals that all the tutors followed the general trend fairly closely when it came to differences between their tutor-read and client-read sessions in sentence-level concerns. Though each of the tutors' percentages are different, all the tutors discussed these kinds of issues 15-20\% more often in their tutor-read sessions than in their client-read sessions. This would appear to add credence to the belief that most tutors are likely to discuss local issues more frequently when they are the ones reading the manuscript aloud (in the absence of employing another method while reading, such as point-predict).

Figure 2.3 shows that all of the tutors discussed issues of organization and signposting more often in point-predict sessions than in either of the other session types, in keeping with the 
general trend. Both Maude's and Clarissa's percentages jump by about 20\%, Beverly's by 15\%, and Kathleen's by a striking $41 \%$ between their client-read and point-predict sessions. The differences between tutor-read and point-predict are even more dramatic, in keeping with the general trends discussed in relation to Figure 1. Overall, Figure 1.3 confirms the trends discussed in earlier sections: discussions of organization and signposting noticeably increase in pointpredict sessions over other session types regardless of tutor.

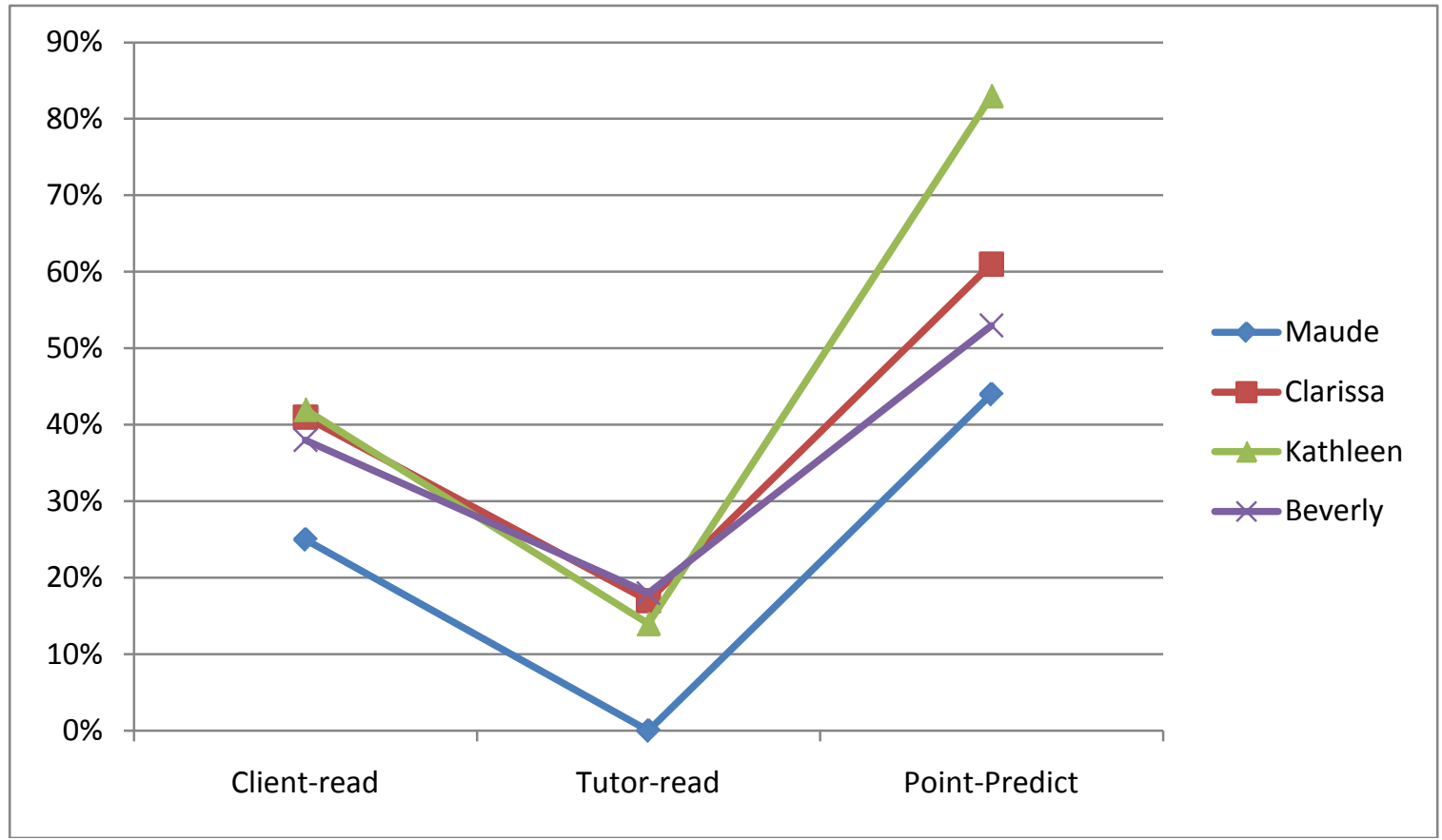

Figure 2.3: The frequency with which issues of organization or signposting arose in topical chains containing writing issues by tutor across the three conditions (Note: percentages add to more than a hundred because each topical chain could contain multiple writing issues)

Figure 2.3 also demonstrates that all of the tutors' tutor-read sessions addressed significantly fewer issues of organization or signposting than their client-read sessions did, which also matches the general trends discussed previously. It is particularly striking to realize that these issues did not arise even once in either of Maude's tutor-read sessions, when they arose in 25\% of the topical chains containing writing issues in her client-read sessions. Though this change appears the most dramatic of all the tutors because of the total absence of these issues in her tutorread sessions, all the tutors demonstrated about this much of a proportional change between their 
tutor-read and client-read sessions. Overall, this table suggests that when it comes to issues of organization and signposting, all the tutors are affected similarly by the differences between tutorread and client-read approaches.

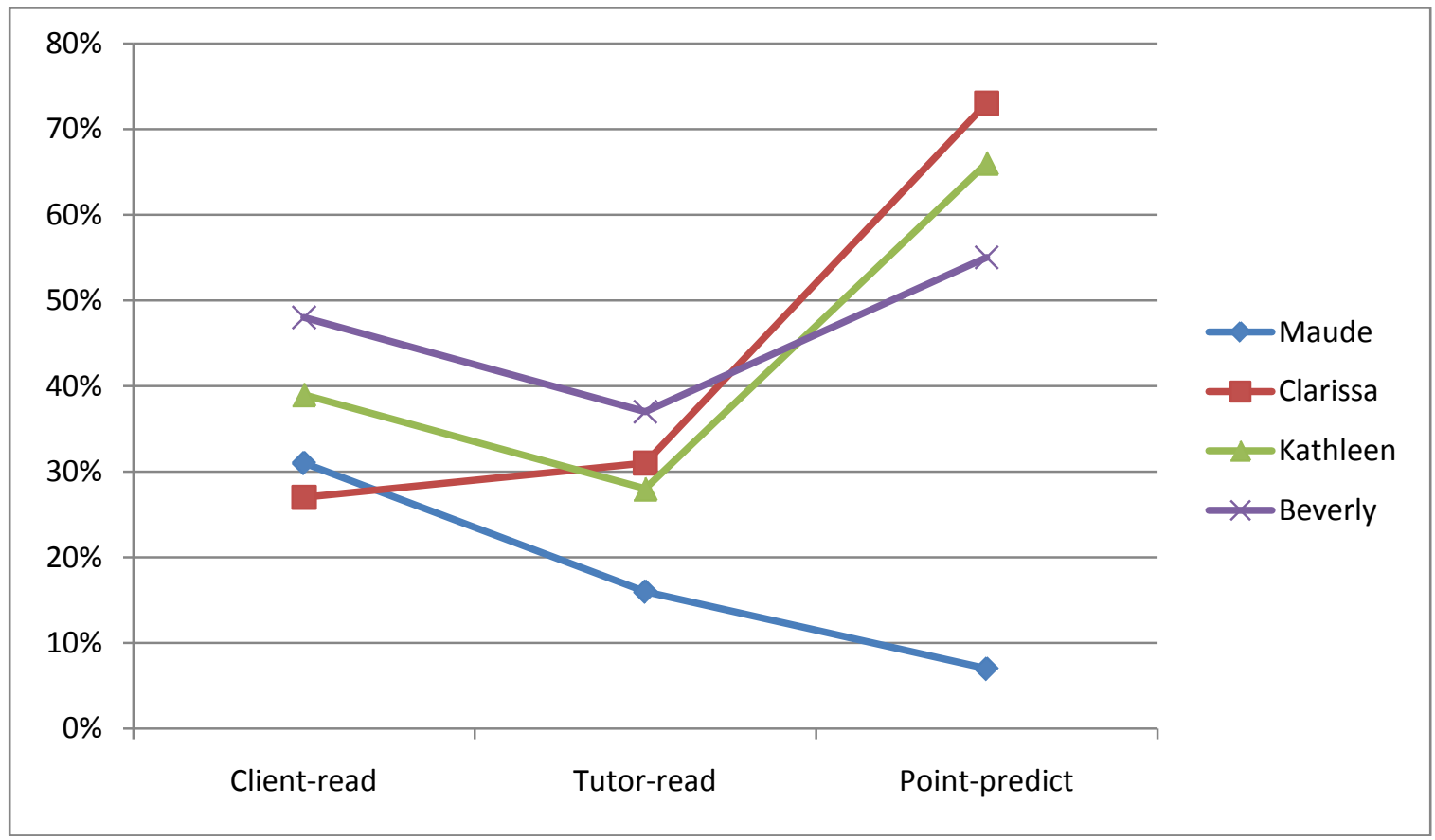

Figure 2.4: The frequency with which issues of content or evidence arose in topical chains containing writing issues by tutor across the three conditions (Note: percentages add to more than a hundred because each topical chain could contain multiple writing issues)

Figure 2.4 indicates that tutors showed the most variance from the general point-predict trend in discussions of content and evidence. Still, most tutors discussed issues of content and evidence more frequently in point-predict sessions than in other sessions with the exception of one tutor: Maude. Whereas the other three tutors discuss these issues anywhere from $55-73 \%$ of the time in point-predict sessions, Maude addressed these concerns only seven percent of the time--about half as often as she addressed them during her tutor-read sessions and about a fourth as often as she addressed them in her client-read sessions. The raw numbers underlying these percentages aren't quite as dramatic (these issues came up five times in her client read sessions, four times in her tutor-read sessions, and twice in her point-predict sessions), illustrating that there just wasn't much discussion of these issues in any of her sessions. Still, there is a notable 
difference and this variance is hard to interpret; possible reasons for it will be discussed in the next chapter. Overall, however, Figure 2.4 generally confirms the overall trend that point-predict methods appear to elicit more discussions of content than other methods for most tutors. Figure 2.4 also indicates that most of the tutors followed the trend of discussing issues of content and evidence less often in tutor-read sessions than in client-read ones, again with one exception: Clarissa. Clarissa discussed these issues $27 \%(n=12)$ of the time in client-read sessions and 31\% $(\mathrm{n}=11)$ of the time in tutor-read sessions. However, as the raw numbers indicate, these kinds of issues actually came up one more time in client-read sessions than they did in tutor-read. The raw numbers, combined with the mere four percent variation, indicates that this break from the general trend is not as significant as some of the others that will be discussed in more detail later. Overall, then, Figure 2.4 generally upholds the larger trend that issues of content or evidence are discussed more often in client-read sessions than in tutor-read sessions.

\section{Who is initiating topics and what is being initiated?}

Because of the interest amongst writing center scholars in promoting client agency and involvement, this study examined trends in client initiation of topics. Table 2.5 indicates that clients were almost equally likely to initiate a discussion containing writing issues across all session types, though they were slightly more likely to do this in client-read and tutor-read sessions and slightly less likely to do so in point-predict sessions. Clients initiated 38\% of the topical chains containing writing issues in both tutor-read and client-read sessions, though in raw

numbers clients initiated more total topical chains containing writing issues in client-read sessions than in tutor-read sessions. Clients initiated slightly fewer of these chains in point-predict sessions, a total of $34 \%$, though the raw number of client-initiated topical chains containing writing issues was slightly higher in point-predict sessions (63) than in tutor-read sessions (59). 
Overall, Table 2.5 would seem to indicate that patterns of client and tutor initiation of topical chains containing writing issues are not strongly affected by session type.

Table 2.5: Percentage of topical chains containing writing issues initiated by clients or tutors across the three different types of sessions

\begin{tabular}{lll}
\hline Condition & Client initiated & Tutor initiated \\
\hline Client-read & $38 \%(\mathrm{n}=73)$ & $62 \%(\mathrm{n}=119)$ \\
Tutor-read & $38 \%(\mathrm{n}=59)$ & $62 \%(\mathrm{n}=95)$ \\
Point-Predict & $34 \%(\mathrm{n}=63)$ & $66 \%(\mathrm{n}=120)$ \\
\hline
\end{tabular}

However, the session type did appear to strongly affect the types of writing issues most likely to be discussed in client-initiated topical chains. As Table 2.6 demonstrates, almost twothirds of point-predict sessions' client-initiated chains discussed concerns with either organization or signposting, whereas less than a fourth of these chains touched on these concerns in tutor-read or client-read sessions. Similarly, over half of point-predict sessions' client-initiated chains discussed concerns with either content or evidence, whereas only about a third of these chains touched on these issues in tutor-read and client-read sessions. Conversely, less than a fourth of point-predict sessions' client-initiated chains discussed issues of grammar, spelling, punctuation, syntax, diction, or citation style. Compare this to the other session types, where well over half of these client-initiated discussions addressed sentence-level or formatting issues. Overall, then, while Table 2.5 may seem to indicate that issues of client initiation do not vary much across session type, the evidence in Table 2.6 demonstrates that the writing issues actually being initiated by clients are far more likely to focus on global issues in point-predict sessions.

Table 2.6: Percentage of client-initiated topical chains containing writing issues that addressed sentence-level or formatting issues, content or evidence issues, and organization or signposting issues across all three session types.

\begin{tabular}{llll}
\hline Condition & $\begin{array}{l}\text { Client-initiated topical } \\
\text { chains addressing } \\
\text { organization or } \\
\text { signposting issues }\end{array}$ & $\begin{array}{l}\text { Client-initiated topical } \\
\text { chains addressing } \\
\text { content or evidence } \\
\text { issues }\end{array}$ & $\begin{array}{l}\text { Client-initiated topical } \\
\text { chains addressing } \\
\text { sentence-level or } \\
\text { formatting issues }\end{array}$ \\
\hline Client-read & $23 \%(\mathrm{n}=17)$ & $30 \%(\mathrm{n}=22)$ & $59 \%(\mathrm{n}=43)$ \\
Tutor-read & $19 \%(\mathrm{n}=11)$ & $34 \%(\mathrm{n}=20)$ & $54 \%(\mathrm{n}=32)$ \\
Point-Predict & $63 \%(\mathrm{n}=40)$ & $54 \%(\mathrm{n}=34)$ & $24 \%(\mathrm{n}=15)$ \\
\hline
\end{tabular}


A look at the transcripts provides some illustrative examples of these trends in client initiation. For example, in one point-predict session, the tutor, Beverly, finishes reading a paragraph and begins to move on to the next paragraph when the client pulls her back to discuss the content of the initial paragraph.

Tutor: [finishes reading one paragraph] Okay, it seems like right now the main point of this paragraph is saying that TV is not always right, because there are a lot of money considerations that don't go into it.

Client: Mm-hmm.

Tutor: Okay. [Begins reading new paragraph]. "Another reason why teenagers do not see teenage pregnancy as a negative thing is because they want to grow up faster."--

Client: Should I maybe include in there [initial paragraph] "looking up." I don't know if I said that or not. Like they look up to her [Jamie Lynn Spears, who was discussed in the initial paragraph] because I know a lot of kids did...'cause she had a Nickelodeon show. And the parents--

Tutor: Yeah, I think that would be interesting.

Client: --were mad because, you know, she's supposed to be an idol to their kids, and now she's pregnant. (Transcript 18, turns 134-141)

Though there is, of course, no way of knowing for sure exactly what prompted the client to bring up this idea for the addition of content, the fact that she brought it up after hearing Beverly's summary of the main point of the paragraph is striking. Regardless of the precise cause, it illustrates the trends shown Table 2.6 and offers an example as to how the point-predict method can lead to more client-initiated discussions of content.

In addition to pausing tutors to initiate more global discussions during the readings, clients also initiated discussions of these kinds of issues once the reading had been completed in point-predict sessions. What follows are several illustrative examples of this tendency from a variety of clients:

Do you think that my conclusion goes with the thesis? Because I don't know if I should refer back specifically to the painting or if I should, like, some people-like before with other papers I've referred back to the quote that I've used...I don't know if I should do that, and add more about--I guess I don't know, I feel like I rushed through the conclusion. (Transcript 9, turns 89-91)

I think I probably need to look at a more developed conclusion... with more transitioning here... you know, with all this, maybe this is too much information. (Transcript 16, turns 237-241) 
What I'm trying to do here is explain how...education will rise up. But you have this major rift between urban and rural, and like here, at the start, I'm just trying to give a background of which way it was going and then lead into this is how education is looked at... and then here are the many things that deal with education. But I don't want people to look--because their education is a little different than ours--but all in all I didn't want people to look at it and say--like here [in the U.S.] we look at education as this [traditional schooling] is education--and I didn't want it to look like that. (Transcript 17, turns 96-100)

Each of these examples illustrate one of the variety of ways in which clients took the initiative in discussing issues beyond the sentence level in their point-predict sessions after the reading was completed. Discussions of larger structural issues, such as the discussion here of how to transition effectively and use information efficiently, or how to link the conclusion to the introduction, were more likely to occur in point-predict sessions than in more traditional session types. Client comments like these help to illustrate how the relationship between organization and content was drawn to the fore in point-predict sessions.

Additionally, as mentioned in the discussion of Table 2.1, trends in client initiation also help support the hypothesis that point-predict sessions contain fewer turns because less explanation is required to get the client and tutor on the same page about revision issues. It may be that the method itself helps clients and tutors see the same issues, and that seeing those same issues allows clients to initiate discussions of the kinds of global issues that in other sessions tutors may need to initiate (and thus explain). The examples from the transcripts above support this hypothesis, as does the following exchange at the end of the reading portion in another pointpredict session with a different tutor, Kathleen. Kathleen begins this exchange by reading a comment from the client's professor that was written on the paper.

Tutor: "You have a good interpretation, pretty well supported. The lack of a clear thesis statement, and a poor structure to the paper, don't bring out the interpretation very well, however."...What do you think after hearing me read this [your paper and the note] aloud?

Client: I think I can see where I messed up with the structure. It's like with your predicting what's going to come next and then it's completely off...So, yeah, I see what I could do better to it. (Transcript 14, turns 147-152) 
Here the client explains how hearing the tutor summarize points and offer predictions helped her see why her structure wasn't working, when she had previously been baffled by her professor's note. The client reiterates the significance of the point-predict method to her again about 30 turns later.

Client: I have one quick question. I really wanted to write down, you know how you were predicting what was coming?...Can we go through, like you know you'd go to a paragraph and predict and then it was completely different...I wanted to...go through and maybe put it in order, or get some kind of order to the paper? (Transcript 14, turns 188-194).

These examples make it clear that the client found the tutor's predictions a clear way of conveying why her structure was confusing and not supporting her "good interpretation." Furthermore, her initiation of this topic makes it unnecessary for the tutor to try to go into explaining what the client's professor might have been referring to and why it's an issue--the client now understands the issue and is ready to tackle a discussion of how to revise for it.

\section{Results: Surveys}

\section{What types of issues did clients and tutors think were receiving the most attention?}

Table 2.7 indicates that clients' perception of the attention to organization in pointpredict sessions and the attention to sentence-level issues in tutor-read sessions matches the trends revealed by the transcript code results. Most significant is clients' perception of the attention to organization within point-predict sessions versus the other two session types; clients average rating of point-predict sessions was 4.38, whereas client-read and tutor-read sessions averaged only 3.0, $F(1,23)=4.01, p<.058$ (3.25 for client-read, 2.75 for tutor read). Clients' perception of the focus on issues of grammar and spelling in tutor-read sessions is also in keeping with the transcript data; they saw tutor-read sessions as focusing on these issues far more than either of the other session types, $F(1,23)=10.178, p<.004$. Overall, then, it seems that clients saw point-predict sessions as focusing more heavily on organization than on grammar and 
spelling, and tutor-read sessions as doing the opposite, all of which is in keeping with the trends found in the transcripts.

Table 2.7: Average client response across session type to the survey question "This consultation addressed ways I could revise for:" out of a 1 - 5 Likert scale, where 1 represented "Focused on a little" and 5 represented "Focused on a lot."

\begin{tabular}{lll}
\hline Condition & Organization & Grammar/Spelling \\
\hline Client-read & 3.25 & 1.38 \\
Tutor-read & 2.75 & 3.75 \\
Point-predict & 4.38 & 2.00 \\
\hline
\end{tabular}

Table 2.8 illustrates that tutors perceived some similar trends in the differences between session types on issues of organization and grammar or spelling as was suggested by the transcript data. Similar to both transcript data and client perceptions, tutors saw point-predict sessions as focusing more on organization than other session types , $F(1,23)=2.934, p<.031$, and tutor-read sessions as focusing far more on issues of grammar and spelling than the other session types, $F(1,23)=14.728, p<.001$. Though generally the trends are similar, there are a few slight differences in how tutors and clients saw the sessions. Unlike client perception and transcript data, tutors did not see as large a difference between client-read and point predict sessions in their focus on organizational issues, though they did perceive a large gap between point-predict and tutor-read sessions on these concerns. Unlike their clients, and more in keeping with the transcript data, tutors saw point-predict sessions as focusing on grammar and spelling less than other session types. However, these differences between tutor perception and transcript data, or tutor perception and client perception, are both slight and hard to interpret. Overall, though, the data in both tables 2.7 and 2.8 illustrate that tutor and client perception basically correspond with the trends shown by the transcript data.

Table 2.8: Average tutor response across session type to the survey question "This consultation addressed ways the client could revise for" out of a 1 - 5 Likert scale, where 1 represented "Focused on a little" and 5 represented "Focused on a lot."

\begin{tabular}{lll}
\hline Condition & Organization & Grammar/Spelling \\
\hline Client-read & 4.00 & 1.86 \\
Tutor-read & 2.25 & 2.53 \\
Point-predict & 4.75 & 1.25 \\
\hline
\end{tabular}




\section{What did clients find most helpful about their sessions?}

The type of session a client experienced made a big difference in the kind of response they gave to an open-ended question about what the most helpful portion of their session was in their post-session survey. As Table 2.9 shows, half of the eight clients in point-predict sessions noted without prompting that developing an awareness of their audience was one of the most helpful elements of their sessions. Meanwhile, none of the clients in the tutor-read or client-read sessions referenced their audience when asked what was most helpful about their session. ${ }^{3}$ What follows are a couple of illustrative excerpts from client responses to point-predict sessions when asked what was most helpful about their session:

Her opinion on the message I was trying to express [because] now I know how others see what I'm saying. (Session 9, emphasis added)

After every paragraph I was getting feedback...it helped me to understand what other people are getting from my paper and things I could change. (Session 18, emphasis added)

These responses would suggest that clients in point-predict sessions not only became more aware of their writing as an object intended for an audience, but that they specifically valued this awareness over other things that occurred in the session.

Table 2.9 also indicates that more clients in point-predict sessions saw the reading method itself as extremely helpful than did clients in client-read or tutor-read sessions. Five point-predict clients, again without prompting from the survey, referenced the reading as part of what was most helpful about the session, whereas only one tutor-read and two client-read clients did this. Some of these comments from point-predict sessions tied the benefit of the reading method specifically to increased audience awareness, as indicated by the examples in the previous paragraph, and some tied it to other things, as the following example illustrates:

\footnotetext{
${ }^{3}$ It should be noted, however, that a few of the clients from these more traditional sessions did mention audience when specifically asked for their thoughts about the portion of the session spent reading aloud later in the survey (one, or 13\%, from the client-read group and three, or 38\%, from the tutor-read group)
} 
The reading aloud, you definitely see the flaws in the paper [because] when I read the paper to myself, I didn't find the issues with the thesis. (Session 15)

In contrast, references to the reading made by clients in client-read or tutor-read sessions in response to the "most helpful " question were more likely to be either very vague or refer to the reading as useful at helping them find "mistakes" or "errors."

The trend of seeing reading in client-read and tutor-read sessions as helpful primarily for catching mistakes and errors continues at a later point in the survey. When specifically asked whether they had any further thoughts, comments, or suggestions about the portion of their session spent reading aloud (a question not all clients chose to answer), clients of tutor-read and client-read sessions were more likely to note errors and mistakes in their responses:

It helped catch my mistakes. (Session 23, client-read, emphasis added)

Reading out loud helps me catch mistakes and expand ideas. (Session 22, clientread, emphasis added)

It helps me to recognize where my errors occurred. (Session 11, tutor-read, emphasis added)

In fact, one client indicated that this was precisely why she was not fond of reading aloud, explaining her low rating of the read-aloud portion of her session with the following note:

It [reading aloud] was helpful seeing grammatical errors but not really content. (Session 21, client-read)

What these survey results may indicate is both that reading aloud was seen as more helpful by clients in point-predict sessions and that it was seen as helpful for very different reasons in pointpredict sessions than in other session types.

Table 2.9: Client responses to the question of what was most helpful to them about the session

\begin{tabular}{lllll}
\hline Condition & Audience & Reading & Content & Sentence \\
\hline Client-read & 0 & $25 \%(2)$ & $38 \%(3)$ & $25 \%(2)$ \\
Tutor-read & 0 & $13 \%(1)$ & 0 & $75 \%(6)$ \\
Point-predict & $50 \%(4)$ & $63 \%(5)$ & $50 \%(4)$ & $13 \%(1)$ \\
\hline
\end{tabular}

Note: Percentages add up to over $100 \%$ because survey responses were coded for multiple topics.

Half of the clients of point-predict sessions also referenced issues of content when asked what was most helpful about their session, whereas 38\% (3) of the clients from client-read and 
none of the clients from tutor-read sessions referred to this issue as important to their session. Interestingly, the responses of point-predict clients often tied the method of reading to this helpful focus on content, whereas those who referenced it from client-read sessions did not. Two of the point-predict examples above (from sessions 9 and 18) exemplify this, as does this answer from another point-predict client:

Going over my paper and breaking down each individual paragraph [because] it helped me fix my errors and improve my interpretation. (Session 14, emphasis added)

In contrast, all three of the client-read references to content did not connect this focus to the reading method employed in the session. Their responses to what was most helpful about the session were:

Organizing, expounding on ideas. (Session 20)

Telling me to expand on ideas. (Session 21)

Helping to expand ideas. (Session 22)

Most striking, however, is the difference between the survey responses from the clients of pointpredict versus tutor-read sessions. The finding that none of the clients from tutor-read sessions referenced a content issue as part of what was most useful about their session, when half of the clients of point-predict sessions did, further substantiates the results of the transcript coding that showed the most attention was given to content in point-predict sessions and the least in tutorread sessions.

In keeping with the differences already discussed, clients' responses to what was most helpful about tutor-read sessions were more likely to focus on sentence level issues. As Table 2.9 shows, half of the clients in tutor-read sessions named some issue of grammar, punctuation, or citation style issue as part of what was most helpful about their sessions. In contrast, only one (13\%) client of a point-predict session, and two (25\%) clients of client-read sessions, referenced these issues. Given the heavy focus tutor-read sessions placed on these kinds of issues, it is unsurprising that clients found this to be part of what was most helpful about their sessions. Generally, this result adds further support to the data from both the transcripts and Table 2.7 in 
indicating that sessions where the tutor simply read the client's paper aloud were far more likely to focus heavily on sentence-level concerns than other session types.

\section{Discussion:}

This study found that the type of reading method greatly influenced the content of the consultations. Most notably, point-predict sessions focused far less on sentence-level issues than the other two traditional reading methods. Instead of sentence-level issues, point-predict sessions were more likely to focus on issues of content, organization, and signposting than sessions begun with more traditional reading methods, and far less heavily on sentence-level issues. Additionally, while levels of client initiation were almost equal across all session types, in point-predict sessions the topical chains initiated by clients were around thrice as likely to cover issues of organization or signposting, and almost twice as likely to cover issues of content or evidence, than the client-initiated discussions in tutor-read or client-read sessions. Both clients' and tutors' surveys support these trends, showing that both perceived point-predict sessions as focusing more heavily on organization than grammar and spelling.

In addition to what the study reveals about the potential results of introducing new reading methods into writing center consultations, this study revealed interesting and significant differences between the two most common approaches to reading clients' texts in writing centers: client-read and tutor-read sessions. Between these two traditional approaches, client-read sessions were likely to focus more on issues of content and organization and less on sentence-level issues than tutor-read sessions, a finding that appears to confirm the beliefs expressed by many on WCenter (e.g. Gillespie, Palm); the surveys support these findings: clients commonly cited discussions of content as part of what was most helpful about client-read sessions, and both clients and tutors saw client-read sessions as focusing less on sentence-level issues than on broader concerns like organization. 
When one considers these findings in light of the encouragement tutors receive from tutor training manuals to focus more heavily on global issues than local ones, especially if the client is bringing their text into the writing center for the first time (e.g. Ryan and Zimmerelli, 21), the results of this study are all the more striking. In light of these manuals' suggestions, perhaps the most surprising difference among the three methods is that between tutor-read and point-predict sessions. Before beginning the study, I hypothesized that tutor-read and point-predict sessions would have had the most in common, since both feature the tutor reading a client's writing aloud. The fact that tutor-read and point-predict sessions instead proved to be almost opposite in terms of the amount of focus they gave to issues like content, organization, sentence-level concerns, and signposting merits further examination. Tutor-read sessions focused on sentence level issues in $76 \%$ of their discussions, almost three times as much as these issues arose in point-predict sessions. Conversely, tutor-read sessions rarely touched on issues of organization (10\%) or signposting (5\%), in stark contrast with the point-predict sessions where these issues were discussed over 3 times as often. Moreover, point-predict sessions discussed content almost twice as often as tutor-read sessions did. Again, these trends from the transcripts were further supported by the results of both clients' and tutors' surveys, both of which indicated a heavier focus on issues like grammar and spelling in tutor-read sessions.

In examining these findings about tutor-read sessions, it might first prove helpful to reexamine the assumptions about tutor-read sessions as expressed in writing center literature and on the WCenter archives. These assumptions can be summarized as follows: (1) tutor-read sessions are more likely to focus on sentence-level issues because they will get caught up on these issues while reading (e.g. Gillespie; Palm), (2) tutor-read sessions deprive tutors of time needed to think about how to approach more global issues (e.g. Gillespie; Levin) (3) tutor-read sessions decrease client agency because the tutor is "in control" of the paper (e.g. Gillespie and Lerner; Caposella; 
Palm), (4) tutor-read sessions should be avoided unless a client's specific needs or comfort level ${ }^{4}$ demand it (e.g. Powers; Ritter; Gillespie). The results of this study appear to indicate that assumption one, that tutor read sessions (when not aided by a specific strategy like the pointpredict method) focus more on local concerns, may be true. Assumption two, that reading aloud distracts tutors, may be an assumption worth exploring in attempting to understand number one, since one of the differences between a standard tutor-read session and a point-predict session is that in the latter the tutors have the chance to pause and express their reactions to the text as they read, rather than holding everything in check until the end of the session.

What this study appears to undermine, however, is assumption number three, that clients have less agency in tutor-read sessions simply because it is the tutor who is reading. There is virtually no difference in the frequency of client initiations in the three conditions, indicating that having tutors read does not seem to cause clients to be less involved in the sessions. Though initiation is not the only indicator of control, this finding implies that the assumptions that clientread is superior to tutor-read methods at ensuring that clients are more in control of their text are ripe for further inquiry. Additionally, and perhaps most importantly, the fact that the kinds of topics clients initiated in point-predict sessions were more globally focused indicates that entirely new reading methods may be better suited at eliciting client initiation of the kinds of writing issues valued in writing centers.

The fact that the clients themselves were so enthusiastic over the point-predict reading method is also promising, especially in light of the belief that some clients only want to focus on "fixing" their papers and not on becoming more rhetorically aware writers (Ryan and Zimmerelli, $i x, 11)$. Many of the clients from point-predict sessions enthused, unprompted, over their better developed sense of audience when asked what was most useful about their session; some of these

\footnotetext{
${ }^{4}$ Generally this is discussed in terms of clients with specific learning disabilities or for whom English is a foreign language. The concern is generally focused on the difficulties clients may have with the actual act of reading aloud. These issues certainly merit consideration, but this study suggests that these are not the only considerations to keep in mind when deciding on reading methods.
} 
same clients came in saying they were most concerned about issues like grammar and sentence structure. While undoubtedly some students will only want the writing center to work as a "fix-it shop," this may indicate that a change in reading methods could make a difference in some clients' interests and goals for their tutoring sessions.

On a separate note, the striking differences between point-predict and tutor-read sessions also indicates a potentially promising area for future research into what kinds of reading methods clients might engage in while reading their texts out loud and how those methods might shape the session. Spontaneously, one of the tutors in this study happened to do something like that in one of her client-read sessions: she directed the client to take notes as she read aloud about what content each paragraph covered and whether there had been adequate sign-posting for that content in the introduction. The results in just this one session were striking, and they offer a variety of questions and hypotheses for future research in this area, all of which will be discussed in more detail in the following chapter on individual tutors and sessions.

Of course there are limitations in this study that open up questions for future research, the most significant of which is in the size of the study; since this was a preliminary study, only eight of each session type were able to be analyzed. Moreover, we don't know if the discussion actually led to student learning or student revision. Examining a larger group would serve several purposes: (1) it would allow for more revisions to be collected, hopefully making a study of the effects on revision of different reading methods feasible, and (2) it would allow for more transcript data to analyze, to see if the trends found here truly hold up on a larger scale. Another potentially significant limitation to the study design was the absence of analysis of time. Specifically, comparing not only the number and types of writing issues that arose but also the amount of time spent on these writing issues would provide a more nuanced look at the work of these tutoring sessions.

Additionally, the selection of tutors for this study was fairly homogenous: all female graduate students in English who were interested in reflecting on their tutoring practices. All of 
the tutor participants had worked with me in the writing center, and I was a mentor or advisor to all of them at various points during that time. Additionally, all of the participants self-selected to be a part of this study, despite the extra time commitment it involved over and beyond their other responsibilities, because of their interest in tutoring and teaching practices. Both of these factors might have influenced the results, the former by making it more likely that they would want to help me achieve promising results in my study, and the latter by making it more likely that they would be more inclined towards introspection and reflection about their tutoring and teaching practices than perhaps the average tutor. Thus, it is conceivable that future research conducted with less enthusiastic and curious participants may yield different results. Given that writing centers across the country have tutors who are male, or undergraduate students, or non-English majors, or perhaps even just not that interested in their tutoring work, studying the effects of these methods on a greater variety of tutors is essential. Furthermore, though most of the tutors exhibited the same trends in their different tutoring sessions, not all tutors were affected the same way, and not all tutors seemed to take to the point-predict method equally well ${ }^{5}$; future research done on a larger scale could hopefully provide more information as to how tutors and directors can determine just who different reading methods are best suited for, and under what conditions.

More research is also needed to determine what kinds of texts point-predict is best suited for, and at what stages in the writing process; studies that examined the same clients across multiple session types might help address these questions. Finally, additional research is needed to uncover just what the significance is of the tendency for point-predict sessions to have the most topical chains and the fewest turns, assuming that trend held up in a larger study. This trend could indicate that point-predict sessions are covering writing issues more efficiently, or it could indicate that important discussions are being elided, elisions that this study design may not have

\footnotetext{
${ }^{5}$ This will be discussed in more detail in the following chapter.
} 
been equipped to catch. Incorporating the afore-mentioned analysis of time might be one way of addressing these issues.

In other words, this study does not make the argument that the point-predict method works equally well for all papers or all tutors, nor that it is the only reading method to share with tutors. However, it does indicate that traditional reading methods may not be as well-suited to the goals writing center texts and scholars espouse, and that new reading methods may be needed to better meet these goals. Only further research can confirm just what the best reading methods are to address all these concerns. Overall, however, most striking about all the transcript and survey results is this: many of the standing assumptions about the nature and effect of various methods of reading aloud in tutoring sessions are ripe for reconsideration. 


\section{CHAPTER III TUTOR INTERVIEWS}

\section{Introduction}

Chapter Two found that the type of reading method employed in tutoring sessions greatly influences what is discussed in those sessions. Specifically, point-predict sessions tended to focus more heavily on global issues, while both client-read and tutor-read sessions gave greater attention to local issues; tutor-read sessions focused on local issues more heavily than client-read sessions. Additionally, transcript data showed that levels of client initiation did not vary significantly across session types; however, the types of issues clients initiated did change significantly: in client-read and tutor-read sessions clients were more likely to bring up local issues, whereas in point-predict sessions they were far more likely to bring up global issues. The survey results from both clients and tutors supported the trends found within the transcript data, and indicated that clients found the point-predict method helpful.

Eight months after the last tutoring session was recorded, tutors were interviewed about their perceptions of the study, tutoring methods, and the effects of their tutoring work on their teaching and their teaching on tutoring methods. This delayed interview time was selected so that all the tutors would have completed one semester of teaching an introductory composition course before reflecting on their tutoring practices. The purpose of this was to allow tutors to reflect on the long term effects of the study and so that they could offer their opinions on the study's data as individuals with both tutoring and teaching experience.

These discussions include the tutors' general opinions of the point-predict method as a tutoring tool, ideas on the influence of reading structure on tutoring sessions, thoughts on what 
causes sessions to focus more heavily on local issues, and concerns with both client and tutor agency and engagement. This chapter uses these interviews as a way to critique assumptions in tutor training manuals and to reflect on writing center practices more broadly.

\section{Methods}

Each interview was conducted individually, either over the phone or in person. All four tutors were asked the same initial 19 questions; each tutor was then asked a few additional unique questions about their individual practices at the end of the session. The first six questions asked for their general recollections and opinions on: the influence of teaching on their opinions of tutoring practices, whether participating in the study influenced their teaching practices, what their general impressions were about the differences between the three reading methods examined in the study, what their overall impressions were on the point-predict method, whether they generally felt reacting to a text while reading or only after all reading was completed was preferable, and how they balanced between client requests and what they felt clients needed when tutoring. The seventh question inquired as to how the training methods employed in the study could have been improved.

The next section of the interview focused on tutors' expectations about, and reactions to, the specific transcript data that was discussed in the previous chapter. This section contained 11 questions. The first two questions asked about their general expectations regarding the data: what differences, if any, they expected to see between the different session types and which session types they expected to be the most similar. The next question asked what they understood the goals of the point-predict method to be and how that fit into their understanding of effective writing.

Tutors were then shown the four line graphs from the previous chapter that reveal the frequency with which different kinds of writing issues appeared in the different session types. All tutor names except for the name of the interviewee were blocked out to preserve anonymity while 
still allowing the tutor to see individual trends. The methods of transcript analysis were explained, as they were in the previous chapter, so that tutors understood how topical chains and writing issues were defined.

Once the information within the figures had been fully explained, tutors were asked five questions about their thoughts on this data. The first question in this sub-section asked for their first reaction on seeing the results and whether they were surprised by the data. They were then asked why they thought tutor-read and point-predict sessions produced such different effects when one might expect their results to be similar since both positioned the tutor as reader. The next question asked why they thought tutor-read sessions had such a high focus on sentence level issues and such a low focus on organization and content. The fourth question asked for their thoughts on the number of sentence level issues in client-read sessions, and the fifth question asked whether they were surprised to see how much focus point-predict sessions paid to content and organization.

The next sub-section, containing two questions, addressed client initiation. The first question asked what their expectations were regarding levels and types of client initiation in the different session types. Tutors were then shown the two tables from Chapter Two on trends in client initiation — both the frequency with which they initiated topical chains and the kinds of writing issues that arose in the topical chains they initiated. After tutors looked at this data, the second question asked for their thoughts on these results.

The next interview question asked whether seeing all the data changed their answers to questions five (regarding reacting to texts as they are being read versus waiting until after all reading has been completed) and six (regarding balancing between client and tutor concerns in tutoring sessions). The final common interview question asked tutors to describe what kinds of texts, clients, and tutors they thought each reading method was best suited for.

Once the common portion of the interview was completed, each tutor was asked a few additional personalized questions, generally about specific methods they employed in one or 
more of their sessions from the study. For a full record of all common and individual interview questions, see Appendix D.

\section{Results}

Several interesting ideas emerge within these interviews. The first is that tutors generally enjoyed the point-predict method; they not only found it useful for tutoring, they also continue to employ the method in their teaching and personal revision. Tutors' interviews also revealed that all reading methods are structures that influence what is discussed in tutoring sessions; more significantly, less methodical reading structures, like traditional client-read and tutor-read approaches, put tutors in the uncomfortable position of trying to balance between preventing memory overload and refraining from tackling the paper until they understand the text as a whole. More methodical structures like point-predict help alleviate these concerns by building in descriptive commentary, giving their memories time to absorb the text while preventing a focus on evaluative or prescriptive commentary before the full text has been read. Other structures, such as a glossing-while-reading method employed by one of the tutors in one of her client-read sessions, may help achieve similar effects.

These interviews also revealed some of the potential causes for local issues receiving undue focus during tutoring sessions, including the structure of the session, the tutors' confidence level, the apparent ease of "fixing" local issues, and the urge to fill time at the end of a session. Finally, these interviews indicate that tutor training manuals tend to conflate ideas of client control or agency and attention or engagement, while completely ignoring concerns with tutor engagement. 


\section{Tutors generally favored point-predict as a reading method}

On the whole, tutors were generally fond of the point-predict method and said they would have continued using it in tutoring sessions if they had had time to do so after the study was completed $^{6}$ :

I liked it, I've been using it ever since. (Maude)

I liked it, just in general ... I like that it's dealing with audience, with reader expectations. (Beverly)

I really liked it; I would have definitely used it [in my own tutoring] if there was more time in the semester. (Clarissa)

I enjoyed it ... I think it's a really unbiased way to provide some good feedback . .. and I do think I would have employed it in my own sessions if I had a chance. (Kathleen)

A couple tutors expressed additional reasons for liking the point-predict method. For example,

Kathleen, at a different point in the interview, noted that she liked this method because:

I think the whole idea of "I'm anticipating that you're going to do this because of something that's in the writing” gives you a different way to talk about why it's not working. It's almost like a diagnostic, you know, here look this symptom is right here in this paragraph.

In a slightly different vein, Clarissa, when looking at the data about the kinds of issues clients

initiated, said:

I think that's why I like [point-predict], because it makes . . . clients initiate a lot more [global issues] . . . I think generally it's difficult for them to think about global issues while they're writing; it's not really what they were trained on in high school ... so I think [point-predict] gives them an easy way to see things more globally, and they know that's what they should be doing because it's what we're always telling them to do ... so once they see a way to do it they get really excited, they're like "oh this is what I've been needing to do all this time!"

The interviews revealed that all the tutors were fond of the point-predict method; their reasons for liking it included the focus it brought to audience awareness, the way the method focused and specified discussion of issues within the text, and its influence on client attention to global issues.

\footnotetext{
${ }^{6}$ Because this study was conducted in the last weeks of the school year, tutors only continued their regular tutoring duties for about a week after the study was completed.
} 
Additionally, all of the tutors found that employing the point-predict method as part of this study influenced their teaching and writing practices. Maude noted that she "used the prediction method a lot in my conferences; it helped." Beverly also employed the point-predict method in her class, for both peer-review and conferencing, and "found it helpful." Clarissa mentioned that she hadn't used point-predict in her classes in the Fall term but wished she had because "it ended up where organization and topic sentences were the biggest things; it would have really helped with stuff like that." Kathleen noted that it not only influenced her conferencing practices as a teacher but also the kind of feedback she provided to her husband and friends when they asked for her help on some graduate school application essays. Additionally, all of the tutors felt it had contributed to their own writing and revising skills:

I think about it in my own writing when I'm trying to make sure it's organized. (Maude)

I feel now that I really do . . . understand audience expectations more, and that's something that I do think of more now when I'm revising--before I just had this vague thing of “does it make sense to me?” (Beverly)

Just knowing sort of the way people read and how it helps people read helps [my revising] a lot. (Clarissa)

I think that point-predict is one of a number of tools that I've learned [in graduate school] that has changed the way I'd give feedback or want feedback on my own work. (Kathleen)

These answers appear to indicate that tutors not only found the point-predict method useful for their tutoring sessions, they also found it helpful for their work as teachers and writers. Beverly even stated that learning and practicing point-predict as part of the study "made me more confident; it just gave me more ideas, and it made me feel better having some experience with it-I think I probably wouldn't have touched it at all if I hadn't been exposed to it [as a tutor]."

However, all of the tutors also saw some limitations to the practice. Some of these limitations related to the kinds of texts or client concerns that could be the focus of a tutoring session. For example:

The sessions I ended up having for point-predict ended up being the kind of sessions you'd want for point-predict, so I thought they were great. But I think 
point-predict is pretty specific to a client's needs; if they have more grammar problems and less organization problems it's not going to work as well ... the two people I did point-predict with, organization was their main thing ... so [point-predict] really helped them. (Clarissa)

Point-predict was best for longer papers where organization was more important-for shorter papers, like memos, it didn't really apply. (Maude)

Point-predict wasn't useful for talking about grammar or style. (Beverly)

I think it's well suited for strong writers who are a little too close to the work to see ... . [but] if there isn't a point [to the writer's paper] and you're just noticing 'well this really seems to go nowhere and I'm hoping you're going to go into this and you don't'--you know, I just think it would take a writer in that situation to tears. (Kathleen)

Other limitations concerned the tutors' level of comfort and familiarity with the method:

I thought it would have worked pretty well in the writing center with more training, I felt like I didn't do a very good job because I wasn't as confident. (Beverly)

I think in a certain sense I feel like I don't really get point-predict still. I mean I understood the gist of our training, but then when it was actually you and the client you end up adapting things . . . like I remember I made a lot of "this is making me feel" comments and maybe that isn't really part of point-predict ... I don't really know if it is or not. (Kathleen)

Finally, there were also concerns with how one would decide when and where to employ the method in tutoring sessions, or whether it should be used for an entire reading:

I don't think I would have wanted to do the entire session like that. I think I probably would have been looking ahead, thinking 'okay I'm starting to a see a pattern in the next couple paragraphs, maybe I should stop and try this and switch my method,' but I don't think I would have done it for an entire session again. (Beverly)

I don't think I would have done it as much--because of the study I felt like I needed to pause every couple of sentences. I think I would not have used it so much on my own. (Kathleen)

[In the study] we were assigned the [point-predict] sessions, and in a regular writing session at some point the tutor would have to decide ... to do this pointpredict, rather than it being decided ahead of time, and that's going to be more difficult. So basically I think it's good if you're using it at the right time ... but figuring out how to know if it's the right time remains the question. (Clarissa)

As their answers make clear, none of the limitations would have caused tutors to refrain from using the point-predict method again. However, their concerns do point out relevant issues that would need to be addressed if point-predict was introduced as a potential method to employ in 
writing center sessions. Clarissa's point is especially salient--determining how and when to make the decision as to what reading method will best suit a particular session is not a question this study was designed to answer; future research would need to investigate this.

One additional remark Clarissa made revealed a distinct point about the demands pointpredict makes, in her opinion, on both clients and tutors.

Point-predict forces you to do true revision, so [clients and students] have to have a level of maturity and a certain willingness. And I think for the tutors too, it can be a lot to tackle all at one time, so I think you have to have a certain willingness to get involved in all you're getting involved in.

When asked what she meant by true revision, Clarissa explained that:

To me, true revision is above and beyond sentence level revision, primarily. I see that most of my students only want to revise within paragraphs, and I think true revision involves deletion or addition of whole paragraphs or sections, or substantial reorganization. I also think true revision takes place on the level of ideas. That is, true revision involves rethinking one's ideas, not just one's writing — engaging in true revision means looking at the "big picture," in order to revise the work as a whole.

While the "forcing" of this kind of revision may sound like more of a benefit than a drawback in light of writing center ideals, realism demands that this limitation be considered. There will always be some who are not willing to do the work required for "true revision," and for those who fall in that category, point-predict may simply be an exercise in frustration or a waste of time.

\section{All reading methods are structures that affect what occurs in tutoring sessions}

Because the act of tutors or clients reading aloud without defined pauses for commentary seems so matter-of-fact, it is easy to forget that these are structured methods just as much as the point-predict method. Tutors' discussions of the study tended to reflect this kind of dichotomy, where point-predict was seen as a structured method and tutor-read or client-read as unstructured.

For example, when Clarissa was hypothesizing as to why the different reading methods would have produced different results, she said the following about point-predict: 
To me having a framework applied to reading aloud, especially for tutors who have been trained to use frameworks to look at things, even though there's always certain things we have to do but there is not a specific framework on a basic read aloud, but when there's that really specific framework put on the point-predict that's going to give us really specific goals and really specific things to do, I think, even if you are a trained tutor you're still going to have the tendency to be scatter brained, you're going to want to cover both the things the client asked for and everything you noticed, rather than like the one, well there isn't really just one, but the basic framework of the point-predict. (Emphasis added)

Though it is not the point of her reflections, Clarissa's remark reveals an underlying conception of point-predict as a structured method and client-read and tutor-read as unstructured. A remark from Beverly in response to a question about why tutor-read and point-predict would generate such different results reveals a similar idea:

I would probably say because when it's tutor-read, it's me being directive, but I guess when it's point-predict it's something else actually directing me...so it was kind of guiding me... with what exactly to be directive about. (Emphasis added)

Both of these remarks indicate that the tutors felt there was more structure in the point-predict method, and that it was this structure that was largely responsible for the difference in results between point-predict sessions and more traditional session types.

In a certain sense, these tutors are absolutely correct: point-predict is more structured than the loose conglomeration of suggestions on reading practices offered by tutor training manuals, as the various excerpts from those manuals that have been discussed previously reveals. Those manuals have to be more flexible in their advice, of course, because they are intended to provide a general set of guidelines that a tutor can adapt to any situation they might encounter; they have to be somewhat vague in order to be more widely applicable. The point-predict method, on the other hand, was taught as a specific practice that the tutors would employ in a specific way in two specifically pre-assigned sessions. In contrast, tutors were told to do their client-read and tutorread sessions just as they would normally, with no other directions or specific guidelines. That the tutors would then see the point-predict method as a definitive structure and the more traditional methods as nearly structure-less is therefore unsurprising. 
However, the debate over reading methods within the writing center community indicates that there is a clear structure-or, perhaps more accurately, a set of structural options— to traditional reading methods. Within manuals and on WCenter, this debate circles around two issues: who should read, and whether tutors and clients should react to the text during or after the reading. It is important to note that this debate is over these structures, not over the goals practitioners hope the structures will achieve; most everyone generally agrees they want to help maintain or increase client agency, interest, audience awareness, and global revision skills, but, as shown in Chapter One, there is no consensus over what structural combination most reliably produces these goals. Tutors' interviews revealed some of the potential underlying causes of the second disagreement, over whether it is preferable for a text to be read straight through, reserving all comments until the end, or read with pauses for commentary during the reading. They saw advantages and disadvantages to each approach, and their points help clarify what is at stake in this structural debate.

In their interviews, tutors generally expressed a preference for pausing to comment during the reading rather than withholding comments until the end. This preference was based on two related issues: memory overload and the desire for specificity.

When you read the whole paper first, especially if it's longer, you forget a lot of what you wanted to point out ... it's generally less overwhelming to stop every few paragraphs without waiting for the end to just unload everything on them. (Maude, emphasis added)

I think there's more advantages to responding while reading because, even if you are keeping notes, and I'm not one to keep notes because it distracts me from reading, you're going to forget...your initial reactions, and I think your initial reactions to something are important because most people aren't going to read something you wrote a few times, so it's important to be clear the first time. (Clarissa, emphasis added)

I think offering short reactions as you go you sort of give a more nuanced kind of complexion of what the paper is doing, than at the end making just an end comment. Because, again, it's the difference between being general or specific. (Kathleen, emphasis added)

As these quotations show, tutors felt that when they read a text all the way through they often forgot "a lot of what [they] wanted to point out" or their "initial reactions.” Maude and Clarissa 
both thought this loss was significant; Clarissa especially noted that she felt clients' hearing initial reactions “are important because most people aren’t going to read something you wrote a few times.” Perhaps another reason this loss matters is because, as Kathleen points out, “it’s the difference between being general or specific.” Though Kathleen does not explain why a tutor can “give a more nuanced” response to the paper by responding during the reading, Maude’s and Clarissa's remarks about how easy it is to forget what you were thinking may be the cause of this loss. A similar concern with cognitive overload and its negative effects is expressed by one of the participants in the 2009 WCenter discussion:

If I am listening to a talk or a conference paper, I have to work very hard to keep following what the speaker is saying, and it's almost impossible for me to operate simultaneously on a second level to think of questions or make connections...Similarly, as the consultant, whether I am reading aloud or being read to, I just can't *think* like a consultant...I can't keep track of the big picture, so to speak. (Levin, emphasis added)

Levin, like Maude and Clarissa, also obviously experiences a kind of cognitive overload, and she notes it can happen "whether I am reading aloud or being read to." Her remarks indicate that the tutors from this study are clearly not the only ones who can find traditional read-aloud methods to be "overwhelming" at times. Clarissa's remarks are especially telling, as they relate to improving clients’ audience awareness, an important issue to many writing center practitioners.

These comments would appear to support those in the writing center community who would argue for the value of offering commentary as the reading progresses. However, a review of the pauses that occurred during traditional tutoring sessions may indicate that the kinds of commentary tutors are likely to offer is the not the type hoped for by those advocating this method. Ryan and Zimmerelli, the training manual authors who most explicitly advocate for tutor commentary during the reading, suggest that tutors respond by "reflect[ing] what [they] hear after the writer has spoken" and that tutors "focus on the larger issues . . . [because they] might otherwise end up spending much of the tutoring session on a section that is ultimately deleted" (46). Their advice, in other words, is to describe rather than evaluate and prescribe, and to 
comment on the global rather than local. Though all the tutors were familiar with this advice, the commentary they offered in both client-read and tutor-read sessions did not appear to meet these goals. Both of the following remarks occurred within the first half of the reading, within one-tofive paragraphs of the paper's beginning; the first example is from a tutor-read session and the second from a client-read session.

Tutor: Ok, before we go on to the next page, I just wanted to point out a couple things we can work on as far as grammar ... Umm, whenever you have sort of like an introductory word or a phrase that begins your sentence, you always want a comma after it. Like, umm, especially when you say "according to" one of your sources, you want a comma after that. (Transcript 1, turns 25-7)

Client: [reading] "The importance of sharing” [pause] "of sharing teaches” [pause] "The importance of sharing teaches the student that the teacher is knowledge but accessible."

Tutor: "knowledgeable"?

Client: Yeah [pause]. And that probably needs to be “and” doesn't it?

Tutor: Mm-hmm. (Transcript 12, turns 174-6)

Tutor: Okay, um, I know you're giving background, and it's hard to- 'cause you, you haven't really gotten into your argument yet. Do you think you could, a little bit more, sort of front load your point here? 'Cause it doesn't, it seems like you get to it, you're talking about the preference, and the value of education for women, and it seems like this could be sort of a central point when you're talking about, um, sometimes they have to, is this part of the working, is they have to drop out of school and work, excuse me, work?

Client: Oh, it's in the next paragraph. Do you want to just read that and then come back to it? (Transcript 22, turns 70-7)

In the first example, the tutor, Maude, pauses the session in order to offer a brief lesson on comma usage, a comment that is neither descriptive nor global in nature. In the second example, the tutor, Kathleen, pauses the session to offer a quick fix for a sentence the client seems to be struggling with, and confirms the client's second local solution. In the third example, the tutor, Clarissa, pauses the session in order to offer a somewhat more global remark, but it is both evaluative and prescriptive (“you haven’t really gotten to your argument yet. Do you think you could . . f front load your point here?”). This suggestion is then somewhat undermined by Clarissa's uncertainty about the text, shown in her fragmented and somewhat confusing comment following this suggestion. As a result, the client concludes that she needs to hear more of the paper before they can discuss this issue (“Oh, it’s in the next paragraph. Do you want to just read 
that and then come back to it?”), a conclusion that is probably apt. Had Clarissa’s remark been more descriptive, however—something more like “thus far I’m hearing mostly background, and I'm not understanding how this background ties into your argument from the first paragraph”then it might have prevented this confusion and lost time, while enabling the client to decide how best to address this issue and whether he needed help figuring that out.

These kinds of evaluative, prescriptive, and usually local remarks occurred regularly in both tutor-read and client-read sessions, and were initiated by both clients and tutors. Tutors’ comments on the potential disadvantages of reacting during the reading may offer some ideas as to why offering these kinds of remarks during the reading is a bad idea. Each of the tutors who expressed a preference for reacting during the reading also pointed out potential dangers of reacting; these dangers involved the importance of understanding the text as whole before responding to it.

On the other hand, if you read the entire paper you get more of a feel for the overall point and how the whole organization is working. (Maude, emphasis added)

At the same time, I know ... there were sessions where I would respond to something as I was reading, and then it would change . . . so maybe just like shorter thoughts while reading and longer thoughts after? (Clarissa, emphasis added)

I mean obviously there's a disadvantage of possibly really hanging your hat on something in the first third of the paper that doesn't turn out to really be key to the paper. (Kathleen)

One of the tutors, in fact, focused more on these pitfalls than the benefits of offering commentary, pointing out potential client frustration caused by offering reactions during the reading.

I think sometimes the students, they have this feeling of frustration perhaps, a little bit, with asking questions before they got to it--kind of like "if you had read the whole paper, you would have understood this, and then you wouldn't have needed to ask me this question in the beginning." (Beverly)

Though Beverly is more oriented on the clients' reactions to this potential limitation, she is pointing out a similar issue to that discussed by the other tutors: that offering reactions while reading can lead you to address issues that are either resolved or insignificant by the close of the 
paper, a point that the excerpts from the transcripts above appears to substantiate. The potential pitfalls the tutors point out here may illustrate why Ryan and Zimmerelli’s advice to focus on "larger issues" is so difficult-if a tutor does not have "a feel for the overall point” then it would be easy to react to something that "would change," to slip into the danger of "really hanging your hat on something ... that doesn’t turn out to really be key to the paper," causing clients to experience “frustration.”

These disadvantages the tutors describe, and the kinds of comments seen within the reading portion of traditional sessions, illustrate why it is so critical for tutor commentary that occurs during the reading to be more descriptive than evaluative and prescriptive. In the absence of the big picture, most evaluations and prescriptions will either focus on local issues or, if they attempt to focus on the global, will be weakened or seem confusing due to the tutor's lack of knowledge about the paper as a whole, as with Clarissa's commentary. Perhaps it is the hope to avoid these issues that motivates Gillespie and Lerner to advise that the paper be read without interruption, or Caposella to emphasize that the client should be the only one to interrupt. However, these may be impractical solutions if their result is to overload the tutor's memory. Interestingly, the reading comments offered during point-predict sessions were rarely evaluative and prescriptive, which may indicate that the advice to be descriptive and global when reacting may be hard to follow for some structural reason during a traditional reading. Additionally, this trend may explain why the point-predict method is effective. First, it prevents the tendency for tutors to become overwhelmed by building in pauses for commentary in every paragraph. At the same time, it structures these comments so they focus more on the descriptive than the evaluative or prescriptive, thus making the concern about the tutor offering advice without understanding the "big picture" irrelevant. As discussed in Chapter Two, this descriptive commentary helps writers by giving them a more nuanced understanding of how a reader specifically reacts to the text, productively increasing their sense of audience awareness, as client surveys indicated. The value for writers of readers emphasizing descriptive rather than evaluative 
comments when first offering feedback on a text is further supported by other research, which shows that creative writers tend to get the most use out of feedback when the reader first describes her reactions to, and understanding of, the text as a reader, and then offers suggestions grounded in those descriptions (Block). Thus, the more methodical structure of point-predict helps to balance between the two structural weaknesses of traditional reading methods: it prevents tutors from overloading their memories while giving them a specific and descriptive format within which to frame their reading commentary. In doing this, point-predict may also help writers gather more useable feedback and develop a better understanding of their audience.

There is one other important reason why the structure of point-predict readings may prove more helpful than the traditional choices: this structure may invite a more productive and equal collaboration between tutor and client on the text. This effect is possible precisely because the tutor is not familiar with the text as whole, while the client is. The point-predict method, in fact, relies upon the tutor's unfamiliarity with the text—-the tutor is summarizing what she thinks is the main point so far, what she consequently expects will come next. If she definitively knew what the main point was, or where the text would go next, the method would be irrelevant-it relies on her ignorance of the text. This ignorance becomes a benefit because it requires the client to compare these thoughts to his own intentions, these predictions to where he knows the paper will go next. If both tutor and client participate in point-predict in this way, then each brings a respective area of expertise to the paper - the tutor her expertise as a thoughtful reader, the client his expertise as the author of his own text. Clients notice when tutors' predictions do not match the direction the text takes, and they draw evaluative conclusions and seek revision strategies as a result, as the examples in the initiation section of the previous chapter and the descriptions of the tutors ${ }^{7}$ illustrate.

\footnotetext{
${ }^{7}$ For quotations from the tutors on their recollections of clients' involved reactions to their predictions, see the section below on control and engagement.
} 


\section{Other reading methods may have similar benefits to those provided by point-predict}

Point-predict is not the only reading method that reduces memory load, focuses on descriptive rather than evaluative commentary, balances between specificity and the big picture, and facilitates shared expertise. There are likely a variety of reading methods that could accomplish this, and Kathleen employed one in a client-read session. In this session, Kathleen asked the client to gloss her paragraphs and decide how they tied back to her introduction as she read aloud. This session's structure was not planned in advance--as previously mentioned, tutors were not given instructions about how to conduct their tutor-read and client-read sessions other than to simply do what they normally did. In her interview, Kathleen said that her approach to this session was a strategy she commonly used in both her tutor-read and client-read sessions, though she could not recall where and when she had learned it. When asked about this session and whether her participation in this study prompted this approach, she said:

I did generally do it even before the point-predict training because I felt like it lead to a lot of "a-ha" moments, where I felt like it was just really reflecting the paper back and they would be like "Oh! Well then"...it seemed like my clients really responded well, and it gave me something to do that was higher order, and I felt like it was generally a better session. So that was something I did a lot, and I felt like it was very useful. I'm sure there was a lot of variation, and I bet I could find sessions where it worked a lot better than others, but there were enough sessions where it went well that I generally thought it was a good strategy.

Interestingly, the results of this session far more closely resembled Kathleen's point-predict sessions than they did her other client-read session, where this method was not employed.

Table 3.1: The percentages of topical chains with writing issues that addressed content or evidence issues, organization or signposting issues, and sentence-level or formatting issues within some of Kathleen's sessions.

\begin{tabular}{llll}
\hline Condition & Content or Evidence & $\begin{array}{l}\text { Organization or } \\
\text { Signposting }\end{array}$ & $\begin{array}{l}\text { Sentence-level or } \\
\text { formatting }\end{array}$ \\
\hline $\begin{array}{l}\text { Kathleen's Traditional } \\
\text { client-read }\end{array}$ & $14 \%(\mathrm{n}=4)$ & $25 \%(\mathrm{n}=7)$ & $110 \%(\mathrm{n}=31)$ \\
$\begin{array}{l}\text { Kathleen's Altered } \\
\text { client-read }\end{array}$ & $59 \%(\mathrm{n}=22)$ & $57 \%(\mathrm{n}=21)$ & $32 \%(\mathrm{n}=12)$ \\
$\begin{array}{l}\text { Kathleen's Point- } \\
\text { predict }\end{array}$ & $66 \%(\mathrm{n}=35)$ & $83 \%(\mathrm{n}=44)$ & $15 \%(\mathrm{n}=8)$ \\
\hline $\begin{array}{l}\text { Note: Percentages add up to over 100\% because topical chains were coded for multiple writing issues. The } \\
\text { values of " } \mathrm{n} \text { " differ significantly between the client-read and point-predict sessions because there is only } \\
\text { one of each client-read session, whereas the two point-predict sessions were grouped. }\end{array}$
\end{tabular}


As Table 3.1 shows, the focus on global issues within this altered client-read session was far higher than it was in Kathleen's more traditional client-read session. Though this is only one case study, it supports the hypothesis that reading methods that incorporate guided tasks and reactions to a text during the reading of it may be better suited at eliciting a global focus than those which lean more towards reading a text straight through with minimal or unguided reactions during the reading.

While this study only chanced to record one session that employed this alternative reading structure, the results are certainly promising enough to warrant further investigation. Other alternative reading practices might also warrant further study, such as those Ryan and Zimmerelli briefly sketch out in their section on "Making Global Revisions.” Some of their sketches include the suggestion that tutors read the paper as a "naïve reader, and indicate those places where it needs more details or more specific details” during their reading (47). As a separate suggestion, they even briefly describe a point-predict style method of reading and reacting to writers' texts (47). All of these approaches suggest some kind of interaction during the reading of the text - their central shortcoming is simply that the methods are only barely described. Given how most of the tutors expressed a wish for more training and practice in the point-predict method when they had already received a great deal more information than what is provided in Ryan and Zimmerelli, it may indicate that brief descriptions like these are insufficient for many tutors, making the seemingly easier task of simply reading straight through look more appealing than trying to construct a method out of a brief description in a training manual.

\section{A variety of factors can cause local issues to receive undue attention in tutoring sessions}

The high percentage of local issues that arose in most of the tutors' traditional sessions, especially their tutor-read sessions, was a surprising finding of this study. In fact, this finding was so surprising to Kathleen that she expressed some skepticism about the results. 
I mean [the difference between] the client read and the tutor read really surprises me, because it seems to suggest that having the client read is really a better situation than having the tutor read, so I feel almost a little bit skeptical about that, because...it seems like the session is just so much more effective when I read it, just in terms of my understanding the paper, that its harder to believe that when we have a lower comprehension of the paper we're doing more of what really counts. (Emphasis added)

Kathleen had a strong preference for being the one to read the paper because she found it much harder for her to focus on the material if the client read. She also said she frequently employed the glossing method, described in the previous section, in her tutor-read sessions in general.

Therefore, she was very surprised to see the high percentage of local issues that arose in her tutorread sessions, since she felt that generally these sessions were heavily focused on organization and structure. She was inclined to think that either the two tutor-read sessions she participated in for the study were anomalous or that the study's methods did not pick up on some of the global issues raised within the session. If she did employ this method as frequently as she believed, then her tutor-read sessions could be considered anomalous, since she did not employ this method in either of her recorded tutor-read sessions. Additionally, she may have been recalling her sense of how much time she felt was spent on local versus global issues, and one potential reason for the finding of increased local issues is that this study counted the number of issues that arose.

However, even if less time was spent on each local issue than each global one, it still seems that the structure of traditional read-alouds encourage attention to local issues, in part because of the cognitive overload and unmethodical commentary discussed in the last section.

Though the point that all reading methods are structures that influence the focus of tutoring sessions has already been made, the specific role of these structures in increasing the attention given specifically to local issues merits further attention. One of the potential reasons traditional reading methods may increase the focus on local issues is related to the cognitive overload discussed in the previous section: these structures reduce the amount of time tutors have to consider what merits the most attention.

With my experience teaching...there was a big difference when I was reading and grading papers, and I had more time to kind of decide what most needed to 
be focused on, than when I had to respond to something immediately...There were times when I had difficulty with reading aloud, especially because I think it was more difficult for me to try and pick up on things as I was reading them. (Clarissa, emphasis added)

Clarissa's remark that "it was more difficult...to try and pick up on things as I was reading them" is reminiscent both of Levin's remarks on WCenter and Maude's remark that it was "overwhelming" to read through a text all at once. Her comment that she was better able to focus on global issues when she "had more time to...decide what most needed to be focused on" points out the possibility that tutors coming to the end of a traditional reading, especially in a tutor-read session, feel pressured to make decisions very quickly in response to the entirety of the paper. Though the demands of limited time are a part of all tutoring sessions, this pressure would likely be higher after traditional reading methods because there would have been no time to reflect on global concerns during the reading itself.

As a result, local issues receive attention because they stand out to both tutors and clients when reading without a globally-oriented task in mind. Tutors often felt it was the client who noticed these issues in client-read sessions.

A lot of times when the client reads, the tutor will hear something that's off or the client will stop to ask. (Maude)

When clients read they notice [local issues] and want to do something about it. (Beverly)

In client-read the client does tend to stop if they run across something they notice with grammar. (Kathleen)

All of these responses indicate that the tutors felt the reason client-read sessions showed such a high focus on local issues was because clients tend to notice these kinds of issues when reading their texts aloud. Maude also noted that tutors notice and can bring up these issues when they hear the client reading as well. More commonly, however, tutors felt that it was hardest for them not to fixate on local issues when they were the ones reading without a global task in mind: in tutor-read sessions. Most of the tutors expressed the opinion that more local issues came up in these sessions 
in part because those issues stand out when one is reading another's writing, and ignoring them is difficult.

When the tutor is reading the paper we're much more likely to have those things [local issues] jump out at us that we then point out to students. (Maude)

As you were reading if you have a grammar error it's hard to skip it...I do think as readers we have this reaction if there's a grammatical problem, it throws us off. (Kathleen)

Partly it's just a knee-jerk reaction... we're just going to see it and go for it. (Clarissa)

The tutors point out that the act of reading aloud makes it hard for the reader not to notice local issues, whether that reader is the client or the tutor. Obviously, however, this did not occur as often in point-predict sessions, which implies that it is the act of reading aloud without a specific task guiding that reading that contributes to this result. While this hypothesis needs further study, it would certainly make sense that if both the tutor's and client's minds are occupied with a particular task, such as making (on the tutor's side) or evaluating (on the client's side) summaries and predictions, local issues may not “jump out at” tutors or clients so readily.

Thus perhaps one of the reasons that traditional approaches to reading elicit such a high focus on local issues is not only because of the cognitive overload they place on the tutor's memory by requiring them to withhold their responses until the entire paper has been read, but also because these structures fail to occupy both tutors' and clients' minds with a mental task that would counter the tendency to notice local issues while reading aloud. These structural influences can in turn combine with other factors that contribute to the frequency with which local issues are discussed. Tutors' interviews indicate that a few other factors besides, though perhaps affected by, structure can play a role. These include the seeming ease of addressing these issues, a lack of confidence on approaching global issues, and the urge to fill time at the end of the session.

Perhaps because of the way sentence level issues are so easily noticed in traditional tutoring sessions, they can also seem easily solved.

It [local issues] seems easy, like it won't take that much time...I know we don't intend to spend as much time as we do, and it ends up taking longer to explain 
than we think it is. And I think it bothers us, we want to see it fixed, we see it as easier to clean up the basics of writing, to have nice sentences, than to grapple with the other [global] stuff that seems harder for us to work on. (Clarissa, emphasis added)

Clarissa's remark, of course, points out one of the pitfalls of this apparent ease - that discussing how to resolve these local issues “ends up taking longer to explain than we think it is.” Still, if these issues seem like they would be quicker and easier to address, and the global "seems harder," it is less surprising that the local would receive more attention.

Of course, understanding why tutors like those who participated in this study, tutors who strongly value addressing global concerns and are very self-reflexive about their practices, would choose a seemingly easier route raises further questions. One potential cause offered within the interviews is that tutors are more inclined to go for what looks easier if they are not feeling confident in a session.

A lot of times it [local issues like grammar] is a lot easier to explain even if it isn't easier to actually teach. So if I'm not feeling confident in a session, then I'm thinking that's something I know how to do." (Beverly, emphasis added)

Beverly's remark introduces the relationship between these two factors-if a tutor is "not feeling confident in a session,” then she is going to turn to what seems easier and, therefore, more confidence-inspiring: solving sentence level issues within the text. Thus the apparent ease of addressing local issues as an explanation for what can cause these issues to receive more attention in a session may be quite closely tied to a second potential cause of this happening: a lack of confidence on the tutor's part.

Confidence and comfort played a particularly large role for Maude in determining how often local issues arose in her tutoring sessions. As mentioned in the previous chapter, Maude generally addressed more sentence-level issues in her sessions than the other tutors. At the end of her interview, she answered a few specific questions to try to explain these trends, and these answers help interpret the results of her sessions. The last question noted that she generally had shorter sessions than the other tutors and seemed to focus more often on issues like grammar, sentence structure, and citation style, then asked why she thought that was the case. She said: 
A little of it is my personality and teaching style. I do tend to focus on grammar and sentence structure, especially when students come in the day before it's due, a little because that's what I'm more comfortable talking about and teaching to students, especially when it's an assignment I'm not as comfortable with. (Emphasis added)

In this response, Maude indicates that part of the reason her tutoring sessions focus on more local issues is because of her own comfort levels. A similar issue came up in her response to the second-to-last question, which pointed out that her point summaries and predictions were generally shorter than those offered by the other tutors, and then asked her why she thought this was the case.

It wasn't the training, it's just the method was initially a little uncomfortable for me. Last year I was definitely a quieter tutor; I was afraid I'd make a wrong prediction and it would be my fault rather than the writer's fault, so I tried to make them [the predictions] shorter and more general. Developing familiarity with the method is important because as I've become more confident with pointpredict [in my teaching and conferencing this year] I've been better at not holding back with predictions, unlike what I did in those sessions last year. (Emphasis added)

Taken in conjunction with her response about her increased focus on local issues in all her sessions, this last comment confirms that comfort and confidence are key issues for Maude in shaping her tutoring (and teaching) practices: when she feels less confident, she is more likely to focus on local issues or offer vague and general reactions to a text; when she feels more confident the reverse seems to be true, at least in her assessment of herself.

Though confidence may have played a larger role for Maude than for other tutors, Beverly's remark about falling back on a discussion of local issues when feeling less confident about a session makes it clear that Maude is not simply an exception to the rule. The role of confidence, in fact, may be particularly important for writing center practitioners to consider since it has the potential to undermine any reading method, alternative or traditional. Though the overall results of this study indicate that confidence is not the only, or probably even most significant, factor in determining the effects of reading methods on tutoring sessions, 
consideration of its influence on giving a heavy local focus to tutoring sessions may be helpful for writing center tutors, directors, and scholars alike.

The interviews revealed one additional factor that may play a role in determining how much attention is given to local issues in tutoring sessions: the urge to fill time. Because Beverly's sessions were by far the longest, regardless of session type, she was asked to explain this trend. She said, "I feel like that is their time, and they came wanting to use all that time, and I'd feel like I was shortchanging them [if I stopped early]." Whereas other tutors would end their sessions early if they felt that the most significant issues had been covered, all of Beverly's sessions took the full 45 minutes allotted for tutoring--in fact, she often ran over this time and took 50 or even 55 minutes on tutoring sessions. This is significant because Beverly generally constrained most conversation about local issues to the end of her sessions. This trend persisted across all of her sessions, and the effect the session type appeared to have on her was of altering the number and type of global issues that received attention before she turned to local issues. This tendency may help explain why Beverly's point-predict sessions focused on more local issues than Clarissa's and Kathleen's, which both focused on local issues about half as often as Beverly's. Since Beverly felt obliged to fill an entire session regardless of the circumstances, perhaps that meant that, where other tutors stopped after the point-predict method had brought up a variety of global issues for clients to examine in their revisions, Beverly felt she needed to continue past that point into a discussion of local patterns of error to fill time. Obviously, all of this is primarily hypothesis--the structure of the study was not designed to answer how tutors made decisions about when they had discussed enough to prompt a client's next revision. However, there is enough to suggest that an examination is warranted of how tutors decide when to end their sessions, and how this decision process affects the amount of attention given to local issues. If tutors feel the need to fill time at the end of their sessions, this may cause a spike in the amount of attention given to local issues — and it may have the added disadvantage of overwhelming clients with too many issues to consider in their next revision. 
Writing center practitioners who wish to prevent undue attention being given to local issues must first understand what can catalyze a heavy focus upon them. These interviews offer some preliminary ideas about the kinds of issues practitioners might want to investigate, issues that include, but are not limited to, the effects of various reading structures. Still, these other factors — of apparent ease, confidence or lack thereof, and the urge to fill time—cannot be entirely divorced from reading structures either. The kind of focus required by employing a method like point-predict, or Kathleen's glossing method, may keep both the client and tutor too busy to notice as many local issues. The memory overload caused by traditional reading methods might easily undermine tutors' confidence in their grasp of the text, causing them to resort to discussing local issues because they did not have space and time enough to organize their thoughts on larger concerns; alternately, tutors who lacks confidence in their grasp of a new reading method may turn to local issues as a result of their confusion. And the amount of time reading methods require tutors and clients to spend on reading and offering initial reactions to a text will necessarily affect the amount of time left at the end of the session available for less significant issues. Overall, then, the implication is that practitioners who wish to lessen the amount of attention given to local issues need to consider a range of factors that can influence this tendency-and probably there are many more than were revealed by these interviews—as well as the relationships between these factors.

\section{Ideas of control and engagement are too easily conflated}

Most of the tutors expected that clients would initiate the greatest number of issues in client-read sessions. They expected this because they believed that levels of client control and agency would be higher when clients were reading.

Clients are likely to initiate more chains in client-read out of all three because I feel like they probably have the most ownership of their paper when they are reading it aloud and they have more choice over when to stop and when to keep going. (Maude, emphasis added) 
I would expect clients to initiate more in client-read sessions because they have more agency, I think, in those. I don't expect a huge difference, but I think when they've been reading they're more likely to have picked up on their own issues and to bring them up on their own. (Clarissa, emphasis added)

I think I'm just very, very surprised that the clients didn't get any more agency . . . I was hoping [that] would happen in this study when they were reading. (Beverly, emphasis added)

Maude's and Clarissa's remarks occurred before seeing the data on client initiation and addressed their expectations for that data, whereas Beverly's occurred after seeing that clients' levels of initiation did not vary significantly across session type. Still, all of these comments reflect that they expected the data to show clients initiating more in client-read sessions because they assumed clients had more "ownership," “choice,” or "agency” when they were the ones reading — and that this would in turn cause clients to "bring [issues] up on their own."

Yet while tutors equated client-read sessions with client control and initiative, they also noted that point-predict sessions seemed to provoke greater levels of client engagement or involvement. In fact, for one of the tutors, Clarissa, considering client levels of involvement in point-predict caused her to second-guess her prediction that clients would show more initiation in client-read sessions.

When I was reading, just in the regular tutor-read, it seemed like they were uninterested in the session. They were much more involved when they were reading their own papers--but they seemed to get the most involved in the pointpredict sessions, especially if something didn't follow what I predicted. (Maude, emphasis added)

With point-predict I guess I expect [client initiation levels] to be more because they seem to get involved in that, they seem to finish your sentences for you, your predictions... because they're predicting at the same time as you and they know whether it's going to happen or not....They started chiming in right away, like this needs this, this doesn't make sense, this needs to be next, those types of things. (Clarissa, emphasis added)

When I was doing the [point-predict] sessions I remember feeling that they were asking more questions, that they were interested and engaged. (Beverly, emphasis added)

I'm not surprised by [the results] of the point-predict because the clients seemed really into it. In my sessions, whenever we were doing it I just heard a lot of positive feedback as we were going along. (Kathleen, emphasis added) 
All of the tutors, then, noticed that clients in point-predict sessions were "involved," "interested and engaged," or "really into it," more so than clients seemed to be in traditional sessions. Two of the tutors specifically tied this involvement to the prediction element of the method, noting that the fact that clients knew what was coming next caused them to be drawn in by the tutors' predictions, “especially if something didn’t follow what [they] predicted,” as mentioned in the earlier section on structure.

For the tutors, then, client control and client engagement are two separate issues. However, in training manuals, these issues are treated as though they are necessarily interlinked: client ownership, control, and agency are seen as inevitably partnered with client attention, interest, and engagement. Generally, all of these qualities are represented in the manuals as best catalyzed by client-read sessions. For example, Gillespie and Lerner claim that "when the writer reads the paper" he is "in control” and, according to their "anecdotal evidence," he "is listening... to the way the draft is working...he’s giving his draft a critical reading” (30). This assumption that reading one's own writing both causes clients to retain control and be attentive and engaged with their texts is expressed in other training manuals as well.

Asking writers to read aloud engages them more in the tutoring session. (Ryan and Zimmerelli, 46, emphasis added).

Keep the writer involved. This point is intimately connected to the previous one: being in charge requires being involved...Consulting demands interaction...it's not enough for a writer to be merely present in the flesh--she has to be fully engaged in the session. (Caposella, 10, emphasis added).

While control and engagement are most explicitly connected by Caposella's comment that "being in charge requires being involved," all three of these references link the control the writer has when she is reading her own text with the idea that this position will cause her to be "listening" and giving "a critical reading" to her own writing, that reading her own text means both that she will be “in control” and more "engaged."

There are two problems with this marriage of client control and interest. The first is that it operates on a fairly simplistic notion of control: if the writer is reading his own work, he is 
presumed to have more control than if he is not. On the face of it, this makes sense--Gillespie and Lerner's suggestion to tutors to "think of the action of taking your friend's paper and going off with it or writing on it. You're in control. You call the shots" (30) illustrates a valid concern. However, asking writers to read does not necessarily empower them, especially if some are reading only because they know the tutor wants them to, potentially creating awkwardness and discomfort, which are not solid bedrocks upon which to build a sense of agency and ownership. Some tutors noticed that often clients do seem uncomfortable when reading their own work aloud.

I think it [choosing who reads] really depends on the person. If they're uncomfortable with reading aloud, you know ... it helps to have the tutor read, and sometimes that helps them come out of their shell (Clarissa, emphasis added).

When the client read ... it seemed like they were uncomfortable and worried about 'am I reading it right, is my inflection right? And then if they catch an error it's like ... . 'do you think that's an error?' . . . It just doesn't seem to be very fluid. (Kathleen, emphasis added).

While Clarissa felt that only some clients were "uncomfortable” when reading aloud, Kathleen actually felt this was the most common state of affairs when clients were reading, unless it was a client who was particularly interested in being the one to read. These tutors are not alone in noticing that some clients are uncomfortable reading aloud; as mentioned in the first chapter, practitioners on WCenter, in both the 1998 and 2009 discussions, noted related issues as caveats that tutors needed to keep in mind when deciding what reading strategies to use. Clients who are non-native speakers of English, have learning disabilities, or are particularly uncomfortable with reading their own work were all mentioned as clients tutors may not want to push to read (Aleksa; Glennon; Harris; Simpson). In general, however, it seems these issues have been treated more as exceptions to the general rule rather than a reason to investigate the relationship between comfort and control for writers. In other words, these issues get treated almost as a set of rules: have the client read aloud unless they have a learning disability, are a less proficient non-native speaker, feel especially uncomfortable with reading aloud, are painfully shy, or have some other similar 
factor that intercedes. Instead, one might consider whether these "exceptions" illustrate crucial broader questions: how much control, agency, or authorship is a writer really wielding if she is uncomfortable or has felt pressured into reading? Clearly, current notions of the connection between reading, comfort, and control need to be examined.

As one tutor noted, there is a difference between clients actually being in control versus simply appearing to be in control. Superficial representations of how tutors aid clients in maintaining agency may cause some tutors to develop goals for their tutoring practices that are more focused on giving clients the mere appearance of control over other priorities. Beverly was particularly concerned with the role of client agency in tutoring sessions and how she could catalyze it. At one point in her interview, she made the following interesting remark about this focus:

Now that I've had experience in the writing center, I think I'd be better at that, with trying to give them more agency--but then you can't give someone agency, that's kind of ridiculous. [Laughs] But I think I'd be better at making it appear that they had more agency. (Emphasis added)

Beverly's remark, though partially intended as a humorous comment, reflects a very real issue that is created by over-simplified representations of control in tutor training manuals. When an actual sense of ownership and authorship is conflated with the simple appearance of being in control, then it becomes very easy for the focus on the actual to be replaced, consciously or unconsciously, with a focus on the semblance. In the case of reading practices, that can lead to tutors emphasizing that clients perform control more than develop it; that they read so the tutor feels they are in control and thus, perhaps, does not have to really worry about whether or not the clients genuinely feel they are in charge of the text or the session.

The second issue with training manuals deciding that having clients read grants them both control and engagement is the assumption that reading aloud automatically leads to engagement. This assumption is problematic because it is easy enough to read a text aloud, 
particularly a known text, without really attending to what is being read. Beth Boquet makes a salient point along these lines in the 1998 discussion on WCenter.

I think we can't_assume_that [clients are] paying attention just cuz they're reading aloud. In fact, it might preclude their paying attention to the kinds of things we might want them to pay attention to. (qtd. in Gillespie 43-4)

Boquet's comment cuts right to the heart of the matter: reading does not mandate full attention, and we cannot assume that the simple act of reading draws clients to attend to their papers in a “critical” (Gillespie and Lerner, 30) or "fully engaged" (Caposella, 10) fashion. In fact, if "the kinds of things we might want them to pay attention to” are global issues, then this study may indicate that Boquet is particularly insightful in questioning these assumptions.

Additionally, this dual focus on client control and engagement neglects the issue of tutor engagement. When discussing her expectations about the results of the different session types, Kathleen noted a variety of issues, including her own ability to stay involved in the text.

When the client read . . . it seemed like they were uncomfortable and worried ... But then sometimes when I read it, without any stopping, they tune out. So the point-predict seems like a way that you can have an effective reading of the paper while also making it a give and take ... and sometimes I find I can't follow the student when they're reading it, and then I just kind of tune out. (Emphasis added)

Kathleen is clearly concerned with both the likelihood of clients tuning out in standard tutor-read sessions and her own likelihood of tuning out in standard client-read sessions, though this dual concern for both client and tutor engagement is lacking in training manuals. Additionally, she is not alone in having difficulties staying engaged with the text when the client reads aloud; Levin makes a similar point on WCenter, noting that when she is listening to someone read, "it's almost impossible for [her] to operate on a second level to think of questions or make connections.”

Kathleen's and Levin's remarks make it clear that considerations of tutor engagement may be equally important to the success of a consultation as client engagement. Why this issue has been ignored is uncertain, but the fact that it has sends a message to tutors that tutoring methods are designed for engaging clients, not tutors - that tutors are on their own in figuring out 
how to stay involved with clients' texts. Treating tutors in this way is short-sighted, especially since writing centers are both an educational and employment setting. Educationally speaking, most writing center practitioners would probably express the view that tutors learn as much, if not more, from tutoring as clients_-and yet, while interest is generally considered crucial to learning, tutor interest is overlooked. Taken from another standpoint, if the writing center is considered as a work place, one where tutors are employees, this neglect of interest is equally problematic, as it has long been understood that employees who feel empowered and interested in their work perform far better than those who are bored or disengaged. Thus, if we agree that writing centers are both an educational setting and a workplace for tutors, attending to their interest in the tutoring process is essential. While some individual writing centers likely already take this approach, the actual study and consideration of this issue in writing center studies and training manuals demands attention.

\section{Discussion}

To summarize, these interviews enriched the interpretation of the transcripts and surveys in a variety of areas. They not only indicated that tutors generally like point-predict as a tutoring method, but that their reasons for liking it center around the interest it provokes in clients, the focus it gives to readerly responses, and the kind of methodical structure it lends to the tutoring session. The interviews also revealed some of the limitations of the practice, namely the time it takes to become confident with it, the types of papers it is not well suited for, the difficulty that deciding when to employ it mid-tutoring session would pose, the fact that not all tutors will respond to it the same way, and the possibility that point-predict requires a higher level of both client and tutor dedication to work effectively.

Tutors' enthusiasm for point-predict as a methodical reading structure also points to the ways in which traditional read-alouds are structures, albeit less methodical ones. These looser reading structures pose problems for tutors because they require them to choose between 
potentially overloading their memories by reading a text straight through or missing the big picture by offering evaluative comments as they read. Though these results are certainly not the intention of tutor training manuals that advise tutors to either read with or without commentary, the tutors' discussion of this dilemma may indicate that more methodical reading structures are required to avoid these pitfalls.

Tutors' remarks on the effects of point-predict and traditional reading methods also suggest why the point-predict method worked so well: it helps tutors avoid memory overload by allowing them to pause and process the text as they read, while structuring these interjections so they remain primarily descriptive, rather than evaluative and prescriptive. This allows the tutor to emphasize her area of expertise as a trained reader with a fresh eye for the text, while the client is able to bring in his area of expertise as the only one familiar with his own intentions and the direction the text takes. These complementary areas of expertise facilitate a balance between specificity and the "big picture," since the client knows the latter and can therefore define how to use the specific reactions of the tutor. Additionally, a case study of an unusual glossing-whilereading structure a tutor prompted a client to employ in a client-read session may indicate that other reading methods may be able to balance between these different goals in ways similar to those achieved by point-predict.

Tutors' conversations about the effects of these reading methods also revealed a number of hypotheses about what some of the causes for local issues receiving undue attention in some tutoring sessions may be. These causes include the reading methods themselves, the apparent ease of addressing local issues, a lack of confidence about how to deal with the global issues, and the desire to fill time at the end of a session. Many of these causes are interrelated—a reading structure that fails to occupy tutors' and clients' minds with a globally-oriented task may make it more likely both will focus on the apparently easy-to-address local issues, for example. Each of these causes, along with any others revealed by future research, merits further investigation as both distinct and interlinked issues. 
Additionally, these interviews also revealed that writing center beliefs about control and engagement are ripe for further inquiry. Future research may find it useful to investigate not only the effects of reading methods on these qualities in both clients and tutors, but general attitudes towards these concerns in writing center practice and theory. In the meantime, these interviews may indicate that writing center practitioners could find it useful to conduct thoughtful selfanalyses of their own ideas about the relationship between comfort and familiarity, control and agency, and interest and engagement.

There are, of course, limitations to interview data. It is not as objective as other forms of data, and tutors' recollections of what happened in their sessions may be inaccurate. This effect could be exaggerated by the fact that all the tutors worked with me outside the bounds of this study, as discussed in Chapter Two. Still, when combined with the transcript data, the results are promising and show how a simple change in reading method can influence tutorial conversation. The next chapter will focus on the need for additional research on reading methods and the implications for writing center practice. 


\section{CHAPTER IIII}

\section{IMPLICATIONS FOR FUTURE RESEARCH AND TUTOR TRAINING}

\section{Summary of study results}

This study complicates a commonplace assumption in much of writing center literaturethat having clients read their own texts aloud while tutors simply listen and take notes, offering only sporadic comments or questions, is the best approach to reading in tutoring sessions. As the previous chapters have shown, the role and effects of reading methods in tutoring sessions is an area of writing center practice that has been mostly overlooked. This study indicates that this elision is a problematic one, as it appears the most commonly prescribed method of reading - that clients read aloud — may not achieve all the effects it is believed to achieve. Client-read sessions in this study focused far more attention on local issues than global ones, a tendency that occurred even more strongly in the second most common approach to reading in tutoring sessions, that of having the tutor read the text aloud with only rare or unguided pauses for commentary. This study indicates that these two common methods increase the focus on local issues over global ones-in tutor-read sessions, local issues were addressed in $76 \%$ of all discussions of writing issues, and in client-read sessions, these issues were addressed in 58\% of discussions. Though one tutor, Beverly, had a generally lower percentage of local issues in both these session types than the rest of the tutors, the trend of giving greater attention to local issues in tutor-read sessions than clientread ones was seen in all tutors' sessions. Thus, other reading methods may be needed if this heavy local focus is to be avoided. Additionally, this study indicates that assumptions that clients are exerting greater influence over how their paper is discussed when they are the ones reading it 
may be unfounded, as clients initiated roughly the same number of topical chains in all session types.

The most striking finding of the study, however, is how much the point-predict method seemed to change the discussion in tutoring sessions. In contrast to the two traditional methods of reading aloud, sessions that employed the point-predict method focused far more on issues of content (51\%), organization (30\%), and signposting (34\%), and far less on sentence-level or formatting concerns (28\%) than either of the two traditional methods. This trend was also seen in all four of the tutors' sessions. Moreover, clients specifically initiated global issues far more often in point-predict sessions than in traditional sessions - they initiated discussions of organization or signposting three times as often, and initiated discussions of content or evidence almost twice as often-showing that this greater global focus is not simply the result of tutors initiating more discussions along these lines. Additionally, surveys and interviews revealed that both tutors and clients generally appreciate the point-predict method, at least in part because of the global focus it generates. Other reasons both clients and tutors enjoy this method were based around the greater sense of audience awareness they feel it gives them; moreover, tutors found that point-predict influenced their later teaching and conferencing practices and their own writing and revising habits.

Tutor interviews suggest why the point-predict method was so successful in changing conferencing practices and in the process call into question some of our assumptions about writing center conferences. In conjunction with the data from the transcripts and surveys, the tutor interviews, in addition to revealing tutors' interests in point-predict, also reveal other interesting hypotheses about reading methods and writing center practice. For example, they illustrate that tutors tend to think of the point-predict reading method as a structure, and clientread and tutor-read methods as structure-less. However, tutors' other remarks about why they believed so many local issues arose in client-read and tutor-read sessions , and the results from the transcripts themselves, indicate that the seeming absence of structure in traditional reading 
methods is actually a structure itself, one that provokes fairly consistent results in the kinds of issues that receive attention in tutoring sessions. Tutors' remarks indicate that finding reading structures that can balance between the memory overload created by reading a paper without pause and the need not to offer comments during the reading that might prove irrelevant by the conclusion is particularly important. Reading methods like point-predict, which build in commentary that relies upon the tutor's ignorance of the full scope of the text, may be best suited at providing this balance. This hypothesis is further supported by the results of a non-traditional client-read session, where Kathleen asked a client to gloss her paragraphs as she read them and tie them back to her thesis. This alternative structure produced very different results from Kathleen's other traditional sessions, significantly increasing the focus on global issues and decreasing the focus on local issues.

These interviews also revealed a variety of reasons that writing center practitioners who are interested in reducing the amount of attention given to local issues might want to consider. First among these is the influence of the reading methods themselves, as indicated. Other factors can also play a role, however, such as the apparent easiness of addressing local issues, an ease that becomes even more tempting if tutors lack confidence about their ability to address the global issues. Additionally, tutors who feel the need to fill all the time allocated to a tutoring session may discuss many more local issues at the end of the session as a way of filling that time. Undoubtedly there are other factors like these not revealed by the interviews that can play a role in how much attention is given to local issues, factors that can be influenced by reading methods but are not entirely dependent upon them.

Finally, the interviews revealed that tutor training manuals' tendency to conflate client control with client engagement is problematic; not only are these not mutually dependent, but the conception of what they are and how to determine if they are present may be too simplistic or superficial. Furthermore, not enough attention is given to the role of tutor engagement, and this 
failure may be part of the reason that so many hasty conclusions have been drawn as to the purportedly near-universal benefits of having clients read their own texts aloud.

\section{Drawbacks of study design}

A few drawbacks to the study design somewhat mitigate the results and, therefore, future research would want to address them. The most significant of these, as discussed at the end of Chapter Two, is the small size of the study. This size means that only hypotheses can be drawn from these results, and though these hypotheses may be useful to future research they do not, on their own, provide answers to questions about the effects and uses of reading methods. Additionally, as discussed in Chapter Two, the small size meant that this study was unable to gather enough revisions to analyze the effects of the different reading methods on actual client writing, an issue that a larger study would be better able to address.

The self-selection of the tutors involved in the study is another limitation. This selfselection meant that only tutors who were already interested in reflecting on their tutoring practices became involved in the study; tutors of this nature might be more likely to be influenced by a change of reading methods than tutors who are indifferent about their position. As previously mentioned, the fact that the tutors were all graduate students who knew me and had worked extensively with me for months before the study began may have also contributed to this effect. A study which examined a larger and more comprehensive variety of tutors would be better suited at determining whether alternative reading methods like point-predict can have as dramatic an effect on all tutoring sessions as this study indicates.

The coding methods employed within this study also proved to have shortcomings, specifically the multiple coding of writing issues within topical chains. Though this method was employed so that topical units could be examined as a whole in order to better understand trends in initiation, the multi-coding of writing issues produced confusing and possibly slightly distorted results in the examination of the frequency with which different kinds of writing issues arose. 
Most problematic, in retrospect, was the fact that local issues were coded individually but only discussed as a group. Therefore, if a topical chain discussed both spelling and diction, that chain would have been coded as containing two local issues, thereby increasing the total percentage of local writing issues within that session with perhaps more dramatic an effect on the final numbers than may have been warranted. Although this heightened emphasis may be a drawback in some ways, it also has the beneficial effect of shining a spotlight on just how many different kinds of local issues can slip into writing center sessions; if all chains were simply coded for whether or not they contained any discussion of any local issue it might create a problem in the opposite direction by somewhat obscuring just how many discussions of local issues are occurring. Still, this effect would need to be considered in the coding design of any future research.

The fact that this study did not examine the amount of time spent on writing issues is a related drawback to this coding issue. It is possible, for instance, that local issues were generally talked about for much briefer periods of time than global issues. If this is the case, it could be that sessions that discussed more local issues than global ones still might have spent more time on global issues than local ones. This does not indicate that future research should examine time instead of number, but rather that it should examine both, as this would provide a more nuanced understanding of how both global and local issues are treated in writing center sessions. Looking at time would also enrich initiation data, as it might illustrate whether client-initiated discussions tend to receive more or less attention than tutor-initiated discussions in different session types.

Another element of tutoring sessions that this study did not examine and future research might benefit from analyzing was indirectly pointed out by one of the tutors, Kathleen, in her interview. She said:

I don't know, I almost want to go back....and look at the paper, cause I think sometimes whenever I'm reading there might be some writing that's going on, like I told you how I tag paragraphs and try to get the student to tag, and while I don't know if I was doing that in these sessions, it could be that the talking isn't reflecting some of the higher order stuff that's happening. 
Her idea to look at the writing produced during the session—-both independent notes and markings on the original copy of the text used—would also provide a more complete understanding of what is occurring in tutoring sessions. This approach would not only provide more information about what kind of writing issues are receiving attention that may not be revealed in the vocal discussion, as Kathleen points out, but also would provide an additional source of information about what clients may be focusing on in the session through showing what they found important enough to write down. Future research might also examine gestures as additional ways in which issues may be discussed, building on work such as that conducted by Thompson.

Due to time constraints, this study was only able to examine two of each session type per tutor. This may have been especially problematic in the observation of point-predict sessions as some of the tutors, especially Maude, felt that they did not develop complete confidence in their use of the method until practicing it more extensively. It may be that studies of tutors using alternative reading methods will have quite different results if those methods have been practiced more extensively by the tutors. On the one hand, this could cause the results to be all the more dramatic_-as Maude believed hers would be. On the other hand, if familiarity lessens tutors’ heightened attentiveness to the session, this may render the differences between alternative and traditional reading practices less distinct.

Overall, the results of this study, while promising for alternative reading methods, are provisional and leave many questions unanswered. Writing center administrators and scholars who are interested in these results need to keep these drawbacks in mind when implementing their own research and practice. However, the real value of a small study like this is in the hypotheses it raises and the directions it suggests for future research. The following sections will discuss these possibilities in more detail, offering ideas for how both researchers, administrators, and the authors of training manuals might productively build upon the results of this study. 


\section{Implications for future research}

In addition to the ideas for future research generated by the drawbacks of the study design, this study raises questions for future research to investigate in other areas as well. For example, future research might benefit from examining single clients across multiple tutoring conditions. In this study, each client was observed in and surveyed about only one reading method, thereby leaving them unable to analyze the differences between the methods for themselves, unless they happened to have experienced a different reading method at the writing center prior to participating in the study. Gathering information from clients on their perceptions of the differences between the reading methods would allow for a more precise study of the differing effects of the reading methods on clients, as it would eliminate the potential that the variance in effects was caused only by a coincidental variance in client tendencies.

Another question future research might productively seek to answer is suggested by Clarissa's concern, mentioned in Chapter Three, about how tutors should decide when to use point-predict in their tutoring sessions. A study which sought to answer this question would likely need to look at several factors: what types of writers benefit most from point-predict, what types of texts benefit most from point-predict, and what stages in the writing process are best aided by point-predict. The answers given by the tutors in this study to these questions may offer some preliminary hypotheses for this research to examine, such as the possibility that writers need to be willing and able to do "true revision,” as Clarissa suggested, and that the text has to be complete enough to have all its main ideas down but not so complete as to primarily need assistance with syntax and grammar.

In order to answer the questions about writers, texts, and stages in the writing process, future research may want to focus more heavily on the effects of writing center sessions on client revision practices, and perhaps even on the results of multiple visits on a series of revisions. It may be, for instance, that point-predict is well suited for a writer who has put out all her initial 
major ideas but is not yet completely certain that those ideas are interlinking as they should be. After participating in a point-predict session, that writer may be better able to restructure her text, and decide she wants to bring that revision back in for another reading. The question this would pose is whether another point-predict reading would help this writer-perhaps it would, by showing her how her revisions have affected the way the reader reacts to the new structure-or perhaps a more locally focused reading, like a traditional client-read structure, would be better suited to her next round of revision needs. By examining the revisions writers make in response to their writing center sessions, especially if one is able to examine serial revisions, we will better understand the real effects of writing center practices and how to refine them in individual tutoring situations.

In addressing questions about the kinds of texts point-predict is best suited for, future researchers might also wish to analyze the effects of this method on non-academic writing, especially creative writing. Creative writing is an area of tutoring often overlooked, with writing centers delegating creative writing clients only to those tutors who have experience in creative writing courses themselves. While there is nothing overtly wrong with this approach, it may cause some clients to be excluded if they cannot find a writing center consultant who is both available and has a creative writing background. In the early work of this study, a preliminary tutoring session was conducted on a creative writing piece using the point-predict method, and the writer reported that she found the method useful. If point-predict proves to be useful for a broader range of tutors and creative writing clients, it may resolve the issue of positioning creative writing as a subject that can only be handled by certain tutors.

Additionally, future research should not focus solely on point-predict as the only alternative to the less structured traditional approaches to reading aloud. Kathleen’s glossingwhile-reading method had promising results as a case study, and merits further examination. Furthermore, there are probably a variety of methods like this one, methods writing center practitioners may not even bother to consciously consider as alternative methods to employ in 
tutoring sessions but simply pull out instinctively in certain situations. Just gathering information on these different methods and how to employ them in writing center sessions would itself be a valuable research project, as it would expand the way in which we conceptualize reading in writing centers. Studying the most promising of these methods to determine their actual effects might accomplish even more.

Beyond further examinations of the effects of reading methods on clients, this study suggests that future research might also benefit from examining the effects of reading methods on tutors, especially tutor engagement. As discussed previously, engaging tutors is important to the success of writing centers as both places of employment and education, and research in this area could pay significant dividends to writing center practitioners. Furthermore, developing a better understanding of how reading methods generally affect tutors' attitudes and practices is necessary in order to make informed decisions about which practices are best suited to different tutoring situations.

A different area of writing center research that might also benefit from further research into reading practices is the area of virtual consulting practices, especially those that are asynchronous or lack a spoken component, such as email or text-only computer consultations. Obviously, when there is not a vocal element of the session, the question of whether or not to read aloud is irrelevant. However, the hypotheses raised by this study that tutors who read a text with a certain structured response method in mind notice different issues than those who read without that structure might have interesting implications for virtual consulting. For example, it may be that tutors conducting virtual sessions find briefly typing point-predict style reactions to the client helps them avoid the tendency to simply “fix” the paper and mail it back, providing descriptive feedback to the writer that aids in his revision without conducting that revision for him. Examining possibilities like these may enrich existing work on virtual consulting, such as that by Griffin. 
More generally, this study indicates that there may be a broader need within writing center research to examine our assumptions about client agency and engagement, both as they relate to reading practices and to writing center practice more broadly. The conversations within tutor training manuals and on WCenter indicate significant disagreements over these issues that are being overlooked; the results of this study indicate that at least some of these assumptions may need significant revision, such as the idea that client control is guaranteed by having a client read, or that seemingly being in control leads to attention and interest. Even more generally, this study may suggest that some areas of writing center practice still rely more on anecdotes and personal preferences rather than substantive research as their justification for being in use; reading practices may just be one area of writing center research that falls in this category. While Gillespie is certainly right that lore serves an invaluable function—and sites like WCenter, where that lore is exchanged and debated, are crucial — the value of this lore is as a beginning place for research, rather than an ending point. There are clearly questions in the field about how best to reach our shared goals of helping writers develop agency, audience awareness, and revision skills, but simply debating individual opinions and stories in person or via email will not resolve these questions; we need to be willing to take a step back and examine our practices with a somewhat more distanced eye, to see whether our ideas about what happens in our writing centers match the reality.

\section{Implications for writing center practice}

This study also offers some ideas for writing center practice; though the results from preliminary studies like these can offer only hypotheses, these hypotheses seem promising enough that writing center practitioners might wish to implement some of them on a trial basis. The first of these ideas is to teach tutors the point-predict reading method and invite them to experiment with other structures for reading, such as Kathleen's glossing-while-reading method. This training may need more scaffolding than was incorporated in this study, where tutors 
received a one hour training session and some opportunity to practice on their own before implementing the point-predict method in an observed session. Some of the tutors in this study suggested that observing someone else using the method, and then practicing the method with each other, would have helped them feel more confident before beginning their first point-predict session with a client.

As an extension of this practice, it may help to ask tutors to attend to their sense of how these methods affect their own and client engagement, client agency, and the amount of attention given to global issues. Doing so might help encourage productive self-reflection, while also letting tutors know that their perceptions of these methods are important in evaluating their efficacy. Tutors who are enrolled in some kind of course work as part of their employment might also benefit from doing some transcript analyses of their own sessions to compare with their impressions. The purpose of this would be to allow tutors and their instructors to see how their perceptions of their sessions compare to the data from their sessions, thus giving everyone an interesting starting point from which to discuss questions of how tutors can evaluate their own practices in the writing center and what transcript analysis might allow us to see that simple recollection may not.

Encouraging self-reflection and analysis could also be used as a tool to help build tutor confidence. Both Maude and Beverly mentioned that a lack of confidence in their sessions could cause them to turn towards local issues, and this may indicate that attending to tutor comfort and confidence is important to the success of writing center sessions. By encouraging tutors to reflect on their practices in a way that rewards, rather than critiques, tutors for recognizing areas where they do not feel as proficient, directors may help improve the level of tutoring offered in their writing centers. Writing center administrators need to be sure not to overestimate their tutors' confidence and comfort, nor underestimate the importance of these attitudes to high-quality sessions. 
Additionally, this study suggests that writing center administrators may not want to draw their conclusions about tutoring methods solely from casual observation and anecdotal evidence. Building other forms of analysis and experimentation into the standard practice of the writing center could give directors more nuanced information upon which to base their decisions about tutoring policies. While obviously many administrators are too busy with the day to day work of the writing center to do full scale research projects, even introducing small and falsifiable ways of measuring whether what we think is happening in sessions is what is actually happening in sessions will help us move past those assumptions that are incorrect and serving only to hamper the effectiveness of our writing centers. For example, as both a tutor and administrator, I always had a strong fondness for the traditional tutor-read method over the client-read method—but analyzing the results of just the eight tutor-read sessions in this study showed me that what I imagined was happening in these sessions was not actually what was happening. Had I not conducted this study, I may have been tempted to focus only on confirming what I wanted to see in casual observations of tutor-read sessions; similarly, other administrators might benefit from setting up more methodical ways of evaluating the sessions they observe so as to avoid this potential pitfall.

This study also suggests that administrators and instructors in writing center theory and practice may want to complicate the advice offered by tutor training manuals in regards to reading methods, especially if they are using a manual that advises offering no commentary during the session. Given that this study appears to indicate that the choice of reading method has a significant effect on what is discussed in the session, and that this effect does not appear to match most of the claims made within tutor training manuals, allowing tutors to read the advice on reading within training manuals without pointing out other thoughts about, and approaches to, reading methods may do them a disservice. Pointing out the potential advantages and limitations to various reading methods and encouraging tutors to be conscious of what effects they notice 
reading methods have on their own sessions may make for more productive tutoring sessions, and would work as a natural introduction to instruction in alternative reading methods.

\section{Implications for tutor training manuals}

In addition to the possibility that writing center administrators may want to complicate the content of the training manuals they employ, the authors of these manuals may wish to reevaluate the amount of attention they give to, and the way in which they discuss, reading methods in their texts. Generally, tutor training manuals do not devote more than a page or two to their discussion of reading methods, and this limited discussion may mislead tutors into thinking that reading methods are not a critical component of the tutoring session, or that there is no debate about what reading methods are optimal.

Furthermore, this study indicates that some of the claims being made in popular tutor training manuals are not nearly as certain as the manuals represent. For example, the equal rates of client initiation across all session types may indicate that the claim that having the client read is the best way to ensure his control (Gillespie and Lerner; Caposella) over the text is either an exaggeration or simply incorrect; the fact that tutors noted how uncomfortable clients can be in client-read sessions validates this concern. Furthermore, though the amount of issues initiated did not change much across session types, the fact that clients were far more likely to initiate discussions of global issues in point-predict sessions may indicate that traditional reading methods are not well suited to catalyze client control over the kinds of issues manuals and practitioners agree are most significant.

Similarly, training manuals’ assumptions about the higher quality of client listening (Gillespie and Lerner) and engagement (Caposella; Ryan and Zimmerelli) in client-read sessions are also shown to be problematic by this study. Client survey responses indicate that they were particularly enthused about the point-predict reading method, often citing the method itself as what they found most useful about their sessions. Additionally, all of the tutors commented on 
how engaged clients were in point-predict sessions. Combined, these results may indicate that authors of tutor training manuals may want to reevaluate their claims as to which reading methods can best encourage client interest and attention, as it may be that traditional methods do not engage clients’ interest nearly as effectively as these manuals claim.

Finally, tutor training manuals may wish to reevaluate their encouragement of client-read as the best method if their goal is to encourage sessions with a higher focus on global than local issues. This study indicates that traditional client-read sessions give a lot of attention to local issues, and tutor interviews suggest that this may be at least partially a direct result of the method itself. Standard client-read sessions may be more likely to overload tutors’ memories and disengage them from the text, thus making it hard for tutors to focus on more global issues. These results may indicate that tutor training manuals that wish to help tutors learn how to catalyze productive sessions, ones giving primary attention to global issues, need to offer guidelines on how to structure the reading portion of their sessions so as to elicit this kind of focus more readily. In other words, tutor training manuals may need to devote several pages to outlining specific, methodical reading structures that have been found to develop a global focus in tutoring sessions, so that tutors can practice employing these structures in their own sessions.

Though this study is only preliminary, and thus cannot suggest definitive alternate content for training manuals to incorporate, it does indicate that, at the very least, current treatments of reading methods in manuals are vastly oversimplified. The varied discussion of reading methods on WCenter, and the conflicting advice among the different manuals, is impetus alone for a change in these manuals' approach to reading; the work of this study adds a few hypotheses to that discussion that manual authors may wish to consider in the writing or revising of their advice. 


\section{Conclusion}

Overall, the most striking finding of this study is that reading methods play a significant role in tutoring sessions, and that this role demands much more extensive investigation and analysis. Reading methods may be one of the most significant areas where our theoretical assumptions have overdetermined our practice, leading us to seek out only superficial evidence to confirm our ideas about how to facilitate agency, engagement, audience awareness, and global revision skills. In both our research and our practice, we need to push ourselves to question our assumptions about traditional reading methods and seek out and study new methods. By doing so, we might both improve the quality and variety of tutoring methods and deepen our ideas about how we define and pursue our shared goals for clients, tutors, and writing. 


\section{REFERENCES}

Anderson, Paul V. Technical Communication: A Reader-Centered Approach. 6th ed. Belmont: Wadsworth, 2007. Print.

Bassett, Elaine. “RE: q about tutoring techniques.” Lyris ListManager. WCenter, 15 Jul. 2009. Web. 8 March 2010. <http://lyris.ttu.edu/ read/messages?id=8583111\#8583111>.

Berthoff, Ann E. "Is Teaching Still Possible? Writing, Meaning, and Higher Order Reasoning" College English 46.8 (December 1984): 743-55. Print.

Biasiolli, Barbara. “RE: q about tutoring techniques.” Lyris ListManager. WCenter, 16 Jul. 2009. Web. 8 March 2010. <http://lyris.ttu.edu/ read/messages?id=8583111\#8583111>.

Bizzell, Patricia "Cognition, Convention and Certainty: What We Need to Know about Writing." Cross-Talk in Comp Theory: A Reader 2nd Ed Ed victor Villanueva NCTE Urbana IL 2003: 387-412. Print.

Block, Rebecca, "What is Good Feedback?: Creative Writing Practice and Pedagogy.” Unpublished Thesis. University of Louisville, 2006. Print.

Byrne, Kathryn. “RE: q about tutoring techniques.” Lyris ListManager. WCenter, 16 Jul. 2009. Web. 8 March 2010. <http://lyris.ttu.edu/ read/messages?id=8583111\#8583111>.

Capossela, Toni-Lee. "Getting to Know You." The Harcourt Brace Guide to Peer Tutoring. Fort Worth: Harcourt Brace, 1998. 8-15. Print.

Charney, Davida. "Experimental and Quasi-Experimental Research." Research in Technical Communication. Ed. Laura J. Gurak and Mary M. Lay. Westport, CT: Praeger, 2002. Print. 
Couzijn, Michel. "Learning to Write by Observation of Writing and Reading Processes: Effects on Learning and Transfer." Learning and Instruction 9 (1999): 109-42. Print.

Flower, Linda S. and John R. Hayes. "A Cognitive Process Theory of Writing." College Composition and Communication 32 (1981): 365-87.

Gantt, Tamara Miles. “RE: q about tutoring techniques.” Lyris ListManager. WCenter, 16 Jul. 2009. Web. 8 March 2010. <http://lyris.ttu.edu/ read/messages?id=8583111\#8583111>.

Gillespie, Paula. "Beyond the House of Lore: Writing Center as Research Site." Writing Center Research: Extending the Conversation. Ed. Paula Gillespie; Alice Gilliam; Lady Falls Brown; Byron Stay. Mahwah, NJ: Lawrence Erlbaum Associates, 2002. 39-52. Print. Gillespie, Paula and Neal Lerner. "The Tutoring Process." The Allyn and Bacon Guide to Peer Tutoring. Boston: Allyn and Bacon, 2000. 23-36.Green, Ann. "The Writing Center and the Parallel Curriculum." Praxis 2.1 (2004). Print.

Griffin, Jo Ann. “Distance Learning Technologies and Writing Center Conferences: A Comparative Analysis of Two Methods for Delivering Consultation at a Distance.” Unpublished Dissertation. University of Louisville, 2008. Print.

Harris, Muriel. "Modeling: A Process Method of Teaching." College English 42.7 (1983): 74-85. Print.

-----. “RE: q about tutoring techniques.” Lyris ListManager. WCenter, 15 Jul. 2009. Web. 8 March 2010. <http://yris.ttu.edu/ read/messages?id=8583111\#8583111>.

Higgins, Lorraine. "Reading to Argue: Helping Students Transform Source Texts." Hearing Ourselves Think: Cognitive Research in College Writing Classroom. Ed. Ann M. Penrose and Barbara M. Sitko. New York: Oxford U. P., 1993. 70-101. Print.

Jordan, Kerri. “RE: q about tutoring techniques.” Lyris ListManager. WCenter, 15 Jul. 2009.

Web. 8 March 2010. <http://lyris.ttu.edu/ read/messages?id=8583111\#8583111>.

Kuniavsky, Mike. Observing the User Experience: A Practitioner's Guide to User Research. San Francisco, CA: Morgan Kaufmann, 2003. Print. 
Lapointe, Michael. “RE: q about tutoring techniques.” Lyris ListManager. WCenter, 15 Jul. 2009. Web. 8 March 2010. <http://lyris.ttu.edu/ read/messages?id=8583111\#8583111>.

Levin, Katie. “RE: q about tutoring techniques.” Lyris ListManager. WCenter, 16 Jul. 2009. Web. 8 March 2010. <http://lyris.ttu.edu/ read/messages?id=8583111\#8583111>.

Mueller, Susan. “RE: q about tutoring techniques.” Lyris ListManager. WCenter, 15 Jul. 2009. Web. 8 March 2010. <http://lyris.ttu.edu/ read/messages?id=8583111\#8583111>.

Palm, Rebel. “q about tutoring techniques.” Lyris ListManager. WCenter, 15 Jul. 2009. Web. 8 March 2010. <http://yris.ttu.edu/ read/messages?id=8583111\#8583111>.

-----. “RE: q about tutoring techniques.” Lyris ListManager. WCenter, 16 Jul. 2009. Web. 8 March 2010. <http://lyris.ttu.edu/ read/messages?id=8583111\#8583111>.

Price, Steven. “RE: q about tutoring techniques.” Lyris ListManager. WCenter, 16 Jul. 2009. Web. 8 March 2010. <http://lyris.ttu.edu/ read/messages?id=8583111\#8583111>. Prodoehl, Dana. “RE: q about tutoring techniques.” Lyris ListManager. WCenter, 16 Jul. 2009. Web. 8 March 2010. <http://lyris.ttu.edu/ read/messages?id=8583111\#8583111>.

Ritter, Jennifer J. "Recent Developments in Assisting Esl Writers." A Tutor's Guide: Helping Writers One to One. Ed. Ben Rafoth. Portsmouth, NH: Heinemann/Boynton-Cook, 2000. 102-10. Print.

Rose, Mike. "Rigid Rules, Inflexible Plans, and the Stifling of Language: A Cognitivist Analysis of Writer's Block."College Composition and Communication 31.4 (1980): 389-99. Print.

-----. "Narrowing the Mind and Page: Remedial Writers and Cognitive Reductionism" College Composition and Communication 39.3 (October 1988): 267-98. Print.

Rankin, Deborah. “RE: q about tutoring techniques.” Lyris ListManager. WCenter, 16 Jul. 2009. Web. 8 March 2010. <http://lyris.ttu.edu/ read/messages?id=8583111\#8583111>.

Ryan, Leigh and Lisa Zimmerelli. The Bedford Guide for Writing Tutors. $4^{\text {th }}$ ed. Boston: Bedford/St. Martins, 2006. Print. 
Schriver, Karen A. Dynamics in Document Design. New York: Wiley Computer Pub., 1997. Print.

-----. "Revising for Readers: Audience Awareness in the Writing Classroom." Hearing Ourselves Think: Cognitive Research in College Writing Classroom. Ed. Ann M. Penrose and Barbara M. Sitko. New York: Oxford U. P., 1993. 147-69. Print.

-----. "Teaching Writers to Anticipate Readers' Needs: A Classroom Evaluated Pedagogy." Written Communication 9.2 (1992): 179-208. Print.

Simpson, Jeanne. “RE: q about tutoring techniques.” Lyris ListManager. WCenter, 16 Jul. 2009. Web. 8 March 2010. <http://lyris.ttu.edu/ read/messages?id=8583111\#8583111>.

Sitko, Barbara M. "Exploring Feedback: Writers Meet Readers." Hearing Ourselves Think: Cognitive Research in College Writing Classroom. By Ann M. Penrose and Barbara M. Sitko. New York: Oxford U. P., 1993. 170-87. Print.

Thompson, Isabelle. "Scaffolding in the Writing Center: A Microanalysis of an Experienced Tutor's Verbal and Nonverbal Tutoring Strategies." Written Communication 26.4 (2009): 417-53. Print. 


\section{APPENDIX A}

\section{Tutor Script for Point-Predict Sessions}

Now that we've discussed the assignment and your particular concerns, I'd like to read your piece aloud. While I'm reading aloud I'll be jotting down notes to myself, in the margins and on a pad of paper, of things I want to ask you about once we've finished reading. I'll also be pausing every time I come across anything that seems like a main point to summarize that point and predict what I think will come next based on the main points that have been made so far. The purpose of doing this is to let you know, as the writer, how your writing is being interpreted by me as a reader; if you find that the main points I'm summarizing are not in keeping with your intent, then you might want to make note of it as an area of the text to consider revising. Similarly, if you notice my predictions don’t mesh at all with the direction the paper actually follows then that might also indicate an area for revision. Take note of these kinds of things as I read so you can either use these notes to revise or to tell me what areas of your paper you want to focus on once I finish reading; you can also take note of anything else that catches your attention during the reading for us to talk about once I finish. If any of my summaries or predictions don’t make sense to you when I say them, let me know so I can clarify them then; you can also pause me with any other immediate questions that come up as I read.

Does that sound okay to you? Do you have any questions before we get started?

[If the answer to either of these questions is anything other than "yes" then discuss further as needed] 


\section{APPENDIX B}

Post-consultation survey for clients
1a) Age:
b) Gender: M/F
c) Major:
d) Year in school:

e) Is English your native language? Y/N

2) Course this writing is for (e.g. ENGL 101, HIST 303, etc.):

3) This assignment is due: Tomorrow 2-4 days 5-7 days more

4a) How many times have you visited the W.C. previously? $\quad \begin{array}{lllll}1-2 & 3-4 & 5-6 & 7-8 & \text { more }\end{array}$

b) How many times have you brought this particular assignment in previously?

5) Overall, how well do you think this consultation went?

$\begin{array}{llllcc}1 & 2 & 3 & 4 & 5 \\ \text { Terribly } & & & & \text { Great }\end{array}$

6) The most helpful portion of the consultation was

(optional: because

\section{) .}

7) The least helpful portion of the consultation was

(optional: because 
8) This consultation showed me ways to make my meaning clearer to readers:

$\begin{array}{lllll}1 & 2 & 3 & 4 & 5\end{array}$

Strongly Disagree

Strongly Agree

9) This consultation addressed ways I could revise for:

\begin{tabular}{lcccccc} 
& \multicolumn{3}{c}{ Focused on } & & Focused on \\
& \multicolumn{3}{c}{ a little } & & & a lot \\
Nrammar/Spelling: & N/A & 1 & 2 & 3 & 4 & 5 \\
Sentence Structure: & N/A & 1 & 2 & 3 & 4 & 5 \\
Citation Style: & N/A & 1 & 2 & 3 & 4 & 5 \\
Research: & N/A & 1 & 2 & 3 & 4 & 5 \\
Organization: & N/A & 1 & 2 & 3 & 4 & 5 \\
Content: & N/A & 1 & 2 & 3 & 4 & 5 \\
Readers/Audience: & N/A & 1 & 2 & 3 & 4 & 5 \\
Other:__n & N/A & 1 & 2 & 3 & 4 & 5
\end{tabular}

10) The portion of the consultation spent reading my paper aloud was the most useful portion of the session:

$\begin{array}{rrrrrr}1 & 2 & 3 & 4 & 5 \\ \text { Strongly Disagree } & & & & & \text { Strongly Agree }\end{array}$

11) The time spent reading my paper aloud was useless:

$\begin{array}{cccccc}1 & 2 & 3 & 4 & 5 \\ \text { Strongly Disagree } & & & & & \text { Strongly Agree }\end{array}$

12) Do you have any other thoughts, comments, or suggestions about the portion of your session spent reading aloud? 
13) I would have liked more control over what was discussed in this consultation:

$\begin{array}{rrrrrc}1 & 2 & 3 & 4 & 5 \\ \text { Strongly Disagree } & & & & & \text { Strongly Agree }\end{array}$

14) Any other thoughts, including any details or examples explaining your answers to any of the survey questions, that you'd like to share? 


\section{APPENDIX C}

\section{Post-consultation survey for tutors}

1) How many times have you worked with this client before this session?

2) How many times have you worked on this particular assignment before this session?

3) Overall, how well do you think this consultation went?

$\begin{array}{lllll}1 & 2 & 3 & 4 & 5\end{array}$

Terribly Great

4) I thought the most useful portion of the consultation for the student was because

5) I thought the least useful portion of the consultation for the student was because

6) The read aloud portion of the consultation seemed to help the client with things s/he might not have gotten otherwise in the session:

$\begin{array}{lllll}1 & 2 & 3 & 4 & 5\end{array}$

Strongly disagree Strongly Agree

5a) If you agree or strongly agree, what specific things do you think it helped with?

5b) (Optional) I thought this because: 
7) The writer took control of his/her paper during most of the session:

$\begin{array}{lllll}1 & 2 & 3 & 4 & 5\end{array}$

Strongly disagree

Strongly Agree

8) The session focused heavily on global issues:

$\begin{array}{lllll}1 & 2 & 3 & 4 & 5\end{array}$

Strongly disagree Strongly Agree

9) The session focused heavily on local issues:

$\begin{array}{lllll}1 & 2 & 3 & 4 & 5\end{array}$

Strongly disagree

Strongly Agree

10) This consultation addressed ways the client could revise for:

\begin{tabular}{lcccccc} 
& \multicolumn{3}{c}{ Focused on } & & Focused on \\
& \multicolumn{3}{c}{ a little } & & & a lot \\
Nrammar/Spelling: & N/A & 1 & 2 & 3 & 4 & 5 \\
Sentence Structure: & N/A & 1 & 2 & 3 & 4 & 5 \\
Citation Style: & N/A & 1 & 2 & 3 & 4 & 5 \\
Research: & N/A & 1 & 2 & 3 & 4 & 5 \\
Organization: & N/A & 1 & 2 & 3 & 4 & 5 \\
Content: & N/A & 1 & 2 & 3 & 4 & 5 \\
Readers/Audience: & N/A & 1 & 2 & 3 & 4 & 5 \\
Other:__n & 1 & 2 & 3 & 4 & 5
\end{tabular}

11) Any other thoughts? (Feel free to use the back of the survey and/or jot down notes here to remind yourself of thing you might like to discuss further in your interview at the end of the study.) 


\section{APPENDIX D}

\section{Tutor Interview Questions}

General warm up questions:

1. Has teaching changed your opinions on any tutoring practices--reading methods or others? In general, what do you know now that you wish you'd known when tutoring?

2. Did participating in this study affect your teaching or conferencing practices at all?

3. I know it's been a while, but what do you remember of your general impressions about the differences between tutoring with the client reading, you reading, and you employing pointpredict?

4. What did you think of point-predict? (possible follow-ups: did you like it? dislike it? why? what did it seem good for? what did it seem poorly suited for? do you think it's a method you would have employed on your own in tutoring sessions if you'd had the chance? did it change your thoughts about writing or revising?)

5. In general, what do you think the advantages and disadvantages are of reacting to or discussing a paper as it is read versus waiting until after the whole paper is read to react or discuss anything?

6. There's a controversy amongst writing center scholars, tutors, etc. over how to balance between doing what the client asks for and doing what the tutor thinks the client needs even if it isn't what they asked for. Where do you stand on this? Did participating in this study change your opinion on this? Did teaching?

7. How could the training have been improved? 


\section{Data review questions:}

8. Before I show you the data, what kinds of differences do you expect to see, if any, between client-read, tutor-read, and point-predict sessions? Do you expect the amount of attention paid to different kinds of writing issues (like grammar, organization, content, etc.) to vary based upon what kind of session it was? If yes, why and how? If no, why not?

9. Which do you expect to be the most similar: client-read and tutor-read, tutor-read and pointpredict, client-read and point-predict, or all pretty much the same?

10. What did you understand the point of summarizing and making predictions to be? How does that fit in with your understanding of effective writing?

[After answering question 10, tutors were then shown Figures 1.2, 1.3, and 1.4see Chapter Two-with all names removed but their own]

11. What's your first reaction on seeing these results? Are you surprised by how big a difference the reading method seems to have made? Why/why not?

12. One might have expected tutor-read and point-predict to turn out similar, since both involved having the tutor read the text aloud. Instead, they turned out to be the most unlike one another. Why do you think that is?

13. Why do you think tutor read sessions focused so much more on sentence-level issues than the other two types? Why do you think issues of organization and content went down in this type of session?

14. Are you surprised to see how many of the topics in the client read sessions were sentence level? what do you think about that?

15. Are your surprised to see how much more often point-predict sessions focused on content? organization?

16. Do you expect any differences in the number of topical chains clients would have initiated in the different session types? Why/why not? Do you expect any differences in the kinds of writing issues they would initiate? 
[After answering question 16, tutors were then shown Tables 3.1 and 3.2—see

Chapter Two-which depict client initiation data]

17. What do you think about this? Why do you think point-predict sessions would lead to clients initiating more discussions on global issues and client-read and tutor-read on more local issues? 18. Now that you've seen this data, does it change your answer at all to questions 5 or 6 ? With 6 specifically, what do you think about clients who came in asking for help with sentence stuff, got point-predict sessions, and left talking about how useful the attention to audience and content was?

19. What types of papers, writing stages, writers, and tutors do you think each of these methods is best suited for?

Tutor specific questions:

Beverly

1. You had the longest sessions of everyone. Any thoughts about why you might prefer longer sessions?

2. Sometimes you asked questions rather than making predictions (see example from transcript 15 below)--what do you think the advantages and disadvantages are of asking questions rather than making predictions?

T: Alright. [laughs] [reading] Um, "In the cafes we even see computers that offer free-wifi. All of these features make the library more appealing, but they also create it more into a social gathering rather than for its original intent.” Um, and I'm wondering here, it seems almost like, I guess I would ask you, let me ask you first.

C: Okay.

T: Um, how do you feel about this change in the library?

C: I mean, I'm okay with it ...

T: Yeah.

C: ... I mean, I, I think it's a good change, a positive change. Um, I mean that, it's, but I'm, part of me's like what if it's, it gets to too much, I mean ...

T: Yeah. 
C: ... honestly, really, I didn’t even care about the prompt until I got it, but.

T: [laughs] Yeah, yeah.

C: So, I mean I guess, like, I don't even know really if I have that much of a strong opinion on it, I just, I feel like I'm just writing about what it is rather than if, if the change is better or worse.

T: Okay.

C: So.

T: I guess the reason that, that I'm asking about this is because I sort of get that like I feel an opinion coming through ...

C: Okay.

T: Particularly “obsolete,” I guess I keep on coming back to that.

C: The “obsolete," yeah.

$\mathrm{T}$ : 'Cause that feels, that feels strange to the rest of this, and also then, um, social gathering place rather than its original intent.

\section{Maude}

1. You had a very long paper for one of your PP sessions - how did point-predict affect your approach to the paper? do you think it helped or hurt the session?

2. Your point summaries and predictions were also generally shorter than the other tutors (show examples of hers). Did the method feel uncomfortable to you? Why/why not? Did you feel the training wasn't sufficient? Was there anything that could have been done to make this a more usable method for you, or does it just go against your personal style, or something else?

3. You in general had shorter sessions and tended to focus more on issues like grammar, sentence structure, and citation style. Why do you think that turned out to be the case?

\section{Kathleen}

1. You had this one client-read session where you had the client gloss the paragraphs as they were reading. Do you remember why you decided to do this? How do you think it went? Was this influenced by your PP training or is it something you'd done before?

2. Did the following moment, from one of your point-predict sessions, change the way you think/thought about tutoring or writing? 
1. C: Um, but it helped. Um, I even liked the pauses, because it gives me a moment to say some things to explain to myself to go over, go back in here and say, well maybe this is where she may have got caught up, and I can move this forward ...

2. T: Mmm-hmm.

3. C: ... and whatnot, things like that.

4. T: Mmm-hmm.

5. C: So.

6. T: Yeah, well what's really interesting to me doing that, is that I realized how heavily I rely on those instances where you would predict what you were gonna do.

7. C: Yeah.

8. T: Like, if you forecasted, then I became, it was hard for me to not become wedded to that forecast.

9. C: Yeah.

10. T: So this moment on page 2 where you forecasted, I was just kept going back to it, but I think it kind of threw me off a little bit!

11. C: The funny part is that I couldn't even remember where it was going, so I was like, oh, I know I went somewhere with that, but I don't know where, so, that was pretty interesting.

(Emphasis added)

\section{Clarissa}

1. You read through a lot of the transcripts--did doing that affect your opinion on the different reading methods? if so, how? did you notice any interesting differences between your approaches and those of the other tutors?

2. Your session with [particular client name removed] was unlike your other client-read session and most client-read sessions I've seen--you all paused and discussed things frequently during the reading rather than saving it all to the end. How did that approach come about with him? Do you think it would help other clients? 


\section{CURRICULUM VITAE}

NAME: $\quad$ Rebecca R. Block

ADDRESS: University of Louisville

Department of English

Bingham Humanities, Rm. 315

Louisville, KY 40292

DOB: $\quad$ Louisville, Kentucky - June 1, 1979

EDUCATION: Ph.D., Rhetoric and Composition, University of Louisville

2006-2010

M.A., English

University of Louisville

2005-2006

B.A., Humanities

New College of Florida

1997-2001

AWARDS

\& HONORS: $\quad$ University Fellowship. University of Louisville, 2006-2007 and 2009-2010

Axton Graduate Teaching Assistantship, University of Louisville, 2007-2008

Graduate Dean's Citation for Master's Thesis. University of Louisville, 2006.

M.A. Thesis nominated for the Regional Award of the Conference of Southern Graduate Schools. University of Louisville, 2006

National Merit and Dean \& Warden Scholar, New College of Florida, 1997-2001

PROFESSIONAL

SOCIETIES: International Writing Centers Association

National Council of Teachers of English

The Conference on College Composition and Communication

CONFERENCE

PRESENTATIONS:

"What We Talk About When We Talk About Tutoring: Complicating the Read

Aloud," Kentucky Philological Association Conference, Mar. 2009.

"Finding Readers You Trust: Creative Writers Talk about Feedback," Conference on College Composition and Communication, Apr. 2008. 